Portland State University

PDXScholar

\title{
Introducing Complex Systems Analysis in High School Mathematics Using System Dynamics Modeling: A Potential Game-Changer for Mathematics Instruction
}

Diana Marie Fisher

Portland State University

Follow this and additional works at: https://pdxscholar.library.pdx.edu/open_access_etds

Part of the Applied Mathematics Commons, and the Science and Mathematics Education Commons Let us know how access to this document benefits you.

\section{Recommended Citation}

Fisher, Diana Marie, "Introducing Complex Systems Analysis in High School Mathematics Using System Dynamics Modeling: A Potential Game-Changer for Mathematics Instruction" (2016). Dissertations and Theses. Paper 2950.

https://doi.org/10.15760/etd.2945

This Dissertation is brought to you for free and open access. It has been accepted for inclusion in Dissertations and Theses by an authorized administrator of PDXScholar. Please contact us if we can make this document more accessible: pdxscholar@pdx.edu. 
Introducing Complex Systems Analysis in High School Mathematics Using System Dynamics Modeling:

A Potential Game-Changer for Mathematics Instruction

by

Diana Marie Fisher

A dissertation submitted in partial fulfillment of the requirements for the degree of

\author{
Doctor of Philosophy \\ in \\ System Science
}

Dissertation Committee:

Wayne Wakeland, Chair

Brian Greer

Robert Fountain

Lisa H. Weasel

Portland State University

2016 
(C) 2016 Diana Marie Fisher 


\begin{abstract}
Complex systems abound on this planet, in the composition of the human body, in ecosystems, in social interaction, in political decision-making, and more. Analytical methods allowing us to better understand how these systems operate and, consequently, to have a chance to intervene and change the undesirable behavior of some of the more pernicious systems have developed and continue to be enhanced via quickly changing technology. Some of these analytical methods are accessible by pre-college students, but have not been widely used at that level of education. Jay Forrester, the founder of one of the methodologies, System Dynamics (SD), used to study complex system behavior involving feedback, laments the lack of understanding of complex systems evident in short-sited decisions made by legislators - global climate change and fiscal policies being cases in point.
\end{abstract}

In order to better prepare future decision makers with tools that could allow them to make more informed decisions about issues involving complex systems efforts have been underway to increase pre-college teacher understanding of the SD method. The research described in this dissertation introduces the mathematics education community to the value of System Dynamics modeling in pre-college algebra classes, indicates a path by which a traditional mathematics curriculum could be enhanced to include small SD models as a new representation for elementary functions studied in algebra classes, and provides an empirical study regarding conceptual understanding of functions by students.

Chapter 2 indicates the numerous beneficial learning outcomes that empirical studies have shown accompany model-building activities. Chapter 3 indicates the need 
for students to become familiar with complex systems analysis, how SD modeling (one method of complex systems analysis) aligns with the Common Core State Standards in Mathematics, and the work that has transpired over the past two decades using SD in K12. Chapter 4 focuses on the importance of the concept of function in high school mathematics, some limitations of exclusive reliance on the closed form equation representation for mathematizing problems and the SD stock/flow representations of some of the elementary functions that are studied in algebra classes. Chapter 5 looks at the issues affecting two traditional teachers and the challenges they faced when trying to reintroduce SD modeling into their algebra classes. Chapter 6 explains the student component of the classroom experiment that was conducted by the teachers who are highlighted in Chapter 5.

The analysis of the results of student model-building activities in the two classroom studies that are part of the third paper did not indicate a statistical difference between the two experimental groups and the two control groups. Many environmental and scheduling issues conspired to adversely affect the experiment. However, positive outcomes were evident from the two pairs of students who were videotaped while they built the final multi-function drug model, the final student lesson in the experiment. Research focused on student outcomes is needed to further assess the strengths and weakness of the SD approach for student learning in mathematics. 


\title{
Dedication
}

\section{To my parents}

\section{Marie F. Sparacino and Vincent T. Sparacino \\ who gave me the gift of an education and lots of encouragement.}

\author{
To my children \\ Kathryn and William \\ the next generation of systems thinkers, \\ and our hope.
}




\section{Acknowledgements}

I would like to thank my husband for his patience, which allowed me to follow my goal. I am indebted to my students who have and continue to inspire me and to my colleagues with whom it is/was a pleasure to work. I am grateful to the many wonderful teachers/professors who have helped me learn at each new stage of my education.

I want especially to thank Dr. Wayne Wakeland for allowing me to design the doctoral path I followed and who gave me guidance and encouragement all along the way. He is amazing. It has been an honor to work with my doctoral committee who were so instructive, responsive, and supportive.

I want to take a special moment to remember Dr. Ronald Narode who was on my doctoral committee for $75 \%$ of the time I worked on my dissertation. Due to his illness he felt he needed to remove himself from the committee. He passed away two months later. He is sorely missed. I remember the wonderful conversations we had which were so important in guiding the direction of the research papers that are part of my dissertation. I thank him also for introducing me to Dr. Brian Greer, another insightful mathematics education researcher who thinks outside the box.

Barry Richmond, a world-class system dynamicist and an educator at heart, created an elegant software, STELLA, that helps us all think in powerful ways. We all owe him a debt of gratitude. Finally, I am so grateful to Jay Forrester for creating a potent analytical approach that helps us understand some of the most important systems in our lives. And I am also grateful that he placed his enormous intellectual weight behind supporting the precollege effort to bring System Dynamics modeling to children. 
Abstract

Dedication................................................................................................

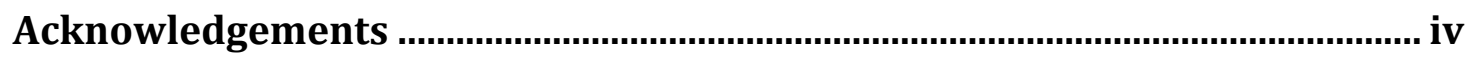

List of Tables ..................................................................................................

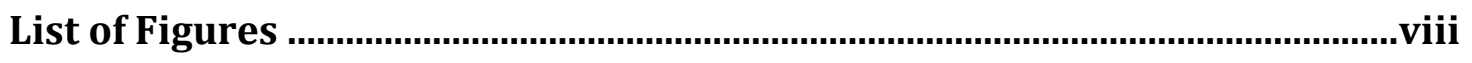

I. Introduction........................................................................................... 1

A.What is a Complex Systems Problem? ............................................................... 1

B.The need for instruction to address complex, dynamic, systems problems ............. 3

C. What does modeling, and specifically system dynamics modeling, have to offer

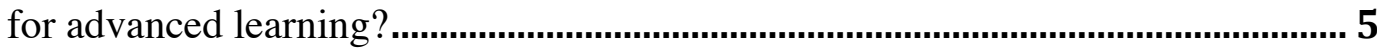

D.What does system dynamics have to offer to enhance mathematics instruction?... 7

1. Systems Thinking as Problem-Solving......................................................................

2. System Dynamics Modeling as Cognitive Technology ........................................8

E.Research on Value of System Dynamics Modeling in High School Algebra........17

II. Background ....................................................................................................19

A. System Dynamics Modeling: A Brief Introduction .................................................19

B. More About System Dynamics and Its Relation to How People Learn ..................23

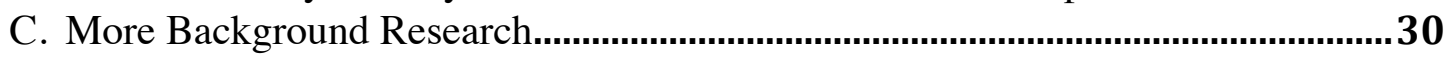

1a. Results from experiments: Students................................................................ 30

1b. Results from experiments: Challenges for Teachers...............................................35

2. Results of non-empirical methods: Students and Teachers......................................... 37

3. Novice versus Expert Problem Solving …………………………………………….... 39

D. Frameworks for Understanding Systems ..............................................................40

E. Techniques for Teaching Students ................................................................44

F. Techniques for Teaching Teachers...............................................................49

\section{Paper 1: System Dynamics Modeling to Teach Algebra and Complexity}

Abstract

A. Modeling and Algebra Teaching and Learning...........................................................53

B. System Dynamics Modeling for Learning Mathematics...............................................55

C. System Dynamics Modeling as Problem Solving and Cognitive Technology .......58

D. System Dynamics Modeling and Common Core State Standards - Mathematics64

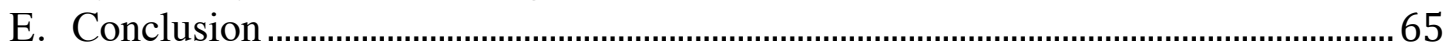

\section{Paper 2: Moving Beyond Closed Form Equations: Analyzing Complex} Systems Using STELLA Reorganizes Algebraic Thinking ...............67

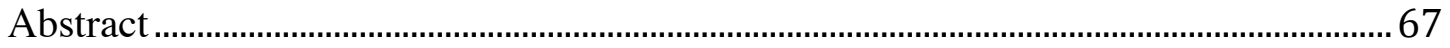

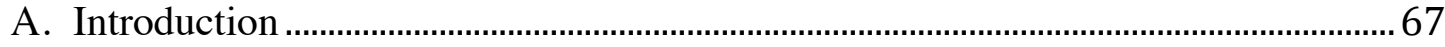

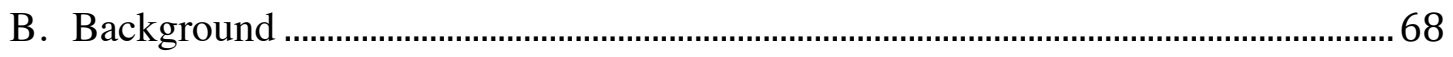




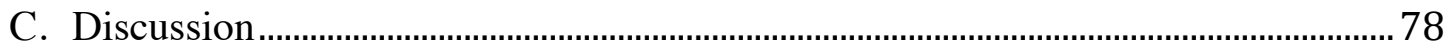

D. Conclusion …………………………………………………………………………....79

V. Paper 3: Attempts to Enhance High School Algebra Through System

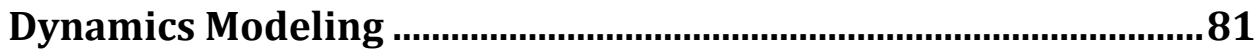

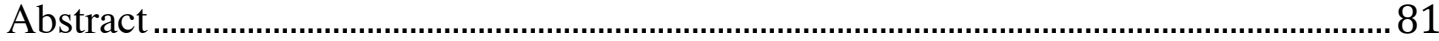

A. Introducing System Dynamics Modeling into K-12 Education.................................... 82

B. Introducing SD Analysis in High School: Two Case Studies ..................................... 91

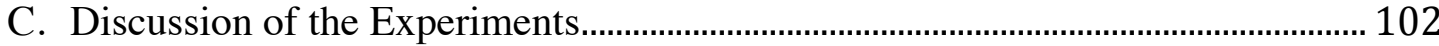

D. General Discussion .................................................................................................. 109

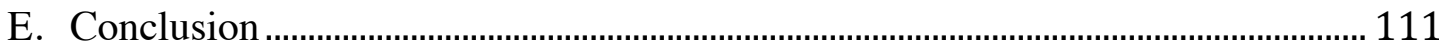

VI. Paper 4: Details of Student Component of Classroom Experiment

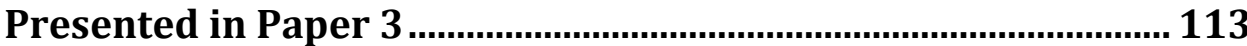

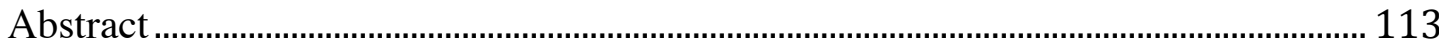

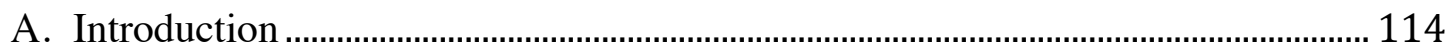

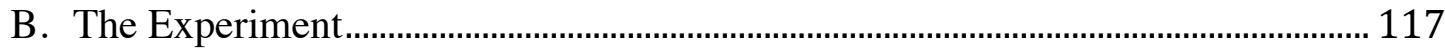

C. Discussion and Lessons Learned............................................................................... 144

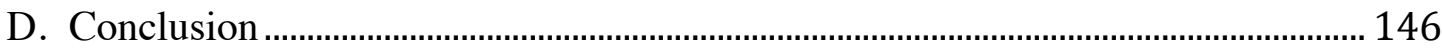

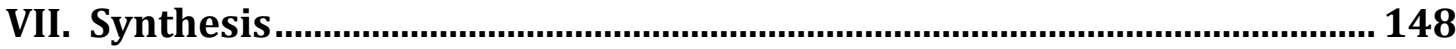

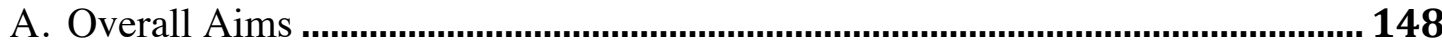

B. Findings/Contributions to Knowledge..............................................................150

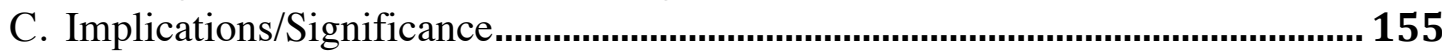

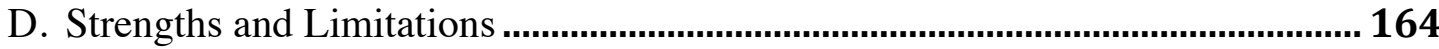

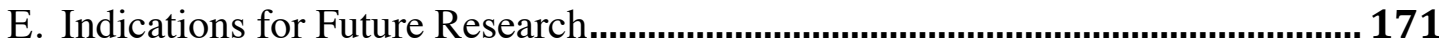

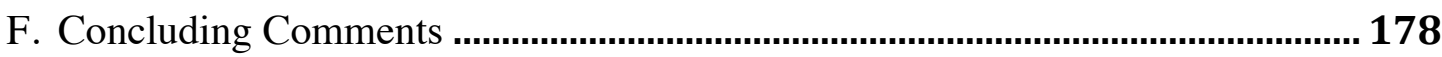

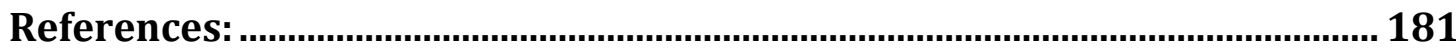

Appendix A: Detailed Explanation of Lessons for the Study ……......................... 195

Appendix B: Detailed Explanation of Pre- and Post-Assessments for the Study

Appendix C: Videotape of Two Student Pairs, One From Each Experimental Class, Building the Drug Model ........................................................... 198 


\section{List of Tables}

Table 1: Research supporting desirable learning outcomes from any effective learning

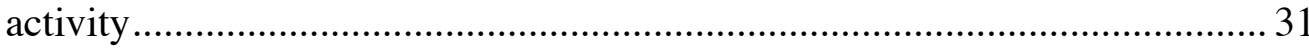

Table 2: Research supporting desirable learning outcomes when students model systems................................................................................... 32

Table 3: Research supporting challenges/barriers for teachers attempting to provide some of the desirable learning experiences previously enumerated. 35

Table 4: Research supporting desirable leaning outcomes from the study of complex

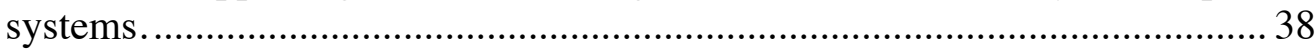

Table 5: Additional challenges/barriers for teachers attempting to teach complex

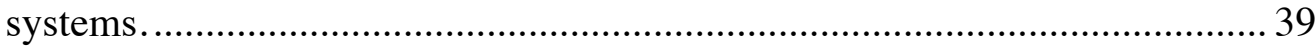

Table 6: The recursive calculations for population growth of $0.6 \%$ compounded

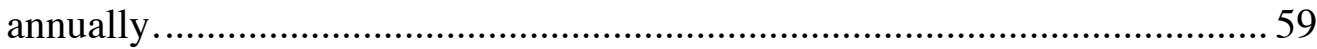

Table 7: Calculations for time needed to purchase the bicycle and helmet................. 70

Table 8: Calculations for time needed to save to purchase the bicycle and helmet if $\$ 2$

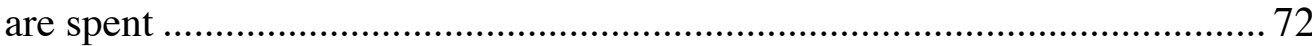

Table 9: Calculations for time needed to purchase the bicycle and helmet placing money in the bank at $10 \%$ annual interest, compounded weekly................. 73

Table 10: Calculating the money in the bank with $10 \%$ annual interest, compounded weekly, $\$ 5$ deposited per week and $\$ 2$ withdrawn per week........................ 75

Table 11: Mean scores of the first semester algebra II grades for the classes in this experiment.

Table 12: Mean scores for each experimental class on the three graded problems from the experimental lessons: motion detector, sketch linear model, sketch exponential model

Table 13: Class mean scores, first semester 2015-2016, for each for the four classes in this experiment.

Table 14: Improvement in scores from pre- to post-assessments for the combined experimental and combined control groups, and then the improvement of the experimental over the control group on each question.

Table 15: Mean scores for each experimental class on the motion detector problem. 134

Table 16: Mean scores for each experiental class on the linear modeling problem. .... 135

Table 17: Mean scores for each experimental class on the exponential modeling problem.

Table 18: Mean scores for each experimental call on the sub-parts of the first and second problem of the drug model lesson.

Table 19: LIkert scale results, student opinions about the lessons. ............................. 141

Table 20: Student comments about their impression of the usefulness of the experimental lessons. 


\section{List of Figures}

Figure 1: System Dynamics model of a population in a region. ................................. 21

Figure 2: The exponential stock/flow model and the graphical output of the stock, Current Population.

Figure 3: The STELLA diagram for simulating a population growth with separate birth and death rates.

Figure 4: STELLA diagram for simulating population growth with carrying capacity. 63

Figure 5: The pictorial representation of depositing money in a shoebox, and the graph of the amount of money in the shoebox over time.

Figure 6: A pictorial representation of depositing money to and spending money from a shoebox, and the graph of the money in the shoebox over time.

Figure 7: A picture showing how the interest on an interest bearing bank account might be calculated and added to the bank account. The graph shows the amount of money in the bank over 1040 weeks (20 years).

Figure 8: A picture of Demitre's savings plan, with interest added to his bank account each week, and a constant amount in weekly deposits and (constant) weekly spending. The (cut-out) graph shows the amount of money in the bank over 52 weeks

Figure 9: A picture (diagram) of Demitre's checking and savings account system. The graph shows the sum of both the checking and savings accounts. ................ 77

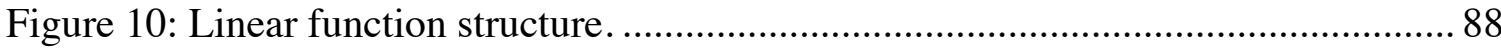

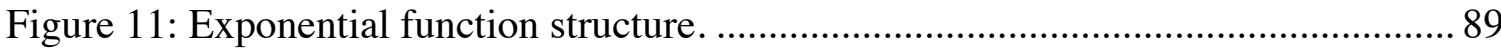

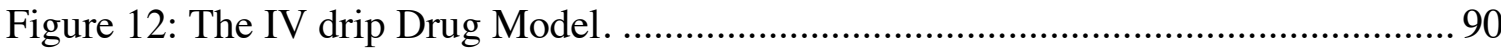

Figure 13: Quick overview of the method for the algebra II student experiment discussed in this paper.

Figure 14: (Pre, Post) assessments plots for each student in each of the four classes involved in this experiment.

Figure 15: Teacher 1: Experimental pre \& post-assessment scores compared to control pre $\&$ post-assessment scores.

Figure 16: Teacher 2: Experimental pre \& post-assessment scores compared to control pre $\&$ post-assessment scores. 


\section{Introduction}

Many of our daily experiences involve interacting with complex systems (Chen \& Stroup, 1993; Lesh, 2006). Our culture requires that we routinely make decisions about social interactions with family and co-workers, transportation choices, scheduling, and interacting with a myriad of systems. Each of these systems is connected to a larger system that comprises the world we live in. For most working adults, the opportunity to return to school to study techniques for increasing our understanding of complex systems will likely not present itself, but our children may yet learn how to incorporate into their thinking techniques for conducting complex systems analysis. Introducing System Dynamics analysis into the K-12 curriculum is both timely and critically needed (Hung, 2008; Lesh, Kelly, Loon, 2008; Sterman, 2002).

Our students are entering a world in which dynamics, feedback, unintended consequences, and delays are hidden within the structure of the problems they will have to address. The following literature review focuses on the need to include dynamic feedback analysis in the high school mathematics curriculum, the symbiotic relationship that such curriculum would provide in fostering a more interdisciplinary approach to problem solving, and the value of bringing a student-centered, model-building approach to the study of change dynamics at a much earlier level of mathematics sophistication than waiting for students to take calculus.

A. What is a Complex Systems Problem? 
Complex systems problems are those that contain a web of relationships between component parts that govern the behavior of the system. Those connections often incorporate feedback relationships of various strengths that when modified can significantly change the behavior of the system. Complex problems contain less predefined structure, are less transparent, and are open to multiple interpretations regarding solutions. Such problems tend to cross disciplinary lines and so can be understood from different vantage points, leading to more thoughtful beneficial alternatives. The boundary within which the problem is situated also fluctuates, causing complex systems problems to change substantially over time. Consequently, analyzing complex systems problems requires a broad knowledge base including both domain methods and content knowledge (Jonassen \& Hung, 2008).

To be able to make progress toward understanding a dynamic complex systems problem, a person needs to be able to explain the feedback structures that generate the problem and to identify the linkages that contribute to the problematic behavior. Analysts should be able to anticipate and explain why changes in the system behavior are occurring. Such understanding does not happen quickly, nor does it occur from merely observing patterns of behavior or manipulating simulations (Dörner, 1996, in Milrad, Spector, \& Davidsen, 2003).

Complex systems problems are significantly different from typical problems studied in high school mathematics today. To teach students to work with complex systems it is necessary to approach problems holistically. Students often need to look at a problem both qualitatively and quantitatively when attempting to gain insight into its 
structure. They must understand the individual component pieces, but also realize that the components change due to the dynamic interrelationships (Hung, 2009).

B. The need for instruction to address complex, dynamic, systems problems

John Sterman (2002), director of the System Dynamics Program at the Sloan School of Management at Massachusetts Institute of Technology (MIT), writes:

"As the world changes ever faster, thoughtful leaders increasingly recognize that we are not only failing to solve the persistent problems we face, but are in fact causing them. All too often, well-intentioned efforts to solve pressing problems create unanticipated "side effects.' Our decisions provoke reactions we did not foresee. Today's solutions become tomorrow's problems. The result is policy resistance, the tendency for interventions to be defeated by the response of the system to the intervention itself. From California's failed electricity reforms, to road building programs that create suburban sprawl and actually increase traffic congestion, to pathogens that evolve resistance to antibiotics, our best efforts to solve problems often make them worse" (p. 504).

Increasingly, people are asked to make decisions about complex phenomenon. Trying to deal with complex systems problems places "severe cognitive challenges on those who are required to develop solutions and formulate policies with regard to these systems" (Spector, 2008, p. 251). Herbert Simon (1996) indicates that people are constrained by bounded rationality, that is, decision makers do not have the all the necessary information, do not have the mental capacity to process all the interconnections, and are not given the time to make well informed decisions. Without training in the skills that might help them gain insight into the unintended consequences of such decisions, solutions will be elusive. "Conventional methods to teach problem solving are inadequate preparation for the wild and wicked [ill-structured] problems that confront society“ (Spector, 2008, p. 253). Forrester (2009), founder of the field of System 
Dynamics, and Germeshausen Professor Emeritus at MIT, stresses that introduction of systems analysis in the K-12 curriculum is a high leverage point for increasing the necessary preparation. If students learn to think more systemically they will make better decisions as adults.

System dynamics theory has been applied to the study of issues dealing with global warming, business and regulatory management decisions, natural resource degradation, supply-chain management, and many more complex systems. Not everyone has direct involvement in these systems, but as an informed citizenry, we are asked to vote on issues that impact parts of many complex systems. People tend to simplify complex issues when trying to understand their behavior and "therefore overlook side effects, feedback processes, and delays" (Reimann \& Thompson, 2009). If people do not have the capability to look at the interrelationships that occur in such complex systems they can have a partial or inaccurate understanding about the problem they are trying to analyze (Hung, 2009; Jonassen \& Strobel, 2006).

Forrester has identified multiple mistakes made in managing complex systems. Among those mistakes is inadequate analysis of potential unintended consequences that might result from implementing a new solution in a complex system. He states that short-term fixes usually result in long-term problems, that local goals often do not match up with global goals, and that policy decisions and implementation are often based on 
low leverage points in the system and so have small impact (Davies, ${ }^{1} 2002$, in Reimann et al., 2009).

Learning to address complex, dynamic, systemic problems is difficult and time consuming.

"Because of their inherent complexity and dynamic nature, systems are hard to model. Nevertheless, the end justifies the means, because systemic understanding is so much stronger than memorization. ... Dynamic modeling tools are the most effective for modeling systems because they can be tested. ... The most important outcomes of efforts to represent systems is the kind of system thinking that may result" (Jonassen, 2006, p. 53).

C. What does modeling, and specifically system dynamics modeling, have to offer for advanced learning?

In the process of educating people to enter the professional world, the educational system must help them develop habits of mind that are useful for their professional growth. Researchers have recommended facilitating experiences that lead novices to develop thinking patterns similar to the experts in their chosen profession (Hung, 2009; Milrad et al., 2003; Spector, 2009). Part of this cognitive growth requires that students alter their mental models (Davidsen, 2000; Jonassen, 2004). Mental models are "deeply ingrained assumptions, generalizations, or even pictures or images that influence how we understand the world and how we take action" (Senge, 2006, p. 8). It has been suggested that model building can be a successful strategy to get students to alter their mental models, deepening student understanding of problems being analyzed (Forrester, 2009; Hillen \& Gonzales, 2009; Jonassen, 2004; Jonassen, Strobel, \& Gottdenker, 2005, in

\footnotetext{
${ }^{1}$ Davies, C. H. (2002). Student engagement with simulations: a case study. Computers \& Education, 39(3), 271-282.

2 Jonassen, D., Strobel, J., \& Gottdenker, J. (2005). Model building for conceptual change. Interactive Learning Environments, 13(1-2), 15-37.
} 
Jonassen, 2009; Nicolaou, Nicolaidou, \& Constantinou, 2009; Seel \& Blumschein, 2009). One part of problem analysis that is very effective in changing mental models is the process of requiring an explicit replication of the system, a model, as the modeler understands it (Carney, Forbus, Ureel, \& Fisher, 2009). The model-building process helps reveal the modeler's mental model and tracks how it changes over the course of the modeling exercise. It also reduces cognitive load, helping the modeler develop nonlinear causal reasoning, dynamic thinking, closed-loop thinking, and more holistic thinking. (Hung \& Blumschein, 2009; Johnson, Bryden, \& Refsgaard, 2009) Research has shown, building dynamic models fosters higher level thinking processes including “analyzing, reasoning, synthesizing, testing/debugging, and explaining" (Stratford, Krajcik, \& Solway, 1998, p. 225).

It has been posited that students might gain insight that is just as useful from using pre-designed simulations, merely by manipulating parameters and observing the altered behavior that occurs from this activity. This type of simulation is referred to as "black-box." Certainly, if one is limited in the time that can be allocated to a simulation experience, a certain amount of information might be learned (Alessi, 2000). But access to the underlying model structure (glass-box) is needed if students are to gain a causal understanding of the system under study (Jonassen, Carr, \& Yeuh, 1998; Milrad et al., 2003; Spector, 2000). Jonassen et al. (1998) and Spector, Christensen, Sioutine, \& McCormack (2001) claim that students learn a great deal more from building objects than from just using them. Jonassen (2006) also states, "if you cannot build a model of what you are studying, then you do not understand what you are studying" (p. 4). 
Dörner (1996) showed that types of thinking that lead to failure (to solve a complex, systemic problem) develop gradually over time. He performed numerous experiments watching people make decisions about how to address the problems that emerge when they try to manipulate complex systems (via simulations). Participants who did not perform well in these experiments tended to act without analyzing the situation carefully and failed to anticipate side effects and long-term consequences of their actions. They assumed that when they dealt with the symptoms of the problem, it was solved, that they had made correct decisions. Dörner said, "people concern themselves with the problems they have, not the ones they don't have (yet)" (p. 52). Lack of systemic understanding tends to cause people to overlook the fact that new problems can emerge because immediate problems were addressed in a short-sighted fashion.

D. What does system dynamics have to offer to enhance mathematics instruction?

\section{Systems Thinking as Problem-Solving}

Understanding the causal relationships in a system is sometimes loosely referred to as systems thinking. Hung (2008) asserts that:

"Systems thinking is an essential cognitive skill that enables individuals to develop an integrative understanding of a given subject at the conceptual and systemic level. A deep, integrative conceptual understanding is the foundation for advanced applications and transfer of knowledge. Developing a deep and holistic understanding of a subject matter requires a full and complex integration of the knowledge under study, in which traditional mechanistic teaching methods and learning strategies fall short. More sophisticated thinking skills are required for students to engage in such higher order cognitive processes. Amongst these, systems thinking is an important one. Systemic understanding of a subject includes static integration of the individual concepts (parts) into an integrative body of knowledge (a system), as well as a dynamic depiction of the nature of the system" (p. 1099). 
Ossimitz ${ }^{3}$ (2000, in Hung, 2008) and Meadows (2008) add "thinking in closed loops" (feedback loops) and "understanding the impact of delays" as critical components in systems thinking, especially related to understanding the dynamics of complex systems.

\section{System Dynamics Modeling as Cognitive Technology}

Access to technology has transformed mathematics instruction in the last decade. Graphing calculators are used in most mathematics classrooms regularly. Access to interactive software such as Geometer's Sketchpad for geometry and web applets for use with statistics have provided much needed visualization tools to support learning difficult mathematical concepts. The use of algebraic solver software has also become almost commonplace in the teaching of Calculus. Examples include programs like Maple and devices like the TI 89 calculator and similar calculators from other companies. There are even web accessible programs that will solve equations (e.g., Wolfram Alpha).

Some of these tools Pea (1985) labeled as "amplifiers of thinking." The tools perform complicated calculations easily or graph relationships quickly so that patterns can be discerned. But Pea indicates cognitive tools provide a method for the human mind to "think differently" about a problem. Pea suggests that cognitive technologies help people "transcend the limitations of the mind, such as memory, in activities of thinking, learning, and problem solving.” Kaput and Roschelle (2000a) suggest computer technology has brought an enhancement to mathematics education in that 1 . previous knowledge is now learnable in new ways, using dynamic interaction capabilities, 2. "new

\footnotetext{
${ }^{3}$ Ossimitz, G. (2000). Teaching system dynamics and systems thinking in Austria and Germany. In P. Davidsen, D. N. Ford \& A. N. Mashayekhi (Eds.), Proceedings of the 18th International Conference System Dynamics Society. Bergen, Norway.
} 
representations provide a reconstitution of previously constructed knowledge," and 3. "construction of new systems of knowledge" is possible, specifically regarding analysis of complex systems, not accessible previously for pre-college students.

But not much progress has been made incorporating techniques that will enhance students understanding of dynamic, complex system problems, especially at the precollege level. There is abundant evidence that understanding complex systems is a pressing problem. What follows are some suggestions for how SD modeling can operate as a cognitive technology in the mathematics classroom.

\section{2.a SD Surfaces Students' Mental Models, Promoting Student Justification/} Discussion

Forrester (2009) says that working with systems should help students fine-tune their mental models. He indicates that people need a method to test their mental models and that SD modeling is an ideal vehicle for doing that. What this means for mathematics is that SD modeling is an ideal tool to help students identify and modify misconceptions about how they think a particular problem or system operates. The building process allows students to surface their mental models and the visual nature of the modeling software, the full word or phrase naming protocol for the icons, and the explicit display of dependences of one component upon another helps students describe and discuss their models with others. Highlighting mathematical structures within the model provide scaffolding for these discussions.

2.b SD Supports an Environment that can Enhance Conceptual Understanding of Algebra Functions 
The Importance of the Function Concept in Mathematics

The concept of functions plays a key role as a unifying concept in mathematics, so there has been a significant amount of research dedicated to trying to determine how best to facilitate student understanding of functions (Akkoc \& Tall, 2003; Clement, 2001;

Dubinsky \& Wilson, 2013; Hollar \& Norwood, 1999; Leinhardt, Zaslavsky, \& Stein, 1990).

"The concept of function is central to undergraduate mathematics, foundational to modern mathematics, and essential in related areas of the sciences. A strong understanding of the function concept is also essential for any student hoping to understand calculus - a critical course for the development of future scientists, engineers, and mathematicians"

(Oehrtman, Carlson, \& Thompson, 2008, p. 27).

Many of the articles talk about how to help students understand the theoretical definition of function, that it is a relationship between two variables with the restriction that for each element of the independent variable there is at most one element of the dependent variable. But Leinhardt et al. (1990) presents a broader window within which functions could be viewed. They suggest that a task involving functions, graphs, and graphing can be viewed from four perspectives:

- action (interpretation: classification, gaining meaning; or construction: prediction, generating an example of a function),

- situation (setting and context, i.e., is the task abstract or is it an application?),

- variables (static or dynamic, i.e. does the task involve discrete or continuous behavior), and

- focus (local/global, i.e., where is the attention placed, on details of given point or on general behavioral shape?).

A broader view of functions is helpful in the same way that understanding the concept of a car does not depend upon understanding how the combustion engine works (even though that is useful knowledge) but that cars can transport people or goods, are 
built for either speed or strength or both, have limitations regarding distance and terrain, have a finite lifetime, etc. Knowing each of these other characteristics gives someone who has never seen a car a better chance to recognize a car if they should happen upon one.

In a study conducted by Carlson, Jacobs, Coe, Larsen \& Hsu (2002) the researchers suggested that students who were entering the university did not understand functions very well. Thompson ${ }^{4}$ (1994, in Carlson et. al., 2002) indicates that an understanding of rate is an essential concept in understanding dynamical functional relationships, and that this understanding is slow to develop. He continues, suggesting that covariational reasoning ${ }^{5}$ is essential for understanding the Fundamental Theorem of Calculus. The results of the study conducted by Carlson et al., (2002) indicate

"the need for students to have opportunities to think about the covariational nature of functions in real-life dynamics events. We recommend that students be given lines of inquiry that compel probing reflections on their own understandings of patterns of change (involving changing rates of change). Accordingly, we believe that curricula at the high school and university should take into consideration the complexity of acquiring L5 (Instantaneous Rate) reasoning and should provide curricular experiences that sustain and promote this reasoning ability, especially when one considers its importance for understanding major concepts of calculus (e.g., limit, derivative, accumulation) and for representing and understanding models of dynamic function events" (p. 374).

\section{Learning Environments that Enhance Conceptual Understanding}

“Conceptual knowledge involves understanding concepts and recognizing their

applications in various situations" (Ben-Hur, 2006, p. 6). The author indicates that

4 Thompson, P. W. (1994a). Images of rate and operational understanding of the fundamental theorem of calculus. Educational Studies in Mathematics, 26, 229-274; Thompson, P. W. (1994b). Students, functions, and the undergraduate curriculum. In E. Dubinsky, A. H. Schoenfeld, \& J. J. Kaput (Eds.), Research in Collegiate Mathematics Education, I: Issues in Mathematics Education, (Vol. 4, pp. 21-44). Providence, RI: American Mathematical Society.

5 "Covariation is the mental process of coordinating the values of two quantities as they vary simultaneously" (Saldanha and Thompson in Thompson, Byerley, \& Hatfield, 2013, p. 126) 
conceptual knowledge grows when problems involve understanding connections and relationships between the individual parts of the problem as well as knowing what parts to include. He further states that this type of knowledge cannot be learned by rote memorization.

"Learning with understanding is essential to enable students to solve the new kinds of problems they will inevitably face in the future" (NCTM, 2000, p. 21). The NCTM Principles and Standards for Mathematics committee goes on to state that children are better able to learn with understanding when they have some control over their learning, where they can monitor their own progress, are challenged with difficult tasks that build their confidence, reflect on their thinking, and learn from their mistakes. Having students explain their work (Brandsford, Brown, Cocking, Donovan, \& Pellegrino, 2000) and reflect on their work (Heid \& Blume, 2008b) appears to be an important component in promoting conceptual understanding in the studies that they reviewed on the learning of mathematics.

In mathematics, visualization has played an important role in helping students "engage with and recover conceptual underpinnings [of problems] which may easily [be] bypassed by formal solutions" (Arcavi, 2003, 63). One might think the multiple representations of functions in mathematics, one of which is a graph (a visual representation), might enhance conceptual understanding of functions. Yet, Thompson (1994) suggests otherwise. He says that students tend to view each representation in isolation, separate bits of knowledge to be memorized. He suggests that to truly use multiple representations to enhance student understanding of functions “... [we must] 
orient students toward drawing connections among their representational activities in regard to the situation that engendered them" (p.24). Again, attention must be paid to explicitly connecting information.

In the book How People Learn it is suggested that environments that optimize learning should be learner-centered, knowledge-centered, assessment-centered, and community-centered (Bransford et al., 2000). Learner-centered learning is easy enough to define. Students must be actively engaged in the learning process. Knowledgecentered involves knowing what topics should be included in the curriculum, why they should be included, and how the teacher can determine if a student has mastered the topic. Assessment-centered means that student-thinking should be made visible to both the teacher and the other students in the class, allowing teachers to determine a student's mental model so they can provide the appropriate instruction. The authors indicate that assessment should be student-friendly so it can be a vehicle for students to improve their thinking. Finally, community-centered incorporates the establishment of classroom norms, for example, building student learning relationships and establishing a positive method of correcting misconceptions and raising questions. Community-centered also involves connecting what is being learned in class to the world outside the classroom. How Does System Dynamics Modeling Support Conceptual Understanding of Functions?

SD modeling addresses concerns raised in the previous section about the importance of functions by incorporating many of the strategies identified as useful in the enhancement of conceptual understanding. 
It is possible to construct small SD models that capture some of the core function behaviors that are used in algebra classes at the secondary mathematics level: linear, quadratic, exponential, convergent (goal-seeking), logistic, and sinusoidal. These models are structured so that a dynamic understanding of the behavior is reinforced. For example, linear model diagrams visually depict constant rates of change, exponential models visually depict rates of change that are proportional to the current function amount, etc. Models are constructed using icons (whose naming protocol uses full words or phrases) that are connected via arrow "wires" that explicitly identify the dependencies of one model component upon another. (See Figure 1 later in this document.) The model structure, developed from an understanding of the function's rate of change, allows a strong connection to be made between the model diagram and its graphical output. Moreover, when the model only depicts a single function, a connection between the model structure and its more traditional closed form symbolic representation can easily be made (Fisher, 2005), reinforcing the information gained by each representation. Since the software allows multiple component values in a model to be graphed on the same grid, covariational reasoning is practiced repeatedly, as the graphs are displayed as time-series. An example of such covariational reasoning is analyzing the graph of the population of a city over time. The graphs of the city's yearly number of births and number of deaths is graphed on the same grid so the relative position of the births and deaths graphs can be used to explain the shape of the population graph dynamics. 
The diagram structure of the functions is so easy to understand (it has been used successfully with students as young as 11 years of age) that the function diagrams can then be combined to study more sophisticated problems, such as drug pharmacokinetics, spread of epidemics, population dynamics, population and natural resource depletion, and predator/prey interactions, to name a few.

The SD modeling experience is a cognitive technology because the focus of the work students do with the functions comes from a "structure determines behavior" perspective, not from a manipulation of the closed form representation. Students look for the dynamic characteristics in the behavior of the problem they are studying and try to determine which functions or combinations of functions could produce that behavior. Students can quickly test "what-if" scenarios, adding model structure to fine-tune their analyses. The focus of the classroom work is on translating the problem to the SD symbolic representation, analyzing the output, having discussions to correct their own or other students' misconceptions, and testing "what-if" scenarios. Students are active learners, have control over their learning, can monitor their progress, and reflect on their thinking and the thinking of their peers as they modify their misconceptions and enhance their models. Assessment can be done using the model diagram as a depiction of the student's or group's mental model. More realistic community, national, and/or world problems can be included in the curriculum, as the SD modeling interface is highly intuitive for students to use.

Jonassen (2006) states that when students work primarily with formulas, they do not gain an understanding of the system within which the function operates. He also 
supports the value of multiple representation afforded by system dynamics software. He claims students are able to extract more meaning using tools that help them visualize concepts.

\section{2.c Access to Introductory Concepts of Calculus in Algebra Classes}

In the broader view of understanding functions, presented by Leinhardt et al. (1990) (constructing dynamic functions in certain contexts and using graphs/graphing) technology provides an avenue for examining patterns (Leinhardt et al., 1990) and for bringing the study of change dynamics to students who are at a mathematically younger level than Calculus (Heid \& Blume, 2008a; Kaput \& Roschelle, 1997; Roschelle, Pea, Hoadley, Gordin, \& Means, 2000; Tinker, 1990)

Core to system dynamics modeling is the concept of a stock (accumulation) and flow (rate of change of the stock value). System dynamics modeling not only provides analytical capabilities for understanding new problems involving complex systems, its tools (and underlying mathematical engine) are built using the fundamental concepts of calculus and differential equations. Students deal with accumulations and rates of change using icons, making the conceptual principles of introductory calculus available to students much younger than those in their junior or senior year of high school.

\section{2.d Access to the Study of Complex Systems}

The tools and techniques for addressing complex problems have been available to the educational community for decades. Fey (1989) presents examples of tools for modeling dynamic systems explaining that using such tools can help students deal with 
real problems that have complexity that would be beyond students' reach using traditional mathematical approaches. He cites Brolin and Greger ${ }^{6}$ (1987) who state that mathematics instruction should not continue to teach students those skills that the computer can do faster and better. Fey claims modeling tools, such as STELLA, provide students not only access to another representation, but support conceptual understanding desired by mathematics teachers. Johnson et al. (2009) also claim that tools such as STELLA are very useful for people who are not experts in complex systems analysis, making it ideal for introducing students to problems involving complex system.

\section{E. Research on Value of System Dynamics Modeling in High School Algebra}

The following chapters in this dissertation will include a relatively large background chapter containing information explaining the components of the STELLA software so the reader will be able to read the model diagrams. The background chapter also includes an extensive list of value-added learning benefits that have been documented to accompany model-building activities for students, a list of barriers that researchers have found that hinder teachers from incorporating modeling/technology/complex systems analysis in their classrooms, suggestions for teaching SD to students, and suggestions for helping teachers become more comfortable using technology in their instruction. It also contains four research papers that each have a specific audience for whom the content is intended. Those papers are described briefly below.

${ }^{6}$ Brolin, H., \& Greger, K. (1987). Computers and the Teaching of Mathematics. Department of Teacher Training, Uppsala, Sweden: Uppsala University. 
Although it is appropriate to use System Dynamics (SD) modeling in quite a few high school disciplines (mathematics, environmental science, biology, physical science/physics, economics, social science, and health), the present research aims to add to the current literature by 1 . Introducing System Dynamics modeling to the mathematics education research community and presenting its value for learning mathematics (chapter 3, Paper 1), 2. Indicating the need for mathematics teachers to move beyond sole reliance on the closed form representation for mathematizing problems (chapter 4, Paper 2), and 3. Providing the results of two case study experiments focused on how one might influence teachers to incorporate SD modeling activities in their in high school algebra II classes (chapters 5 and 6, Papers 3 and 4). Paper 3 explains the experimental design and results as it relates to the teachers and the teaching environment. Paper 4 explains the experimental design and results as it relates to the students.

Kelly, Baek, Lesh, and Bannan-Ritland (2008) indicate that for an innovation to have the potential for adoption it cannot stray too far from existing practice, in a given environment. So, in the third and fourth paper (chapters 5 and 6), although the research experiments will not incorporate the full power of System Dynamics (SD) modeling for student learning, the objective is to test a sequence of simulation activities (enactive, iconic, and symbolic) and determine whether the learning outcomes from the use of these SD simulation can have a positive influence on student understanding of function behavior in the context of real world scenarios, when used in a traditional algebra classroom. That is, the objective is to show that using small models and SD modeling lessons can have an immediate and positive impact on student learning. 
Following the four papers each of which is presented as a separate chapter (chapters $3-6$ ), is a final chapter (chapter 7) that synthesizes and discusses the overall dissertation results and contributions.

\section{Background}

A. System Dynamics Modeling: A Brief Introduction

"System dynamics ... deals with how things change through time. That covers a great deal of what most people find important." (Forrester, 1996, p. 1). Sterman (2000), one of Forrester's students, adds, "Because we are concerned with the behavior of complex systems, system dynamics is grounded in the theory of nonlinear dynamics and feedback control developed in mathematics, physics, and engineering." (p. 5)

Before continuing with how System Dynamics modeling might help students understand the nature of some dynamic systems in the world, it will be necessary to introduce the modeling symbols or icons and structure to enable the reader to conceptualize how it might fit with the theory and research that will be presented later in this dissertation.

Each System Dynamics modeling software contains elements that

represent accumulations of "stuff" over time. This "stuff" can be physical, like people in a city, or can be abstract, like "concern about the level of pollution" in an area. The accumulator is identified as a "stock" and usually has an icon shaped as a rectangle. The stock will increase or decrease in value over time. It represents one of the elements in our model whose value we want to track. 
A flow (usually represented as an arrow with a wide shaft with a valve symbol at its center) represents a rate at which a stock value is changing. If the flow arrowhead is pointing toward the

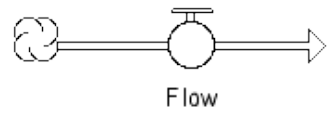
stock, a positive value (within the icon) represents a rate of increase in the stock value. If the flow arrowhead is pointing away from the stock, a positive value (within the icon) represents a rate of decrease in the stock value.

Another icon is called a converter. It is represented as a circle and is used to hold parameter values or formulas for auxiliary variables important to system logic.

Finally, there is an icon called a connector. It is represented by a thinly shafted arrow that connects converters to flows, converters to

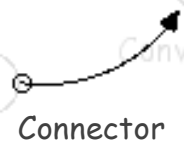
other converters, stocks to flows or stocks to converters. It acts like a telephone line, communicating numeric information between components so that formulas can be updated each time step. A diagram might help clarify the interconnections.

A simple example will be used to demonstrate how one might design a stock/flow model to study population dynamics. 


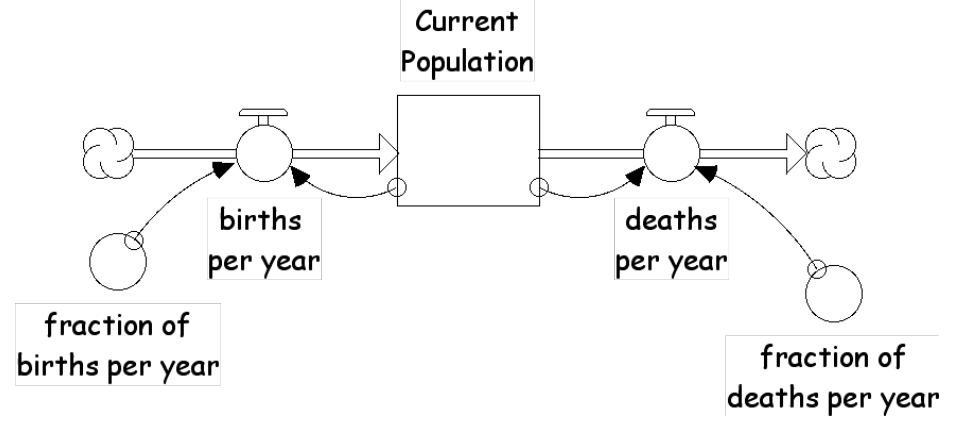

Figure 1: System Dynamics model of a population in a region.

In Figure 1 the stock, Current Population, is the variable whose value we want to track over time. It is given a starting value before the simulation is executed. This stock value is increased by births per year and decreased by deaths per year. Births per year depend upon two pieces of information, the Current Population amount, and the fraction (whose decimal value is held in fraction of births per year) of that population that produces a live birth each year. The two arrow connectors communicate the required information to the flow births per year, each time step, so the flow can multiply them and increase the stock value by the appropriate amount (the product it has just calculated). Similarly, the value of the outflow deaths per year, is calculated as the product of the Current Population value and the fraction (a decimal fraction stored in fraction of deaths per year) of that population that is dying each year. The Current Population is increased by births per year and decreased by deaths per year each time step of the simulation.

The model diagram also makes feedback easy to observe. There is a reinforcing (positive) feedback between the stock and the inflow (observe the closed loop in Figure 1: Current Population to births per year to Current Population). The larger the Current Population the more births per year there will be, and the more births per year there are the larger the Current Population will grow. There is a balancing (negative) feedback 
between the stock and the outflow (Current Population to deaths per year to Current Population). The larger the Current Population the more deaths per year there are, but more deaths per year will produce a smaller Current Population.

The value of any icon in the model can be displayed in graphical form or tabular form, showing the pattern of change in that variable over time. Hence, we are able to explain the graphical time series pattern of change shown in the stock value by comparing it (on the same grid) with the graphical patterns of change of each of its flow values.

The stock is an accumulator, hence is performing a mathematical integration, and the flows represent how the accumulator value is changing over time and hence they represent components of the derivative of the stock variable. The diagram is a visual, conceptual representation of basic calculus principles, in a format easy enough for middle school students to understand. The engine "under the hood" of the software uses numerical methods (Euler or Runge-Kutta) to approximate the solution of the systems of differential equations that is constructed as the model is designed.

There are other constructs available to facilitate the representation and display of non-linear behavior, but they are not essential at this point. The four icons described above constitute the entirety of the foundational components in System Dynamics modeling.

When students build simple models, it is relatively easy to put individual simple model structures together to represent more sophisticated scenarios, similar to the way small Lego structures are assembled to construct a larger Lego system. 


\section{B. More About System Dynamics and Its Relation to How People Learn}

To learn with understanding, the ability to internalize concepts and make them one's own so they become tools for further learning, a foundation upon which intellectual growth can take place, is one of the overarching goals society is called upon to provide for children (Mansilla \& Jackson, 2011; OECD, 2008)

"Deep understanding implies that the information is well-represented and well-connected. The greater the number and strength of the connections, the deeper the understanding. New information can be well-connected to existing knowledge and/or the pieces of the new information can be wellconnected from within" (Grotzer, 1999).

Mathematics education has had, for years, the goal of teaching students so that they gain a deeper understanding of the concepts of mathematics thereby enabling them to apply the concepts to other problems within and outside of the discipline of mathematics (Bransford et al., 2000; NCTM, 2000). Modeling complex systems is almost always a multi-disciplinary endeavor for which it is essential to develop a deep understanding of concepts involved in capturing and analyzing the dynamics of the problem.

To become more informed about strategies for realizing this goal in math and science education, let's turn to some well known learning theorists, Lev Vygotsky and Jerome Bruner. Lev Vygotsky suggested that learning should be a socially active endeavor, where students are expressing their thinking, and the teacher is facilitating the process. This interaction should be cooperative and collaborative (i.e., the teacher uses demonstrations and leading questions) to be effective. Teachers do not transmit concepts. "If concept development is to be effective in the formation of scientific concepts [those new ideas learned in school] instruction must be designed to foster conscious awareness 
of concept form and structure and thereby allow for individual access and control over acquired scientific concepts" (Vygotsky in Daniels, Cole, \& Wertwch, 2007, p. 312).

Vygotsky is best known for his idea called the "Zone of Proximal Development" (ZPD). The zone of proximal development is represented as a gap between what the student could learn by him/herself and what he/she could learn with the help of more knowledgeable peers and/or the teacher. Vygotsky indicated that the trajectories for individual student learning in this zone are quite open and will follow dynamic and divergent paths. The objective of the "instruction" is, however, to help the student eventually internalize the new knowledge. Vygotsky (1978) indicated that essential (good) learning should create a ZPD (“awaken a variety of internal developmental processes in the child that are activated by working cooperatively with peers and other people in his/her environment," p. 90) that is forward looking, developmentally, rather than testing, which is backward (ineffective) looking. In this way, Vygotsky said, once the processes within the child become internalized they lead to independent developmental achievement (Vygotsky, 1997, italics added).

Jerome Bruner was influenced by Vygotsky as we see more of Bruner's writing start to reflect the importance of social and cultural influence on learning in his later writing (Bruner, 2009b). Bruner states that the teacher or peer acts as:

“... a vicarious form of consciousness until such time as the learner is able to master his own action through his own consciousness and control. When the child achieves that conscious control over a new function or conceptual system, it is then that he is able to use it as a tool. Up to that point, the tutor [teacher or peer] in effect performs the critical function of "scaffolding" the learning task to make it possible for the child, in Vygotsky's word, to internalize external knowledge and convert it into a 
tool for conscious control" (Bruner ${ }^{7}, 1985$, p 24, in Newman \& Holzman, 2005, p. 137).

Bruner has written numerous books and articles on education and learning theory. He believes that children progress continuously in their cognitive growth rather than in stages, as suggested by Piaget. He stresses the use of language as instrumental in cognitive development and that a more knowledgeable teacher and/or peer can speed up a child's cognitive development. But what about depth of learning?

Bruner (1966) proposes three modes of acquiring new ideas, referred to as his three modes of representation: enactive, iconic, and symbolic. These modes are especially interesting for those educators interested in system dynamics modeling. The first mode, enactive, involves students working with concrete objects, that is, learning is hands-on. Students manipulate objects or act out a part in a story. The effective use of physical play-acting or manipulating devices when teaching students to create system dynamics models is evidenced in the most popular books/lessons developed by K-12 teachers who have used system dynamics modeling in their instruction for many years. Activities like using popsicle sticks in a jar to represent trees being planted or cut in a forest, or students standing in a circle and moving vertically up or down to represent the two types of feedback (reinforcing or balancing), or students walking in front of a motion detector to replicate linear behavior patterns, are often used as precursors to modeling

\footnotetext{
${ }^{7}$ Bruner, J. S. (1985). Vygotsky: A historical and conceptual perspective. In J. Wertsch (Ed.). Culture, Communication and Cognition: Vygotskian Perspectives (pp. 21-34). Cambridge, UK: Cambridge University Press.
} 
activities (Booth-Sweeney \& Meadows, 2001; Fisher, 2005; Quaden, Ticotsky, \& Lyneis, 2008). ${ }^{8}$

Bruner's second mode of representation is iconic. In the iconic mode students use images, pictures, diagrams, or graphs to represent concrete ideas or situations that they experienced in the first mode. The iconic representation is still quite concrete as the representation is directly connected to the physical activity (from the enactive mode). For system dynamics learning this would be the use of graphs to represent change over time, perhaps representing the level of curiosity of a character from a story that was read, or the graph of motion displayed by a computer projector on the overhead screen in a classroom as a student walks in front of a motion detector. In both the enacting and iconic representations students are developing mental models of how their activity represents some concept the teacher is trying to convey.

The third mode of representation Bruner proposes is symbolic. Here the abstract concepts of numbers and words or other symbols are used to allow a student to organize their thinking. The intention is that the abstraction does not require the direct connection to the concrete activity from which it arose. In this stage system dynamics reaches its most powerful application. The symbols are the stocks, flows, converters, and connectors students use to represent the elements they experienced in the enacting representation. They connect the elements, define the components and finally execute the symbolic model to produce a graph that should display the same type of behavior that was

\footnotetext{
${ }^{8}$ Although not in published form, teacher leaders from the Waters Foundation (www.watersfoundation.org), who also teach a significant number of elementary and middle school teachers systems thinking and some system dynamics modeling often use physical manipulation and playacting to initiate these systems lessons.
} 
evidenced in the iconic mode. Often the simple model structures are then applied to scenarios that the student did not experience in the enacting mode.

Throughout the process of model-building, students work in teams, talking about the elements to use, how to connect and define the elements, and whether the output is realistic. Students are then expected to explain how their model was constructed, why the elements are connected as they are, and experiment with the model to strengthen the belief that the model is a reasonable representation of the system (verification and validation techniques). Finally, students can use the model to test policies that might alter the output of the original model, either changing parameters or adding structure to the model in the policy stage. By working in teams to design and test a model, students are replicating the process used by professional System Dynamics modelers when they study real world problems. So the team method of building System Dynamics models, used consistently in K-12, is well grounded in learning theory as an effective learning strategy.

System Dynamics modeling was first studied at the graduate level at some of the top tier universities around the world. It was thought that the techniques were too difficult for children to learn. Barry Richmond, a student of Jay Forrester, developed the STELLA software in 1985 . The simple design and use-friendly interface make the study of SD accessible to a broader audience. A surprising number of K-12 teachers have figured out how to bring SD modeling into their classrooms. This offers some support to another of Bruner's beliefs, that “... any subject can be taught effectively in some 
intellectually honest form to any child at any stage of development... No evidence exists to contradict it ...” (Bruner, 2009a, p 33).

In his more recent writings Bruner emphasizes the influence of culture on how and what we learn. He says without culture the mind could not exist.

"For the evolution of the hominid mind is linked to the development of a way of life where "reality" is represented by a symbolism shared by members of a cultural community in which a technical-social way of life is both organized and deconstrued in terms of that symbolism.... Meaning making involves situating encounters with the world in their appropriate cultural contexts in order to know "what they are about"' (Bruner, 2009b, p160-162).

Forrester would agree, but goes a step further. He indicates that to capture the behavior of a system one must mine the mental models of those who are involved with the system.

“...all decisions are made on the basis of mental models. ...Decisions are based only on assumptions about separate parts of real systems, and trying by intuition to fit those fragments of knowledge into an estimate of how things change and what will be the consequences of a proposed action. ... a system dynamics model is often built from assumptions in the mental models.... mental models are rich and often sufficiently accurate about pieces of a system.. [but they] are entirely unreliable in deducing what behavior will result from the known pieces of a complex system..." (Forrester, 1996, p.13).

To determine the true behavior of a complex system one must design a computer simulation as it will "reveal the behavior implicit in the structure from which it is constructed" (Forrester, 1996, p. 13).

Mental models can be inconsistent, can change over time, and can be different for different people discussing the same problem (Forrester, 1995). System Dynamics modeling can act as an aid to surface the mental model of a group studying a problem as the stock/flow diagram is drawn to reveal the system structure indicated by the group. 
Through conversations about the model design, and simulated results of the design, the group can come to a more generally accepted structure, thus allowing people in the group to modify their mental models accordingly. Bruner would suggest that this is a way people learn as "'how the mind works" is itself dependent on the tools at its disposal" (Bruner, 2009b, p160).

Another agreed-upon exercise that supports learning is to have students think about how they think, when they solve problems (Chi, DeLeeuw, Chiu, \& LaVancher, 1994; Fusion, Kalchman, \& Bransford, 2005; OECD, 2014; Pea, 1985). Students are able to surface their mental models, using the System Dynamics software, by laying out the structure of how they think a system under study is structured, including dependencies and feedback. It opens to the rest of the team a vehicle for communication. The designers talk about why they have designed the structure as shown and others can comment upon their thinking. The power then is that the computer becomes an arbiter of what is actually displayed. The simulation is executed and, if it does not produce the expected output, the team goes back to the diagram and analyzes how they were thinking about the problem and how they will have to adjust their thinking, and their diagram, to try to capture a more realistic behavior. The model diagram acts as a vehicle for facilitating metacognitive activity.

To take this idea of metacognition one step further, since the software is so visual, it also allows teachers an opportunity to try to design models about how they believe students learn (Fisher, 2010; Hirsch, 2006; Richmond, 2004; Svensson \& Mats, 2002). 


\section{More Background Research}

This section is broken into three parts. The first part reviews the results of experiments conducted to study the effect of learning about complex systems for both students and teachers. The second part supplements the first, but includes observations from researchers who did not conduct experiments. The third section pulls out the topic of comparing novice and expert problem solvers. As with conceptual understanding of core principles in math and science, moving students from novice to expert problem solvers is an overarching concern for educators.

1a. Results from experiments: Students

Improving conceptual understanding of a given problem or set of problems is perhaps the most important product of a learning environment that includes model building. There are, however, many other desirable outcomes that are possible when students are actively engaged in the study of systemic problems.

What follows are two categories of positive outcomes demonstrated and/or observed in research studies where experiments were conducted involving students in the analysis of systemic problems. The first category deals with student behaviors that would be desirable learning outcomes from any effective learning activity. See Table 1 . The second category deals specifically with desirable learning outcomes that address an attempt to have students learn more about complex systems. See Table 2.

The studies cited dealt with six modalities directly or closely related to using modeling or higher level problem solving techniques. To assist the reader with the references and the specific category of problem study the research addressed, the 
following tags will be placed after each cited reference. (1) Will specify the use of system dynamics modeling (model building) strategies, (2) will specify the use of systems thinking strategies, including causal loop diagramming, (3) will specify merely the use of technology in problem solving, perhaps computers and/or graphing calculators, (4) will specify the use of modeling concepts (not system dynamics) and technology, (5) will specify the use of microworlds - predesigned models where students manipulate parameters, and (6) will specify high level problem solving strategies, not necessarily applied to computer modeling.

In the first category, the desirable outcomes from an effective activity that dealt with one (or more) of the six categories described above were:

Table 1: Research supporting desirable learning outcomes from any effective learning activity.

\begin{tabular}{|l|l|l|}
\hline & $\begin{array}{l}\text { Desirable Learning } \\
\text { Outcome }\end{array}$ & $\begin{array}{l}\text { References: Both from empirical research (ER) } \\
\text { and from non-empirical (NER) research }\end{array}$ \\
\hline 1 & $\begin{array}{l}\text { An increased motivation to } \\
\text { learn }\end{array}$ & $\begin{array}{l}\text { ER: Jackson, Stratford, Krajcik, \& Soloway, } \\
\text { 1994 (1) } \\
\text { NER: Steed, 1992; Tinker, 1990 }\end{array}$ \\
\hline 2 & $\begin{array}{l}\text { An opportunity for students to } \\
\text { become active learners }\end{array}$ & $\begin{array}{l}\text { ER: Confrey \& Doerr, 1994 (4); Heid et al., } \\
\text { 2008b (3); Mandinach, Thorpe, \& Lahart, 1988 } \\
\text { (1 \& 2); Mandinach \& Cline, 1993 (1 \& 2); } \\
\text { Mandinach \& Cline, 1994 (1 \& 2); Spector et } \\
\text { al., 2001 (1 \& 2); Stratford et al., 1998 (1 \& 2) } \\
\text { NER: Doerr, 1996; Papert, 1980; Roschelle et } \\
\text { al., 2000 }\end{array}$ \\
\hline 3 & $\begin{array}{l}\text { An opportunity for students to } \\
\text { practice inquiry }\end{array}$ & $\begin{array}{l}\text { ER: Confrey et al., 1994 (4) } \\
\text { NER: Doerr, 1996; Pea, 1985; Steed, 1992 }\end{array}$ \\
\hline 4 & $\begin{array}{l}\text { An opportunity for students to } \\
\text { take ownership of their } \\
\text { knowledge }- \text { construct their } \\
\text { own knowledge }\end{array}$ & $\begin{array}{l}\text { ER: Confrey et al., 1994 (4) } \\
\text { NER: Pea, 1987; Roschelle et al., 2000; Steed, } \\
\text { 1992 }\end{array}$ \\
\hline 5 & $\begin{array}{l}\text { An opportunity for students to } \\
\text { have access to real-world } \\
\text { problems }\end{array}$ & $\begin{array}{l}\text { ER: Stratford et al., 1998 (1 \& 2); Tinker, 1990 } \\
\text { (1 \& 2) } \\
\text { NER: Jacobson \& Wilensky, 2006; Lesh, 2006; }\end{array}$ \\
\hline
\end{tabular}




\begin{tabular}{|c|c|c|}
\hline & & $\begin{array}{l}\text { Papert, 1980; Pea, 1987; Roschelle et al., 2000; } \\
\text { Steed, } 1992\end{array}$ \\
\hline 6 & $\begin{array}{l}\text { An opportunity for students to } \\
\text { explore problems beyond } \\
\text { what they would normally be } \\
\text { able to study }\end{array}$ & $\begin{array}{l}\text { ER: Tinker, } 1990 \text { (1 \& 2) } \\
\text { NER: Blume \& Heid, 2008; Doerr, 1996; } \\
\text { Forrester, 1987; Heid et al., 2008a; Jacobson et } \\
\text { al., 2006; Pea, 1987; Roschelle et al., 2000; } \\
\text { Steed, } 1992\end{array}$ \\
\hline 7 & $\begin{array}{l}\text { An enhancement of } \\
\text { conceptual understanding of } \\
\text { the problem }\end{array}$ & $\begin{array}{l}\text { ER: Heid et al., 2008b (3); Mandinach et al., } \\
1988 \text { (1 \& 2); Mandinach et al., } 1993 \text { (1 \& 2); } \\
\text { Mandinach et al., } 1994 \text { (1 \& 2) } \\
\text { NER: }\end{array}$ \\
\hline 8 & $\begin{array}{l}\text { An opportunity for students to } \\
\text { operate at the top of Bloom's } \\
\text { Taxonomy - creating and } \\
\text { synthesizing }\end{array}$ & $\begin{array}{l}\text { ER: Stratford et al., } 1998 \text { (1 \& 2) } \\
\text { NER: Forrester, } 1991 \text { (as cited in Doerr, 1996, } \\
\text { p. 208) }\end{array}$ \\
\hline 9 & $\begin{array}{l}\text { A demonstration of an } \\
\text { increased need for reflection } \\
\text { upon their work }\end{array}$ & $\begin{array}{l}\text { ER: Confrey et al., } 1994 \text { (4); Dörner, } 1996 \text { (5); } \\
\text { Heid et al., 2008b (3) } \\
\text { NER: Blume et al., 2008; Mandinach et al., } \\
\text { 1988; Pea, } 1987\end{array}$ \\
\hline 10 & $\begin{array}{l}\text { A demonstration of an } \\
\text { increased need for students to } \\
\text { communicate effectively }\end{array}$ & $\begin{array}{l}\text { ER: Jackson et al., } 1994 \text { (1); Stratford et al., } \\
1998 \text { (1 \& 2) } \\
\text { NER: Confrey et al., 1994; Doerr, 1996; Otero, } \\
\text { Peressini, Meymaris, Ford, Garvin, Harlow..., } \\
\text { 2005; Pea, 1985; Steed, } 1992\end{array}$ \\
\hline
\end{tabular}

The previous ten desirable outcomes alone would support the recommendation for more modeling activities in the school curriculum. But these are only the beginning of a more substantive list of positive outcomes that modeling systemic problems has demonstrated. In the second category, the list of desirable learning outcomes from modeling systems, that were demonstrated from research studies were:

Table 2: Research supporting desirable learning outcomes when students model systems.

\footnotetext{
${ }^{9}$ Forrester, J. (1991). System dynamics-adding structure and relevance to pre-college education. In K. R. Manning (ed.), Shaping the Future. Boston, MA: MIT Press.
} 


\begin{tabular}{|c|c|c|}
\hline & Desirable Learning Outcome & $\begin{array}{l}\text { References: Both from empirical research } \\
\text { (ER) and from non-empirical (NER) research }\end{array}$ \\
\hline 11 & $\begin{array}{l}\text { An opportunity for students to } \\
\text { enhance their intuition about } \\
\text { how the world works }\end{array}$ & $\begin{array}{l}\text { ER: Dörner, } 1996 \text { (5); Hung, } 2008 \text { (1 \& 2); } \\
\text { Jackson et al., } 1994 \text { (1); Mandinach et al., } \\
1988 \text { (1 \& 2); Roberts \& Barclay, } 1988 \text { (1 \& } \\
\text { 2); Stratford et al., } 1998 \text { (1 \& 2) } \\
\text { NER: }\end{array}$ \\
\hline 12 & $\begin{array}{l}\text { Accessibility by a wide range of } \\
\text { students to core ideas about } \\
\text { complex systems }\end{array}$ & $\begin{array}{l}\text { ER: Tinker, } 1990(1 \& \text { 2) } \\
\text { NER: Ang, 2001; Jacobson et al., 2006; } \\
\text { Roschelle et al., } 2000\end{array}$ \\
\hline 13 & $\begin{array}{l}\text { A lower level of abstraction } \\
\text { when trying to model problems }\end{array}$ & $\begin{array}{l}\text { ER: Hung, } 2008 \text { (1 \& 2); Tinker, } 1990 \text { (1 \& } \\
\text { 2) } \\
\text { NER: Roschelle et al., 2000; Steed, } 1992\end{array}$ \\
\hline 14 & $\begin{array}{l}\text { An opportunity to understand a } \\
\text { problem more deeply }\end{array}$ & $\begin{array}{l}\text { ER: Hung, } 2008 \text { (1 \& 2); Jackson et al., } 1994 \\
\text { (1); Stratford et al., } 1998 \text { (1 \& 2) } \\
\text { NER: Bliss \& Ogborn, }{ }^{10} 1989 \text { (as cited in } \\
\text { Doerr, } 1996 \text { p. 205); Steed, } 1992\end{array}$ \\
\hline 15 & $\begin{array}{l}\text { An opportunity to express and } \\
\text { experiment with their own ideas }\end{array}$ & $\begin{array}{l}\text { ER: Confrey et al., } 1994 \text { (4); Hung, } 2008 \text { (1 } \\
\text { \& 2); Jackson et al., } 1994 \text { (1) } \\
\text { NER: Coon, }{ }^{11} 1988 \text { (as cited in Doerr, 1996, } \\
\text { p. 271); Papert, } 1980\end{array}$ \\
\hline 16 & $\begin{array}{l}\text { Gaining insight into how } \\
\text { complex systems work }\end{array}$ & $\begin{array}{l}\text { ER: Hmelo-Silver, Marathe, \& Liu, } 2007 \text { (2); } \\
\text { Hung, } 2008 \text { (1 \& 2); Jackson et al., } 1994 \text { (1); } \\
\text { Mandinach et al., } 1993 \text { (1 \& 2); Roberts et al., } \\
1988 \text { (1 \& 2); Skaza \& Stave, } 2009 \text { (2); } \\
\text { Spector et al., } 2001 \text { (1 \& 2); Stave, } 2012 \text { (1 \& } \\
\text { 2); Stratford et al., } 1998 \text { (1 \& 2) } \\
\text { NER: Forrester, 1986, 1987; Steed, } 1992\end{array}$ \\
\hline 17 & $\begin{array}{l}\text { An opportunity to understand } \\
\text { the process of change in the } \\
\text { world }\end{array}$ & $\begin{array}{l}\text { ER: Spector et al., } 2001 \text { (1 \& 2); Stratford et } \\
\text { al., 1998, (1 \& 2) } \\
\text { NER: Chen et al., 1993; Forrester, 1987; } \\
\text { Lesh, 2006; Steed, 1992; Tinker, } 1990\end{array}$ \\
\hline 18 & $\begin{array}{l}\text { Ability to reason qualitatively } \\
\text { about systems }\end{array}$ & $\begin{array}{l}\text { ER: Spector et al., } 2001 \text { (1 \& 2); Spector, } \\
2009 \text { (2); Stratford et al., } 1998 \text { (1 \& 2) } \\
\text { NER: Clauset, Rawley, \& Bodeker, }{ }^{12} 1987 \text {; } \\
\text { Coon, 1988; Mandinach, }{ }^{13} 1989 \text { (previous } 3 \\
\text { references as cited in Doerr, 1996, p. 210); }\end{array}$ \\
\hline \multicolumn{3}{|c|}{$\begin{array}{l}{ }^{0} \text { Bliss, J. and Ogborn, J. (1989). Tools for exploratory learning. Journal of Computer Assisted Learning 5(1): 37-50. } \\
1 \text { Coon, T. (1988). Using STELLA simulation software in life science education. Computers in Life Science Education } \\
\text { (9): 65-71. }\end{array}$} \\
\hline
\end{tabular}




\begin{tabular}{|c|c|c|}
\hline 19 & $\begin{array}{l}\text { An opportunity to formulate } \\
\text { and test hypotheses }\end{array}$ & $\begin{array}{l}\text { ER: Dörner, } 1996 \text { (5); Jackson et al., } 1994 \\
\text { (1); Mandinach et al., } 1988 \text { (1 \& 2); Stratford } \\
\text { et al., } 1998 \text { (1 \& 2) } \\
\text { NER: Coon, } 1988 \text {; Mandinach \& Cline, }{ }^{14} \\
\text { 1989; Roberts, }{ }^{15} \text { 1981; Steed, } 1992 \text { (previous } \\
4 \text { references as cited in Doerr, 1996, p. 208); } \\
\text { Forrester, 1987; Pea, } 1987\end{array}$ \\
\hline 20 & $\begin{array}{l}\text { An opportunity to understand } \\
\text { the importance of feedback }\end{array}$ & $\begin{array}{l}\text { ER: Dörner, } 1996 \text { (5); Hmelo-Silver et al., } \\
2007 \text { (2); Hung, } 2008 \text { (1 \& 2); Spector et al., } \\
2001 \text { (1 \& 2); Spector, } 2009 \text { (2) } \\
\text { NER: Forrester, 1986; Lesh, } 2006\end{array}$ \\
\hline 21 & $\begin{array}{l}\text { An opportunity to gain an } \\
\text { appreciation for } \\
\text { interconnections }\end{array}$ & $\begin{array}{l}\text { ER: Hmelo-Silver et al., } 2007 \text { (2); Hung, } \\
\text { 2008 ( } 1 \text { \& 2) } \\
\text { NER: }\end{array}$ \\
\hline 22 & $\begin{array}{l}\text { An opportunity to experience } \\
\text { the iterative process of } \\
\text { understanding difficult } \\
\text { concepts }\end{array}$ & $\begin{array}{l}\text { ER: Ben-Zvi-Assaraf \& Orion, } 2010 \text { (2); } \\
\text { Confrey et al., } 1994 \text { (4); Dörner, } 1996 \text { (5); } \\
\text { Hung, } 2008 \text { (1 \& 2); Jackson et al., } 1994 \text { (1); } \\
\text { Mandinach et al., } 1988 \text { (1 \& 2); Stein, Grover, } \\
\text { \& Henningsen, } 1996 \text { (6); Stratford et al., } 1998 \\
\text { (1 \& 2) } \\
\text { NER: Mandinach et al., 1993; Steed, } 1992\end{array}$ \\
\hline 23 & $\begin{array}{l}\text { An opportunity to participate } \\
\text { in cognitively demanding } \\
\text { experiences }\end{array}$ & $\begin{array}{l}\text { ER: Ben-Zvi-Assaraf et al., } 2010 \text { (2); } \\
\text { Stratford et al., } 1998 \text { ( } 1 \text { \& 2)). Note: Meer } \\
\text { parameter manipulation of models is the least } \\
\text { cognitively demanding (Mandinach \& Cline, } \\
1993 \text { (1 \& 2) } \\
\text { NER: Doerr, 1996; Mandinach et al., 1993; } \\
\text { Steed, } 1992\end{array}$ \\
\hline 24 & $\begin{array}{l}\text { Ability to transfer } \\
\text { understanding to new topics }\end{array}$ & $\begin{array}{l}\text { ER: Roberts et al., } 1988(1 \& 2)) \text {; Hung, } \\
2008(1 \& \text { 2). Note: Meer parameter } \\
\text { manipulation of models does not often } \\
\text { promote transfer of systemic understanding to } \\
\text { new topics (White, }{ }^{16} 1984 \text { (as cited in Doerr \& } \\
\text { Pratt, 2008, p. 268) (4) } \\
\text { NER: }\end{array}$ \\
\hline
\end{tabular}

\footnotetext{
14 Mandinach, E. and Cline, H. (1989). Applications of simulation and modeling in precollege education. MachineMediated Learning 3: 189-205.

15 Roberts, N. (1981). Introducing computer simulation into the high schools: an applied mathematics curriculum. Mathematics Teacher, 647-652.

${ }^{16}$ White, B. Y. (1984). Deisgnig computer games to help physics students understand Newton's Laws of Motion. Cognition and Instruction, 1, 69-108.
} 
25 An opportunity to gain access to metacognition
ER: Ben-Zvi-Assaraf et al., 2010 (2) NER: Steed, 1992

These desirable learning outcomes, from participating in a modeling activity, do not happen by chance. The teacher must design the lesson and support reflections and conversations that explicitly promote the desired outcomes (Ben-Zvi-Assaraf et al., 2010; Hung, 2008; Mandinach, 1987; Mandinach et al., 1988, Yerushalmy, ${ }^{17} 1991$ (as cited in Heid et al., 2008a, p. 71).

1b. Results from experiments: Challenges for Teachers

Let's turn our attention now to those studies that have focused on preparing teachers to provide such learning experiences. Unfortunately, efforts have been largely unsuccessful in promoting a lasting change, if any change, in most teachers' classrooms that participated in these studies. The challenges/barriers that teachers faced will be identified. Teachers were concerned about:

Table 3: Research supporting challenges/barriers for teachers attempting to provide some of the desirable learning experiences previously enumerated.

${ }^{17}$ Yerushalmy, M. (1991). Student perceptions of aspects of algebraic function using multiple representation software. Journal of Computer Assisted Learning, 7 (1), 42-57. 


\begin{tabular}{|c|c|c|}
\hline & Challenge or Barrier & $\begin{array}{l}\text { References: Both from empirical research (ER) } \\
\text { and from non-empirical (NER) research }\end{array}$ \\
\hline $\mathrm{T} 1$ & $\begin{array}{l}\text { losing control of their class, due } \\
\text { to the change in their expected } \\
\text { role }\end{array}$ & $\begin{array}{l}\text { ER: Mandinach et al., } 1988 \text { (1 \& 2); Roberts et } \\
\text { al., } 1988 \text { (1 \& 2); Skaza, Crippen, \& Carroll, } \\
2013 \text { (5); Zbiek \& Hollebrands, } 2008 \text { (3) } \\
\text { NER: Roschelle et al., } 2000\end{array}$ \\
\hline $\mathrm{T} 2$ & $\begin{array}{l}\text { the need for more domain } \\
\text { knowledge }\end{array}$ & $\begin{array}{l}\text { ER: Mandinach et al., } 1994 \text { (1 \& 2); Roberts et } \\
\text { al., } 1988 \text { (1 \& 2); Skaza et al., (2013) (5) } \\
\text { NER: Hmelo-Silver \& Azevedo, 2006; } \\
\text { Jackson et al., 1994; Mandinach et al., } 1988\end{array}$ \\
\hline T3 & $\begin{array}{l}\text { the lack of time to develop skill } \\
\text { (using the theory, using } \\
\text { technology, in developing } \\
\text { curriculum, in reorganizing } \\
\text { lessons, in developing new } \\
\text { types of assessment) }\end{array}$ & $\begin{array}{l}\text { ER: Mandinach et al., } 1988 \text { (1 \& 2); Roberts et } \\
\text { al., } 1988(1 \& \text { 2); Tinker, } 1990(1 \& \text { 2); Zbiek } \\
\text { et al., } 2008 \text { (3) } \\
\text { NER: Doerr, 1996; Hung, 2008; Roschelle et } \\
\text { al., } 2000\end{array}$ \\
\hline $\mathrm{T} 4$ & $\begin{array}{l}\text { the lack of appropriate } \\
\text { curriculum }\end{array}$ & $\begin{array}{l}\text { ER: Roberts et al., } 1988 \text { (1 \& 2); Tinker, } 1990 \\
(1 \text { \& 2) } \\
\text { NER: Ang, 2001; Doerr, 1996; Mandinach \& } \\
\text { Cline, 2000; Zbiek et al., } 2008\end{array}$ \\
\hline T5 & $\begin{array}{l}\text { the time it takes to learn to } \\
\text { create appropriate models }\end{array}$ & $\begin{array}{l}\text { ER: Mandinach et al., } 1994 \text { (1 \& 2); Tinker, } \\
1990 \text { (1 \& 2) } \\
\text { NER: Hung, } 2008\end{array}$ \\
\hline T6 & $\begin{array}{l}\text { the need for ongoing } \\
\text { administrative support }\end{array}$ & $\begin{array}{l}\text { ER: Mandinach et al., } 1994 \text { (1 \& 2); Roberts et } \\
\text { al., } 1988 \text { (1 \& 2); Skaza et al., (2013) (5) } \\
\text { NER: Doerr, 1996; Mandinach et al., 2000; } \\
\text { Otero et al., 2005; Roschelle et al., 2000; } \\
\text { Tinker, } 1990\end{array}$ \\
\hline $\mathrm{T} 7$ & $\begin{array}{l}\text { the need for ongoing transition } \\
\text { support (tech support people }\end{array}$ & $\begin{array}{l}\text { ER: Skaza et al., (2013) (5) } \\
\text { NER: Doerr, 1996; Mandinach et al., 2000; } \\
\text { Otero et al., 2005; Roschelle et al., 2000; } \\
\text { Tinker, } 1990\end{array}$ \\
\hline
\end{tabular}

As daunting as these barriers might seem, they are not insurmountable.

Appropriate time allocation and appropriate support structures will need to be in place for future efforts to shelter/support teachers who are interested in incorporating modeling as part of their curriculum for the first time. As for the first enumerated barrier that is the most difficult to address it would seem that a recommendation for teachers would be to 
follow a gradual progression of infusion of systems concepts, starting with small steps, building more capacity over time, until the teacher feels he/she has reached a level that is comfortable/desirable for his/her classroom. Unfortunately, most research studies do not last long enough to provide this on-going support.

Another concern for teachers and administrators was how one might assess student learning using the more open-ended activities associated with the study of complex systems. The Jackson et al. (1994), Mandinach et al. (1988), and Spector et al. (2001) studies highlight the value of using system dynamics stock/flow diagrams and causal loop diagrams as methods of both formative and summative assessment of student thinking. Mandinach et al. (1988) also mentions the value of having students make a prediction of how a given model will behave and then explain any discrepancies between their prediction and the actual model behavior. However, Mandinach et al. (1994) speak of the need for more standardized assessments that emphasize the active process of learning.

\section{Results of non-empirical methods: Students and Teachers}

The positive outcomes suggested by researchers, about having students study complex systems problems are worth enumerating, even if these observations were not the product of a study involving an experimental design. Their observations provide insights that might prompt other researchers to design a specific experiment, to try to validate the observation, or might stimulate other creative processes for the reader. Previous positive outcomes will not be repeated. The other observations (not supported by experiments) conclude that students: 
Table 4: Research supporting desirable leaning outcomes from the study of complex systems.

\begin{tabular}{|c|c|c|}
\hline & $\begin{array}{l}\text { General Desirable Learning Outcomes } \\
\text { (as in Table 1) }\end{array}$ & References \\
\hline 26 & $\begin{array}{l}\text { are provided an opportunity for effective } \\
\text { and constructive group collaboration }\end{array}$ & $\begin{array}{l}\text { Mandinach et al., 1993; Pea, } \\
\text { 1985; Roschelle et al., } 2000\end{array}$ \\
\hline 27 & $\begin{array}{l}\text { more easily gain the ability to perform } \\
\text { thought experiments }\end{array}$ & $\begin{array}{l}\text { Kreutzer, }{ }^{19} 1986 \text { (as cited in } \\
\text { Jackson et al., 1994, p. 235); } \\
\text { Steed, 1992; Tinker, } 1990 \text { (as } \\
\text { cited in Jackson et al., 1994, p. } \\
\text { 233) }\end{array}$ \\
\hline \multirow[t]{2}{*}{28} & $\begin{array}{l}\text { have an opportunity to retain information } \\
\text { better due to a structured pattern for details }\end{array}$ & Forrester, 1986; Roberts, 1978 \\
\hline & $\begin{array}{l}\text { Desirable Learning Outcomes Specific to } \\
\text { the Study of Complex Systems (as in } \\
\text { Table 2) }\end{array}$ & \\
\hline 29 & gain a cross-discipline exposure to concepts & $\begin{array}{l}\text { Ang, 2001; Forrester, 1986; } \\
\text { Hmleo-Silver et al., 2006; Pea, } \\
1985\end{array}$ \\
\hline 30 & $\begin{array}{l}\text { gain an understanding that local decisions } \\
\text { can have global impact }\end{array}$ & Lesh, 2006 \\
\hline \multirow[t]{2}{*}{31} & $\begin{array}{l}\text { have the opportunity to access new content } \\
\text { (in math, science, social science, health, } \\
\text { and economics) }\end{array}$ & Heid et al., 2008a \\
\hline & $\begin{array}{l}\text { Desirable Learning Outcomes in } \\
\text { Mathematics When Modeling Complex } \\
\text { Systems is Added to the Curriculum }\end{array}$ & \\
\hline 32 & $\begin{array}{l}\text { have an opportunity to focus on function } \\
\text { concepts in math }\end{array}$ & Heid et al., 2008a \\
\hline 33 & $\begin{array}{l}\text { gain familiarity with structures that } \\
\text { emphasize conceptual understanding of } \\
\text { calculus before using equations }\end{array}$ & $\begin{array}{l}\text { Heid et al., 2008a; Roschelle et } \\
\text { al., 2000; Tinker, } 1990\end{array}$ \\
\hline 34 & $\begin{array}{l}\text { gain experience for horizontal and vertical } \\
\text { mathematizing }\end{array}$ & Doerr \& Pratt, 2008 \\
\hline 35 & $\begin{array}{l}\text { have an opportunity to shift from process to } \\
\text { object understanding of math entities }\end{array}$ & Heid et al., 2008a \\
\hline
\end{tabular}

ing computer simulation into the high schools: an applied mathematics curriculum. Mathematics Teacher, 647652 .

${ }^{18}$ White, B. Y. (1984). Deisgnig computer games to help physics students understand Newton's Laws of Motion. Cognition and Instruction, 1, 69-108.

matics Teacher, 647-652.

${ }^{18}$ White,

B. Y. (1984). Deisgnig computer games to help physics students understand Newton's Laws of Motion.

Cognition and 
Additional observations were made by researchers regarding attempts to assist teachers in their efforts to bring complex systems modeling into their classrooms. These augment the previously mentioned seven observations made about instructing and supporting teachers.

Teachers found:

Table 5: Additional challenges/barriers for teachers attempting to teach complex systems.

\begin{tabular}{|l|l|l|}
\hline & $\begin{array}{l}\text { Teacher Challenge or Barrier (as in } \\
\text { Table 3) }\end{array}$ & Research \\
\hline T8 & $\begin{array}{l}\text { complex systems to be counter-intuitive if } \\
\text { teachers tended to be linear thinkers }\end{array}$ & Jacobson et al., 2006 \\
\hline T9 & $\begin{array}{l}\text { the interdisciplinary nature of complex } \\
\text { systems makes them hard to understand, } \\
\text { especially because there was no right } \\
\text { answer; validation of models was difficult }\end{array}$ & $\begin{array}{l}\text { Doerr et al., 2008; Jackson et al., } \\
\text { 1994; Jacobson et al., 2006 }\end{array}$ \\
\hline T10 & $\begin{array}{l}\text { making the distinctions needed to identify } \\
\text { stock variables and flow variables is } \\
\text { difficult }\end{array}$ & $\begin{array}{l}\text { Doerr, 1996; Riley, 1990; Tinker, } \\
1990\end{array}$ \\
\hline
\end{tabular}

3. Novice versus Expert Problem Solving

Expert problem solvers tend to use more divergent thinking, strive for conceptual understanding, and better appreciate the interconnections that occur in the study of complex systems. These qualities are missing, but desirable in novice problem solvers (Chen et al., 1993; Doerr, 1996; Hmelo-Silver et al., 2007; Jackson et al., 1994; Jacobson et al., 2006; Lesh, 2006; Mandinach, 1987; Pea, 1985). Expanding on some of the research findings:

- Hmelo-Silver et al., (2007) say students tend to understand the elements in a complex system, but not how to connect them and how the connections affect the behavior of the system. Understanding how to connect the elements and how those connections affect the behavior of the system are qualities of expert problem solvers. 
- Doerr (1996) indicates novices often try to develop formal competence (i.e., knowing formulas to use for certain problems) but this type of knowledge is subordinate to conceptual understanding. She says that formal knowledge will hardly ever effect change at a conceptual level, "conceptual awareness is a first critical step in the teaching/learning process" (p. 86).

- Mandinach (1987) says that experts are able to decontextualize their understanding of complex systems that allows them to transfer their knowledge more easily. But she cautions that it is not necessarily desirable to aim novice thinking directly toward expert thinking. Intermediate steps may be needed, allowing students an opportunity to internalize some of the tasks experts perform automatically.

Since SD modeling surfaces the mental model of the person who is constructing the model, it allows mistakes/misconceptions to become visible for review, promoting rich discussion. This makes SD modeling an excellent vehicle for transitioning students from novice toward expert in their thinking about a specific problem. Repeated modeling experiences can reinforce this practice. But how will we analyze the modeling process to identify the misconceptions and provide appropriate recommendations for improving problem solving? Looking at frameworks for model analysis may provide some direction.

The next section identifies four frameworks that have potential to support the instruction of complex systems in the precollege environment.

\section{Frameworks for Understanding Systems}

The first framework is identified as the SBF (structure-behavior-function) framework and is described by Hmelo-Silver et al. (2007). Structure refers to the elements of the system. These elements can be simple, as in the amount of money in a bank account, the interest rate, and the interest added per year, or more complex, for example, lungs, brain, heart as components of the respiratory system (where each element 
is itself a complex system). Behavior refers to the mechanisms that are present within the system to produce an outcome. This would include the interconnections of the particular elements. Function refers to the individual elements and their purpose in the system. Structures are relatively easy for students to identify, but connecting the elements and knowing the purpose of each element within the system is generally difficult and usually dependent upon expert knowledge (Hmelo-Silver et al., 2007, p. 325). System dynamics (SD) modeling could fit into this framework, allowing the modeler to explicitly represent the connections between elements within the system. It does, however, require that the modeler know how to make those connections, some of which might be non-linear connections. Allowing the model to be executed quickly and easily (using current SD software) provides the student with a method for refining the connections in an iterative process.

A second framework is described by Chen et al. (1993). They describe a general systems theory (GST) for helping students understand complex systems. There are five components to this framework: complex systems integrate different domains; complex systems should be understood in their complexity; change is central to the study of complex systems; complex systems need to be studied at both the micro and macro levels; and humans impact complex systems. The first component, that complex systems need to be understood as an integrated approach, implies the need for crossing disciplines of physical, social, and human systems. The second component, that problems need to be understood in their complexity, implies that problems should not be overly simplified. Students should be able to study/address some of the complex issues of the day. The 
third component, the need to understand change, implies the need to understand that the world operates dynamically. Learning to understand patterns of change, how to recognize, describe, and represent them should be exercises students undertake. The fourth component, that students should study systems from both a macro level and a micro level, implies, as SD analysts put it "seeing the forest and the trees." The fifth, and final component, understanding how humans impact and alter systems, implies that our impact on the world is pervasive and potentially destructive. Systems thinking is central to this study, as is feedback analysis. System dynamics modeling would be an appropriate vehicle for providing lessons for students who would be using this framework, as all five component parts are integral to SD analysis.

The third framework was developed by Barry Richmond (1993), a renowned system dynamicist, trained in system dynamics at MIT (Massachusetts Institute of Technology) under Jay Forrester. His framework for understanding complex systems contains seven thinking skills. Complex systems require: dynamic thinking, closed loop thinking, generic thinking, structural thinking, operational thinking, continuum thinking, and scientific thinking. The first skill, dynamic thinking, is the study of change in the system. He says students should see the pattern of behavior that is produced over time, not specific, isolated events. The second skill, closed-loop thinking, requires understanding feedback interactions and recognizes feedback as the cornerstone of the study of complex systems. The third skill, generic thinking, recommends thinking in structures and infrastructure that produce often-observed patterns of behavior in a diverse collection of systems from different disciplines. The fourth skill, structural thinking, 
requires thinking about systems in terms of stocks (accumulations) and flows (rates of change) and how these should be connected. Maintaining unit consistency is part of this skill. The fifth skill, operational thinking, is incorporated when the modeler is trying to decide how the system actually works (operates), its equations of motion, so to speak, and tries to replicate its behavior using the structures of skill five. The sixth skill, continuum thinking, requires recognizing that the complex models that are created, analyzed, and interpreted are representing continuous change on a system, not discrete events. Rather than using "if-then-else" definitions, skill six employs continuous function definitions to reflect how increases or decreases in one component affect other components. The seventh skill, scientific thinking, includes the expected characteristic of positing and testing hypotheses. But it also means being able to include concepts that cannot be measured precisely, like a person's stress or confidence, in a model, allowing the model to reflect the reality of a system more completely.

The final framework is formally represented in Sterman's (2000) book, a seminal work, that lays out the system dynamic modeling process for system dynamics professionals. The SD method involves five stages: 1) problem articulation, 2) dynamic hypothesis generation, 3) model formulation, 4) testing/validation, and 5) policy formulation and evaluation. In problem articulation the student attempts to define the problem more precisely, identify key variables, decide on a time horizon, establish reference behavior modes (that will later be used to help validate the model), and formulate the boundary conditions for the problem being studied. Formulating a dynamic hypothesis entails laying out the feedback mechanisms that are essential to capturing the 
important behavior of the system. When formulating a model the stock/flow map is created to include the feedback structures identified in the dynamic hypothesis. The model will contain the rules controlling the interaction between components upon which the feedback relies. Initial testing also occurs in this stage to insure the model is verified. Additional testing is required to determine if the model can replicate the reference behavior identified in stage one, to determine if the model behaves properly when parameters are set to extreme values, and to test the sensitivity of the model to uncertain parameter values. Finally, policy decisions, made to change the behavior of the system, are tested for viability and sensitivity. Additional experimentation can be performed on the model to gain insight into explanations for possible unexpected behaviors.

The following two sections provide guidelines relevant to teachers and/or researchers who want to design effective learning experiences involving student creation of systems models. The first section focuses on issues and recommendations for instructing students. The second addresses techniques that can help teachers infuse technology-based lessons into their curriculum.

\section{E. Techniques for Teaching Students}

Building SD models is a systems thinking skill. One of the first tasks a student will have when trying to build a model of a complex dynamic feedback system, is to identify the variables that are relevant to the problem. Some of these variables will need to be designated as accumulations (stocks), some as flows, and others as auxiliary (algebraic) variables. Researchers indicate that making this determination is difficult for students (Doerr, 1996; Riley, 1990; Tinker, 1990). Others indicate that learning how to 
build models is hard, due to issues dealing with how to design models, the amount of domain knowledge needed ot build operational models, how to reason scientifically, how to create hypotheses and test them, and how to communicate the results (Hmelo-Silver et al., 2006; Jackson et al., 1994; Mandinach et al., 1988). Researchers suggest that the inter-disciplinary nature of the study of complex systems is hard for students because students are working with problems that do not have simple right answers and they may lack the background needed for them to determine if their model is valid (Doerr et al., 2008; Jackson et al., 1994; Jacobson et al., 2006). Learning to create system dynamics models takes time (Hung, 2008). For those students and teachers who want to take the model building process to its productive conclusion, research suggests that students (and teachers) should apply in their own lives the insights they are gaining from the modeling process. Doing so is not an easy transition for most people (Hung, 2008).

What guidance, then, can we glean from the experience of researchers to shepherd instructional practice to include SD modeling in the pre-college curriculum? Reinforcing Bruner's theory, Tinker (1990), and Doerr et al. (2008) indicate a need to provide physical activities as precursors to building models used to represent physical dynamics. Doerr quotes Vitale $^{20}$ (p. 274) as he explains that physical activities help to de-mystify the process of model validation. She also indicates that the problem being studied needs to be relevant to the students in order to provide them with a purpose for doing the model building. (c.f., Pea, 1987)

Instruction, 1, 69-108.

$\mathrm{m}$ local to global: Programming and the unfolding of local model in the exploratory learning of mathematics and science. In A. A. diSessa, C. Hoyles, R. Noss, \& L. Edwards (Eds.), Computers and exploratory learning (pp. 45-58). Berlin, Germany: Springer-Verlag. 
As mentioned in a previous paragraph, modeling is hard. It is, therefore, important to provide instructional experiences for students that offer a gradual increase in concept and skill development (Ben-Zvi-Assaraf et al., 2010; Confrey et al., 1994; Hung, 2008). Yet, Tinker (1990) notes that students as young as ninth grade can build dynamic models and understand their solution, which is very encouraging.

Mandinach et al. (1994) indicated that the teachers they observed used three types of SD modeling experiences with students. The first they called parameter manipulation (the least cognitively demanding, according to them), the second was called constrained modeling (where students are given brief scenario descriptions and then build small models), and the final experience type is referred to as epitome modeling (where students build original models in a fully open exercise, choosing their own problems to model). Each earlier modeling experience can act as scaffolding for the next modeling experience. They found that many teachers in their study, especially those working with young or at-risk students, tended to use non-computer based activities to work with systems concepts. Most of the teacher lessons that used computer-based instruction in systems fell in the parameter manipulation or constrained modeling categories. They suggest this may be due more to a feeling of discomfort with higher level modeling activities by the teacher, rather than by the student (a hypothesis with which this author strongly concurs).

Stein et al.,(1996) conducted a study involving students participating in complex, high level tasks. Though not a study involving computer modeling directly, it is relevant to this discussion, as system dynamics modeling would fall into the category of a 
complex, high level task. His study concluded that students need to see high level thinking modeled for them by the teacher or by other more advanced students. They need exercises that use their previous knowledge as launching points for new problem exploration. They need to have time to explore ideas and should be required to explain what they are learning and the deeper understanding that the exercises are trying to elicit.

Finally, research suggests that the iterative process required by creating, reflecting upon, and refining computer models to capture the behavior of a system is an important instructional strategy (Alessi, 2009; Confrey et al., 1994; Heid et al., 2008b; Jackson et al., 1994; Mandinach et al., 1988; Stratford et al., 1998).

There is a progression in the sophistication of recommended modeling activities, as has been mentioned above. Steed (1992) reflects upon this progression (though not using an empirical study). He describes hierarchical levels of lessons that could allow students to engage the learning process when studying complex systems. The first (lowest) level provides students with pre-constructed models where students manipulate the parameters in the model. Another possible lesson strategy within this level gives the students the model components, perhaps even with designated pre-drawn stocks, flows, or converters, and has the students connect the variables appropriately. Yet another lesson strategy at this level would have students follow a scripted model-building scenario that accompanies a science lab or problems in a textbook.

On the second level students could create a small model from scratch, given a brief scenario description. Here the topic of the model follows a well established pattern of behavior and the model structure is fairly well defined. Students at this level would 
experiment with the model, after constructing it, to gain additional information about the system (for example, analyzing simple feedback). A third level has the teacher build a model together with the students using classroom discussion, where students get in groups and design sub-modules of the model to solve a certain problem. The fourth level has students take a textbook concept or process and translate it into a dynamic model. The fifth level has students design their own theories about how a process works, and create a model to test those theories, refining their theory in the model building/testing process. The difference between this level and the level two model building is that in level two students are trying to capture an established theory or process. The sixth, and final, level occurs when a student sketches a model diagram as part of a note-taking exercise to better understand an explanation given by the teacher. (Note: These levels of lessons are not the result of an experimental study, but they seem to reflect reasonable and realistic scenarios for lessons involving the application of modeling complex systems at the precollege level. This comment is based on my 20 years of experience teaching system dynamics modeling at the high school level.)

Pea (1987) mentions other important components needed to support deeper learning for students as they use cognitive technologies. Students need to have the opportunity to work in groups as they experiment with technologies that support deeper thinking. Dialog offers them opportunities to reflect, discuss, and collaborate on the mathematics that is part of the problem being analyzed. He suggests that the computer can act as a mediating tool in this discussion, allowing students to test their arguments. He argues that the computer can "free up" a student's mind from the 
drudgery of computation, allowing him/her an opportunity to focus on patterns and larger picture understanding. He suggests that the computer can act as a vehicle for communication, a language to help capture sophisticated ideas and display those ideas in a fashion that is easier for others to understand, i.e. to serve as a reorganizer of mental functioning for the student. Pea also notes the importance of using the technology to externalize the thought processes of the students that allows those thoughts to be modified by inspection and reflection of other students and the teacher.

The rest of this section is highlights characteristics that are not the result of experimental studies, nor do they address system dynamics modeling directly. Yet these studies present instructional strategies that appear to be appropriate as guides for teachers who want to include the study of complex systems in their math and/or science curriculum.

\section{F. Techniques for Teaching Teachers}

As mentioned in a previous section, the efforts to prepare teachers to include the modeling of complex systems in their pre-college classrooms has been largely unsuccessful. Some of the difficulties have been enumerated in a previous section. The research presented below addresses the difficulties that teachers face when trying to incorporate a new computer technology into their instruction. Although this material does not specifically address infusing system dynamics modeling as an instructional strategy, it does suggest some of the preliminary concerns that would have to be addressed for a teacher to feel comfortable using the computer as an integrated teaching tool. 
In order to provide effective lessons to help students gain deeper conceptual understanding of mathematics using technology, the teacher has to be comfortable with the technology. Several articles suggest processes to increase teacher comfort level with technology so they will use it as part of their instruction. Beaudin and Bowers ${ }^{21}$ in Zbiek et al. (2008) describe their PURIA model for teacher development of technology skill. In the PURIA model, the $P$ indicates teachers need to play with the technology, with appropriate guidance (materials and tutoring). $U$ stands for using the technology as a personal tool for learning mathematics. $R$ stands for recommending the technology to other teachers or to students, usually in an informal setting. $I$ represents the use of technology for formal instructional purposes. $A$ indicates that a teacher is able to assess the students' use of technology in the context of learning mathematics. Zbiek et al. (2008) extend Beaudin and Bowers' PURIA model for teacher development of technology skill to include more than calculator based activities, i.e., including computer activities as well, and expanding the process to include more scenarios for teacher communication, especially with experts. A similar sequence (to PURIA) is suggested by Otero et al., (2005): familiarization, utilization, integration, reorientation (redesigning classroom function), and evolution (continually modifying the classroom structure to include new tools and theories using technology).

To effectively use technology in instruction the teacher's concept of what it means to do mathematics has to change. This change may result from technology use or may precede it (Heid et al., 2008b; Zbiek et al., 2008). The most effective way to change

${ }^{21}$ Beaudin, M., \& Bowers, D. (1997). Logistics for facilitating CAS instruction. In J. Berry, J. Monaghan, M. Kronfellner, \& B. Kutzler (Eds.), The state of computer algebra in mathematics education (pp. 126135). Lancashire, England: Chartwell-York. 
a teacher's perception of mathematics is to provide technology experiences for the teacher as he/she studies mathematics. As with pre-college students, the connection between the technology activities and the specific mathematical concepts the activity is designed to introduce/reinforce must be made explicit. Curriculum materials that use the technology effectively must be available for the teacher (Zbiek et al., 2008). Professional development for including technology in instruction must be connected to classroom practice (Otero et al., 2005). Assessment of teachers by administrators must change to accommodate the different classroom environment that often emerges in classrooms where technology is being used effectively (Mandinach et al., 2000).

Rochelle et al., (2000) identified some key factors that needed to be in place for technology to be implemented successfully in the classroom. Teachers need access to the technology and to technology support people. They need a reason to use the technology, for example, to illustrate a concept that has been difficult to convey without the visual or numerical calculation that the technology affords (quick production of graphs, use of numerical approximation techniques, etc.). A sufficient number of teachers are needed who use the technology so there is a constant support organization as they implement the lessons. Along with the number of teachers using the technology, there needs to be a strong collaboration between these teachers. Teachers need time to support planning and collaboration. There is an interdependence between using technology to support school change and school change supporting the use of technology (Mandinach et al., 1994). 


\title{
III. Paper 1: System Dynamics Modeling to Teach Algebra and Complexity
}

\author{
Diana M. Fisher \\ System Science Graduate Program \\ Portland State University \\ 7405 SW Cresmoor Dr. \\ Portland, Oregon 97008 \\ fisherd@pdx.edu \\ 503-708-4642
}

\author{
Ron Narode \\ Associate Professor, Mathematics and Science Teacher Education \\ Department of Curriculum and Instruction \\ Graduate School of Education \\ Portland State University \\ Portland, Oregon \\ naroder@pdx.edu \\ Brian Greer \\ Adjunct Professor \\ Department of Curriculum and Instruction \\ Graduate School of Education \\ Portland State University \\ Portland, Oregon \\ brian1060ne@yahoo.com
}




\begin{abstract}
System Dynamics (SD) is an icon-based, analytical method whose interface is userfriendly and whose model structure is so intuitive that students as young as 11 years of age may be taught how to model complex systems. The diagram structure provides a new vehicle for the mathematical modeling of real-world problems that may be used to: promote classroom discussion, reveal students' mental models (helping to identify misconceptions), provide a dynamic view of many functions studied in algebra, ease transfer of model structure to other disciplines, support practice with covariational reasoning, afford an informal introduction to basic concepts of calculus, and give students access to complex systems. Used by some high school mathematics teachers in algebra, pre-calculus, and calculus, it is a powerful method of problem solving that professionals have used to study global climate change, natural resource depletion, bioterrorist attacks, affordable health care provisions, kidney disease and treatment, among others. In both curriculum and pedagogy, Systems Dynamics aligns well with Common Core State Standards - Mathematics.
\end{abstract}

\title{
A. Modeling and Algebra Teaching and Learning
}

The modeling of complex systems prepares our students for many adult concerns: environmental degradation, health care affordability, global climate change, disease, financial wellbeing, and ensuring the continuation of our democracy, to name a few. Many aspects of our lives are governed by "mathematics in action" (Skovsmove, 2005), 
that is, by the application of mathematical models mostly inaccessible to the citizens whose lives they affect. Mathematics instruction could prepare future citizens with a critical disposition and sense of agency (Greer \& Mukhopadhyay, 2012). In an understandable but misguided attempt to develop children's understanding of how mathematics can be used to model aspects of our physical and social worlds, students are predominantly led to believe that phenomena can be mapped neatly onto mathematical equations. Rather, students should study the modeling process: implications of simplification, importance of assumptions, representations available, communication of results, limitations of mathematical models due to inadequate information, uncertainty and complexity —in short, the embedding of mathematical modeling within its social, cultural, and political contexts.

SD icons capture the behavior of, and enhance understanding of, elementary functions studied in algebra classes. Once students know the SD model structures that represent single function behavior they can begin to combine these structures to study more sophisticated dynamic behavior --- unlike most closed form equations in algebra.

We demonstrate how current SD modeling software technology may infuse realworld modeling activities into the high school algebra curriculum. Such modeling addresses many of the Common Core State Standards-Mathematics (CCSS-M) Practices and those CCSS-M Standards that describe both modeling and function understanding. We provide examples of the System Dynamics modeling that successfully incorporate into high school algebra classes as observed over two decades in inner city and suburban high schools. 


\section{B. System Dynamics Modeling for Learning Mathematics}

In 1915, John Dewey complained that education was not adapting to changes brought about by the industrial revolution, "the primary waste is human life, the life of the children while they are at school, and afterward because of inadequate and perverted preparation" (Pea 1985, p. 179). Today, we have effective technologies that provide powerful mathematics learning experiences (Kaput \& Roschelle 1999). One of those experiences is teaching students to create models to study complex dynamic systems.

There are multiple ways that modeling complex systems supports learning mathematics in algebra classes:

\section{Support for student model building and justification in problem solving}

Model building to solve quantitative problems affords students and teachers the opportunity to discover how students think during problem-solving. Confrey et al. (1994) state that having students create models and explain them helps them develop critical thinking and inquiry skills. Stratford et al. (1998) studied secondary students as they created dynamic models. They report that students developed skills such as analyzing, reasoning, synthesizing, testing and debugging, and explaining. These are skills recommended by the CCSS-M standards.

The visual nature of the STELLA icons, the naming of icons (words or phrases), and the structure of the model, make the model a vehicle that is more accessible to students both for building (translating from a dynamic story scenario to symbolic representation) and for justifying their work. Students can more easily identify the reason they think the model behaves the way it behaves, and they can explain how and why they 
manipulated the model in response to "what if" experiments where adjustments are made to the variables of interest.

\section{Identifying student misconceptions}

The structure of the model externalizes the student's conception about the nature of the phenomenon, often referred to as "surfacing" the student's mental model. Senge (2006) defines mental models as "deeply ingrained assumptions, generalizations, or even pictures or images, that influence how we understand the world and how we take action" (p. 8). Though mental models tend to be incomplete, most of the world's understanding

of complex systems resides in the heads (mental models) of those who interact with such systems (Forrester, 1987). The same can be said about our students' understanding of how the world works. Making one's mental model explicit is a very important step in understanding how complex systems operate (Bliss \& Ogborn in Doerr, 1996; Steed, 1992). Hence, surfacing students' conceptions of how systems work is a prerequisite for modifying their mental models through the experiences provided in school.

\section{Model-building enhances conceptual understanding and transfer to other disciplines}

Many researchers indicate that model building provides students an opportunity to enhance conceptual understanding (Hung, 2008; Mandinach et al., 1993) of real-world problem solving strategies, (Gordon \& Gordon, 2006; Hung, 2008; Lesh \& English 2005) and transfer to other disciplines (Hung 2008).

In algebra, students have built SD models to study drug pharmacokinetics (including alcohol consumption), how population growth impacts renewable resources, and maintaining a balanced ecosystem involving a predator and prey population (Fisher, 
2005, 2011a, 2011b). Each of these student lessons is enhanced using a multidisciplinary approach with modeling.

\section{Practice with covariation analysis}

"Covariation is the mental process of coordinating the values of two quantities as they vary simultaneously" (Saldanha \& Thompson in Thompson et al., 2013). Covariation analysis is difficult for many high school students and necessary for understanding of mathematical functions (Oehrtman et al., 2008). It has been suggested that using "time" as one of the variables that is changing in a covariation analysis is a path that may help students develop this skill (Oehrtman et al. 2008, 31; Carlson et al., 2002). Having students create models of dynamic systems requires repeated analysis of time series graphs, supporting covariational reasoning.

\section{Introducing basic calculus concepts}

SD modeling is based upon understanding rates of change and how those rates create certain patterns of accumulations. Many of the typical functions studied in algebra and in SD are based upon a conceptual understanding of calculus: linear accumulation occurs because its rate of change is constant, parabolic/quadratic accumulation occurs because its rate of change is linear, exponential accumulation occurs because its rate of change is proportional to the current accumulated amount, etc. A teacher can use language that reinforces these conceptual relationships between a given function and its rate of change. Kaput et al. (1997) argue that the use of technology and modeling "continuous change phenomenon" will help "democratize calculus" and constitutes an essential skill for preparing students for the world. 
C. System Dynamics Modeling as Problem Solving and Cognitive Technology

Many of our daily experiences involve interacting with complex systems (Lesh, 2006). Introducing SD into the K-12 curriculum is both timely and critical (Hung, 2008;

Sterman, 2002). According to Jacobson et al. (2006):

The conceptual basis of complex systems ideas reflects a dramatic change in perspective that is increasingly important for students to develop as it opens new intellectual horizons, new explanatory frameworks, and new methodologies that are becoming of central importance in scientific and professional environments (p. 12).

Forrester (1987) observes that the behavior of complex systems is often counter-intuitive, and that the cause of systemic problems can usually be found within the system, yet we don't attempt to understand systemic structure this way. We simplify the problem in the hope that we can grasp it., but the balance between simplification and representing sufficient reality is delicate. Pea (1985) uses the term "cognitive technologies" for tools that capture more realistic causal relationships in systems without overburdening the mental capacity of the modeler, thus "transcend[ing] the limitations of the mind, such as memory, in activities of thinking, learning, and problem solving."

We now introduce the modeling icons that are so critical to successful modeling and transfer to algebra.

\section{Representational Icons}

SD software (STELLA, shown here) contains elements that Stock represent accumulations of "stuff" over time. This "stuff" can be physical, like the number of people in a city, or abstract, like "concern about level 
of pollution". The accumulator is identified as a "stock" shown as a rectangular icon. The stock represents a key variable of interest and may be considered the output of the function being monitored.

A "flow" icon represents a rate at which the stock value is

changing over time. If the flow arrowhead is pointing

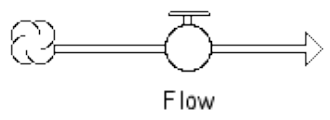

toward/away from the stock, a positive value (within the icon)

represents the rate of increase or decrease, respectively, in the stock value.

Other icons are called "converters", represented as circles holding parameter values or formulas for auxiliary variables.

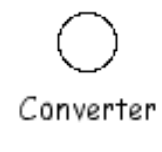

Finally, there are icons called "connectors" that connect converters to flows, converters to other converters, stocks to flows, or stocks to converters. They act like telephone lines, communicating

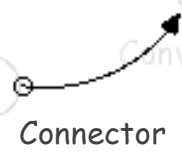
numeric information between components so that formulas can be updated each time step (calculation interval).

\section{Exponential Function Example}

Consider an example where the goal is to calculate the growth in the population of a small town. Table 6 illustrates a recursive calculation approach.

Table 6: The recursive calculations for population growth of $0.6 \%$ compounded annually.

\begin{tabular}{|l|l|}
\hline Year & Population each year. \\
\hline Starting Population & 5000 \\
\hline Population after 1 year & $5000+0.006(5000)=5030$ \\
\hline Population after 2 years & $5030+0.006(5030)=5060.2$ \\
\hline$\ldots$ & \\
\hline Population after 200 years & $16443+0.006(16443)=16541$ \\
\hline
\end{tabular}




\begin{tabular}{|l|l|}
\hline Recursive formula & $\mathrm{P}_{\mathrm{t}}=\mathrm{P}_{\mathrm{t}-1}+0.006\left(\mathrm{P}_{\mathrm{t}-1}\right)$ \\
\hline
\end{tabular}

The stock/flow model (Figure 2) also uses a recursive calculation approach. The amount of flow (the rate at which the Current Population will grow) is not constant, but is calculated each year as the product of the current population and the yearly net growth $(0.6 \%)$. In Figure 2, the asterisk in the flow valve represents the multiplication of the two values sent by the components upon which the flow depends. The Current Population (the stock) will grow exponentially because its rate of change (increase in population per year) is proportional to the number of people that are living in the town in any given year.
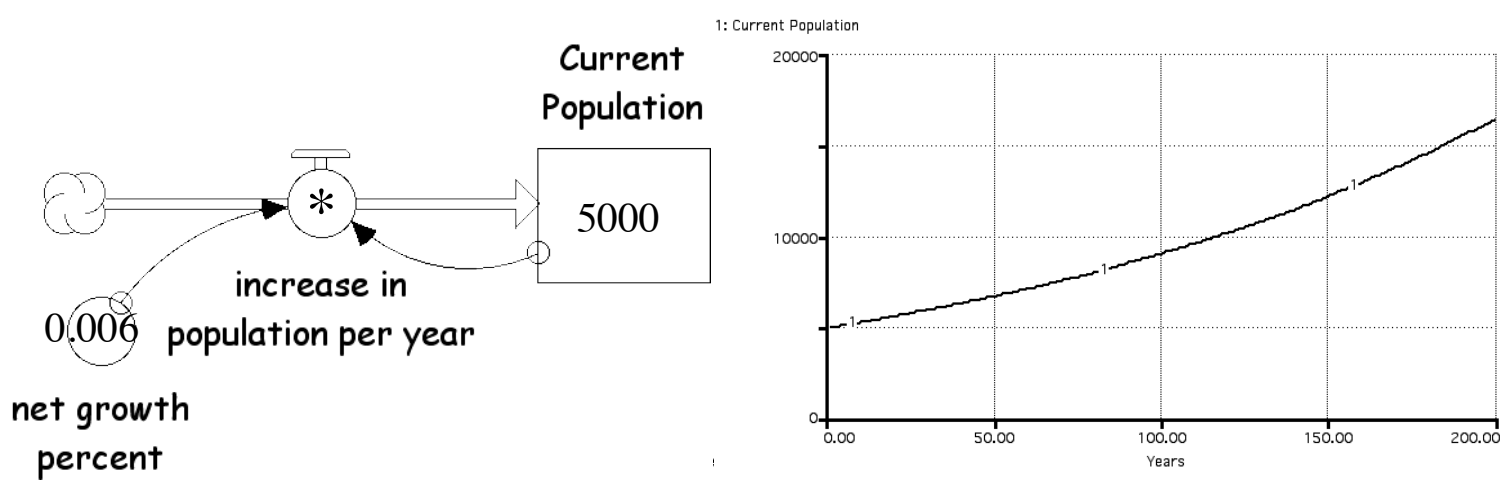

Figure 2: The exponential stock/flow model and the graphical output of the stock, Current Population. The closed form equation for the Current Population is $\mathrm{P}=5000(1.006)^{\mathrm{t}}$.

The following sequence of gradually more sophisticated population models demonstrates an instructional plan to meld SD and algebra. Adding Separate Birth and Death Factors

Assume we want to disaggregate the increase in population flow (Figure 2), into two flows increase in population, say births per year (assume growth at 1.4\%) and decrease in population, say deaths per year (assume decline at $0.8 \%$ ). 
A STELLA model diagram for this scenario (values are superimposed on the diagram to indicate component definitions) is shown in Figure 3. The graphical output of the model is identical to that shown in Figure 2, but disaggregating the inflow from the outflow is useful for the succeeding examples.

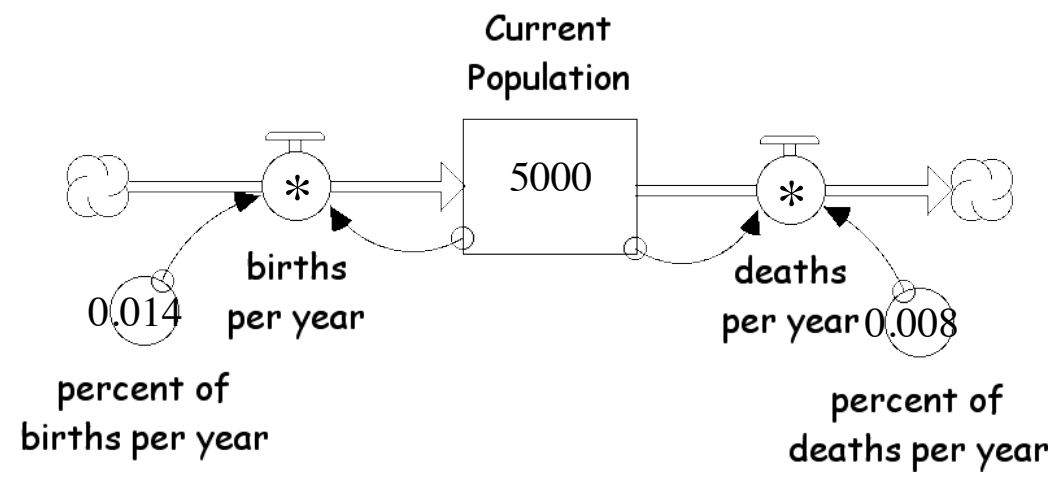

Figure 3: The STELLA diagram for simulating a population growth with separate birth and death rates. The closed form equation is $\mathrm{P}=5000(1+0.014-0.008)^{\mathrm{t}}=5000(1.006)^{\mathrm{t}}$.

Students discuss those features of the model that must be altered to have the model produce a Current Population that is growing exponentially, decaying exponentially, or remaining in steady state.

Extensions: 1. We could also add immigration and emigration to our story with inflow for immigration and outflow for emigration. Those flows would be defined in a manner similar to the definitions for births and deaths flows. Such a model would be very useful in a social studies class when discussing current and suggested immigration laws. 2. Suppose we wanted to consider a predator/prey scenario where one could identify the population structure in Figure 3 as a prey population and add a second population structure representing a predator population. A few additional converters and connectors could be added to indicate how the numbers in each population (stock) affect the death percent and birth percent of the other population. The scenario used in an 
algebra class has each population start out in steady state. Then a new issue is presented: The local farmers and ranchers are upset that the predator is killing some of their livestock, so they want the number of predators reduced. Students are challenged to come up with a predator reduction policy that is effective over the long term. Population Scenario with Fixed Carrying Capacity

Our students will observe that populations cannot grow exponentially forever, since pressures on population slow the growth over time. The upper limit resulting from those pressures is often referred to as "carrying capacity." As the number of people in the population grows near the carrying capacity (say 20,000 people) of the environment, the percent of deaths starts to increase (or the percent of births starts to decrease, or both). The STELLA diagram that would capture this part of the story is shown in Figure 4. The reader will recognize the upper part of the diagram from Figure 3, but with a different definition for the percent of deaths per year. 


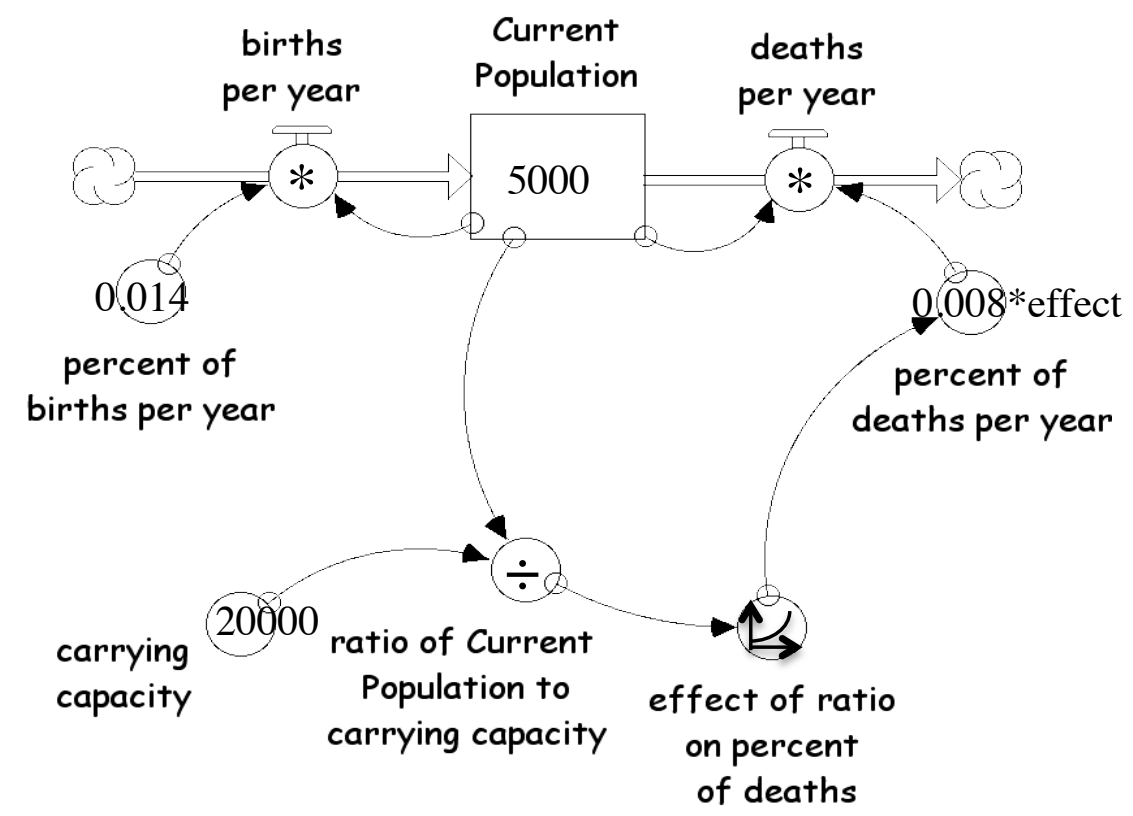

Figure 4: STELLA diagram for simulating population growth with carrying capacity.

The carrying capacity has its own new converter, while another holds the ratio of Current Population to carrying capacity. A third new converter, the effect of ratio on percent of deaths, takes the value of the ratio upon which it depends and transforms that ratio into a new value that is sent to the percent of deaths per year. The effect of ratio on percent of deaths component is defined graphically, with (input from ratio) domain 0 to 1 , and (output) range 0.05 to 2 . The output value of the effect of ratio on percent of deaths is multiplied by the percent of deaths per year (0.008) causing the death percent to grow or decline based upon how close the current population is to the carrying capacity. The model in Figure 4 will produce the typical logistic growth pattern associated with adding a fixed carrying capacity to a population growth model, a concept in some algebra II courses. 
Students could be asked to determine (and test) policies to mitigate the dramatic rise in deaths when the population approaches the carrying capacity of the environment.

Extension: An extension of the model in Figure 4 replaces the fixed carrying capacity with a non-constant resource upon which the population depends. That resource, say food (a stock), could have its own inflow (regeneration) and outflow (consumption). The model enhances conversations about global hunger, especially if team-taught by math, social science, and health teachers.

Modeling is an art as well as a science. There is always a trade-off between capturing enough of the dynamic to be able to gain important insight into a problem but not so much that the most important relationships are hidden in the details. We recognize that significant learning occurs in the model-building process, but having students share that learning with others by explaining the insights or devising experiments to surface important model behavior can add depth to the learning that occurs (Alessi, 2009). Using the SD approach and a model-building tool like STELLA provides an avenue for student experimentation and communication.

D. System Dynamics Modeling and Common Core State Standards - Mathematics

The processes associated with SD modeling address a significant number of the Mathematical Practices and the Functions and Modeling Overview Standards of the CCSS-M. A detailed alignment list can be found at http://www.ccmodelingsystems.com/res-stds-skills-math.html. 


\section{E. Conclusion}

With demonstrations and examples, we have presented some arguments for providing students with more advanced tools and methods of analysis currently used by professional consultants, government officials, and university professors who are trying to address serious dynamic complex problems. These tools are accessible to a broad audience of high school algebra students and can provide an alternate representation allowing students to study dynamic problems that may be used to both teach/reinforce the traditional closed form equation approach as well as surpass it with concepts from computer modeling.

An issue that lies beyond the scope of this paper, but has profound implications for any attempt to introduce SD modeling into school mathematics, is the nature of assessment. It is pertinent to ask whether and how the complexity of modeling processes illustrated in this paper-for example, the progressive development of more and more complex models as extra factors are taken into consideration_ — can be meaningfully assessed through mass tests that afford minimal opportunities for dialogic communication over an extended time period. The issue gains in importance given the known effects of assessment practices on instruction.

There is still significant work to be done. Although some curriculum has been developed using the SD modeling approach, especially for mathematics and the natural and life sciences (Fisher, 2005, 2011a; Creative Learning Exchange ${ }^{22}$ 2015), much more curriculum needs to be developed that connects mathematics to other subjects,

\footnotetext{
${ }^{22}$ See http://www.clexchange.org/cleproducts/default.asp.
} 
specifically social studies, economics, and health, as well as science. While there is some online SD modeling training for math and science instructors (Fisher, 2015), more training, both in-person and online, needs to be developed that emphasizes integrating mathematics with the social and health sciences and helps interested teachers develop SD modeling skills. Infusion of SD modeling strategies in high school mathematics provides significant opportunity for more research, training, and material development that will enhance the learning opportunities for students and expand our students' problem solving toolkits to help them address the challenges they will face in the $21^{\text {st }}$ century. 


\title{
IV. Paper 2: Moving Beyond Closed Form Equations: Analyzing Complex Systems Using STELLA Reorganizes Algebraic Thinking
}

\author{
Abstract \\ System Dynamics (SD) modeling is a powerful analytical method used by \\ professional scientists, academics, and governmental officials to study the behavior \\ patterns of complex systems. It is a method that has been used with middle school \\ students in math and science classes, but has been used more often with high school \\ students, [both levels] for over two decades. In this paper I introduce the modeling of \\ complex systems using SD, an icon based analytical method that, due to its powerful \\ representational interface is simple enough for a $5^{\text {th }}$ grader to use. A sequence of nested, \\ simple bank account examples, increasing in complexity, is used to demonstrate a \\ comparison between using a closed-form approach to mathematizing the problem and \\ using STELLA (an SD software). The article highlights the limitations of closed form \\ equations to (eventually) capture the needed problem elements, even when the problem is \\ still simple enough for analysis by quite young students using STELLA. The SD \\ modeling approach aligns very well with the Common Core State Standards - \\ Mathematics (CCSS-M) Practices and Modeling and Functions Standards.
}

\section{A. Introduction}

In this paper I will show, using a sequence of simple, nested examples, increasing in complexity, why math teachers should not rely solely on the current symbolic representation (closed form equation) for studying dynamic problems in algebra. The value of the new approach and software (STELLA) for mathematizing and analysis include: 
- a visual, icon-based method of defining variables and differentiating their purpose in the problem,

- specifying variables using a naming procedure that includes full words or phrases,

- a structural design that lays out, in two dimensions, the dependencies between the variables and parameters in the problem, allowing a more pictorial view of the overall problem structure,

- a dynamic approach to defining functions (i.e., focus on rates of change),

- a quick approach to testing "what-if" scenarios, altering model structure or parameters, and re-running the model to view the change in behavior graphically or numerically,

- a representation that has been used by adult professionals to perform complex systems analysis, but that is still accessible to a broad section of high school students (who can, therefore, also perform complex systems analysis - Fisher, 2011b).

Mathematizing story problems into closed form has, historically, been difficult for students (Schwartz \& Yerushalmy, 1995). New technologies can provide alternate and more visual representations of many functions studied in algebra, making algebraic concepts accessible to more students. While the closed form representation of problems has served us well in the past, many of the problems our students will face, as adults, will require the ability to understand and make decisions about complex systems (Lesh, 2006). The goal of this paper is to support an evolution in teaching strategy and the content employed so as to make the study of complex systems available to algebra students.

\section{B. Background}

"Change is accelerating, and as the complexity of the systems in which we live grows, so do the unanticipated side effects of human actions, further increasing complexity" (Sterman, 1994). Our nation and the global community face serious problems such as global warming, soaring national debt, unsustainable consumption of natural resources, daunting health costs for families, rising numbers of children in 
poverty, environmental impacts on health, and more. How will our children be able to successfully address these problems if teachers do not have strategies that are designed to help students build understanding of dynamic systemic problems?

Using technology it is possible to have students represent and analyze problems that would typically have been out of their mathematical reach using traditional closed form equation approaches (Blume et al., 2008; Fisher, 2011a; Pea, 1987). One approach to the study of dynamic complex problems, used successfully by professional modelers and by pre-college students, is the System Dynamics (SD) method.

\section{Representational Icons}

The STELLA SD software, described here, contains four main icons. One icon operates as an accumulator of "stuff" over time. This "stuff" can be Stock physical, like the number of cars in a city, or abstract, like "concern about child homelessness." The accumulator is identified as a "stock"

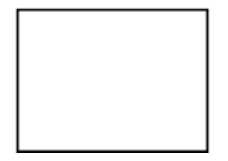
shown as a rectangular icon. The stock depicts an important variable of interest and represents an aspect of the state of the system.

A "flow" icon represents a rate of change in a stock. If the flow arrowhead is pointing toward/away from the stock, a

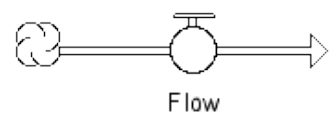
positive value (within the icon) represents the rate of increase/decrease of the stock value.

Another icon called a "converter" could represent either a parameter value or a non-stock variable whose value is computed using a

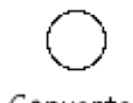
formula. 
Finally, there are icons called "connectors" that link converters

to flows, converters to other converters, stocks to flows, or stocks to

converters. They act like telephone lines, communicating numeric

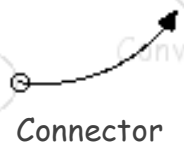

information between components so formulas can be updated each time step (calculation interval).

A simple finance scenario will be used to show how it is possible to think about a problem using different symbolic representations, and will show some of the advantages of each representation.

\section{The First Lesson, Linear Growth: Depositing Money in a Shoebox}

Eleven year old Demitre wants to save money to buy a bicycle and helmet that costs $\$ 198$. His grandmother gave him $\$ 50$ on his last birthday. He has a regular allowance of $\$ 5$ per week for doing some chores around his house. He wants to know how long he will have to save his money in order to buy the bike and helmet. (We will assume he lives in a state that does not have sales tax.) Demitre has not yet studied algebra so he might determine how long he has to wait using a recursive sequence of calculations, as shown below in the second column of Table 7.

Table 7: Calculations for time needed to purchase the bicycle and helmet.

\begin{tabular}{|l|l|l|}
\hline Week & $\begin{array}{l}\text { Money in shoebox } \\
\text { (recursive calculation) }\end{array}$ & $\begin{array}{l}\text { Money in shoebox } \\
\text { (calculation leading to } \\
\text { algebraic equation) }\end{array}$ \\
\hline Starting amount of money: & $\$ 50$ & $\$ 50$ \\
\hline Money after 1 week & $\$ 50+\$ 5=\$ 55$ & $\$ 50+\$ 5=\$ 55$ \\
\hline Money after 2 weeks & $\$ 55+\$ 5=\$ 60 ;$ & $\begin{array}{l}(\$ 50+\$ 5)+\$ 5=\$ 50+2 * \$ 5 \\
=\$ 60\end{array}$ \\
\hline Money after 3 weeks & $\$ 60+\$ 5=\$ 65 ;$ & $\begin{array}{l}(\$ 50+2 * \$ 5)+\$ 5=\$ 50+ \\
3 * \$ 5=\$ 65\end{array}$ \\
\hline$\ldots$ & $\ldots$ & $\ldots$ \\
\hline
\end{tabular}




\begin{tabular}{|l|l|l|}
\hline Money after 30 weeks & $\$ 195+\$ 5=\$ 200 ;$ & $\begin{array}{l}(\$ 50+29 * \$ 5)+\$ 5=\$ 50+ \\
30 * \$ 5=\$ 200\end{array}$ \\
\hline
\end{tabular}

Both calculations lead Demitre to the same conclusion, thirty weeks of saving are required. The calculation shown in the middle column is intuitive, if cumbersome. The calculations shown in the third column are even more cumbersome but lead to a pattern that can be written as a closed form linear formula, $M_{t}=50+5 t$, the type we want students to learn in algebra, because it is useful for mathematical thinking for future courses.

We could represent the calculations in the middle column using the recursive formula, $\mathrm{M}_{\mathrm{t}}=\mathrm{M}_{\mathrm{t}-1}+5$. Pictorially, students could draw a box (or stock) where the money is being stored and draw an inflow to the box showing that a constant amount of money is being deposited into the box each week. (See Figure 5, left diagram.)
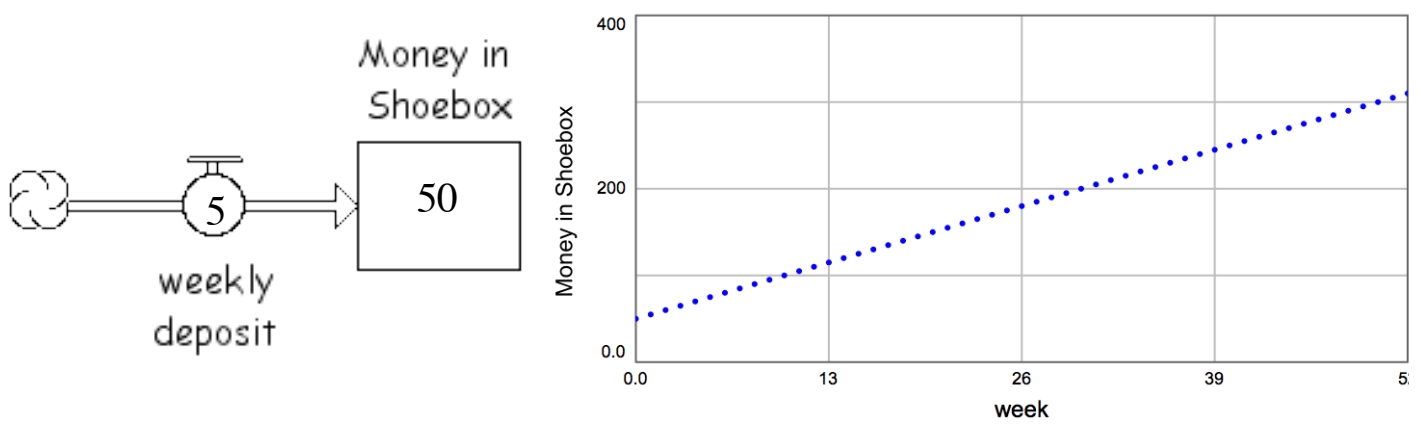

Figure 5: The pictorial representation of depositing money in a shoebox, and the graph of the amount of money in the shoebox over time.

Note: the user can drag the cursor over the graph to read the values of the dependent and independent variables at each point.

Demitre thinks he may want to spend a little of his allowance each week, perhaps $\$ 2$ on treats. So now, how long will it take him to save for his bicycle and helmet? See Table 8 . 
Table 8: Calculations for time needed to save to purchase the bicycle and helmet if $\$ 2$ are spent each week.

\begin{tabular}{|l|l|l|}
\hline Week & $\begin{array}{l}\text { Money in shoebox } \\
\text { (recursive calculation) }\end{array}$ & $\begin{array}{l}\text { Money in shoebox } \\
\text { (calculation leading to } \\
\text { algebraic equation) }\end{array}$ \\
\hline Starting amount of money & $\$ 50$ & $\$ 50$ \\
\hline Money after 1 week & $\$ 50+\$ 5-\$ 2=\$ 53$ & $\$ 50+\$ 5-\$ 2=\$ 53$ \\
\hline Money after 2 weeks & $\$ 53+\$ 5-\$ 2=\$ 56$ & $\begin{array}{l}(\$ 50+\$ 5-\$ 2)+\$ 5-\$ 2=\$ 50 \\
+2 * \$ 5-2 * \$ 2=\$ 56\end{array}$ \\
\hline$\ldots$ & $\ldots$ & $\ldots$ \\
\hline Money after 10 weeks & $\$ 77+\$ 5-\$ 2=\$ 80$ & $\begin{array}{l}(\$ 50+9 * \$ 5-9 * \$ 2)+\$ 5-\$ 2 \\
=\$ 50+10 * \$ 5-10 * \$ 2=\$ 80\end{array}$ \\
\hline$\ldots$ & $\ldots$ & $\ldots$ \\
\hline Money after 50 weeks & $\$ 197+\$ 5-\$ 2=\$ 200$ & $\begin{array}{l}(\$ 50+49 * \$ 5-49 * \$ 2)+\$ 5- \\
\$ 2=\$ 50+50 * \$ 5-50 * \$ 2= \\
\$ 200\end{array}$ \\
\hline
\end{tabular}

We see that Demitre will now need to save for fifty weeks to meet his goal.

Again, the middle column is the most intuitive method of hand calculation for someone who does not know algebra. The third column shows how one might recognize the pattern necessary to write the algebraic formula to summarize this savings plan, $M_{t}=50$ $+5 \mathrm{t}-2 \mathrm{t}=50+3 \mathrm{t}$

The recursive formula for the middle column calculation is $\mathrm{M}_{\mathrm{t}}=\mathrm{M}_{\mathrm{t}-1}+5-2$. (I will purposefully not simplify the arithmetic. The diagram in Figure 6 shows the increase and decrease separately.) If we want to draw a picture of what is happening in this situation we could draw a figure similar to Figure 5, but add an outflow to represent the constant spending that is occurring. See Figure 6. 

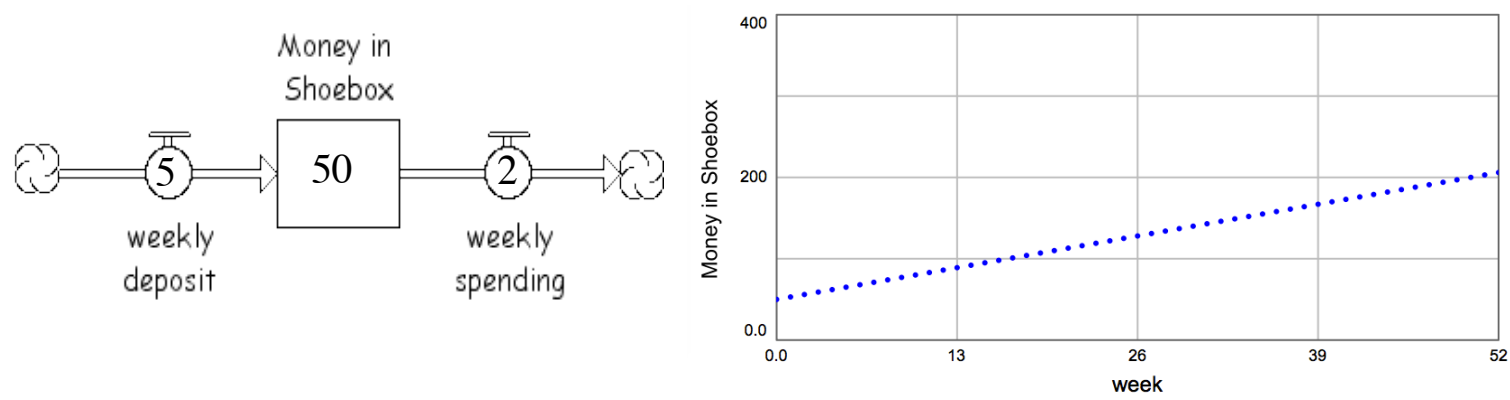

Figure 6: A pictorial representation of depositing money to and spending money from a shoebox, and the graph of the money in the shoebox over time.

\section{The Second Lesson, Exponential Growth: Putting the Money in the Bank}

Demitre's older sister, Helena, says Demitre should put his money in the bank because he will collect interest and that will shorten the amount of time he will need to save to purchase his bike and helmet. She explains how interest works. To make the problem easier for him to understand she assumes the yearly interest will be $10 \%$. She also says that, since he will want to know how much will be saved each week, she will assume that the interest is calculated weekly by the bank. That means the weekly interest rate will be about $10 / 52 \%$ or 0.0019 . She tells him they will only consider interest and no deposits or withdrawals for this initial interest example. See Table 9.

Table 9: Calculations for time needed to purchase the bicycle and helmet placing money in the bank at $10 \%$ annual interest, compounded weekly.

\begin{tabular}{|l|l|l|}
\hline Week & $\begin{array}{l}\text { Money in bank } \\
\text { (recursive calculation) } \\
\text { decimals rounded for } \\
\text { convenience }\end{array}$ & $\begin{array}{l}\text { Money in bank } \\
\text { (calculation leading to } \\
\text { algebraic formula) }\end{array}$ \\
\hline $\begin{array}{l}\text { Starting amount of } \\
\text { money }\end{array}$ & $\$ 50$ & $\$ 50$ \\
\hline Money after 1 week & $\begin{array}{l}\$ 50+0.0019(\$ 50)= \\
\$ 50.095\end{array}$ & $\begin{array}{l}\$ 50+0.0019(\$ 50)= \\
\$ 50(1.0019)=\$ 50.095\end{array}$ \\
\hline Money after 2 weeks & $\begin{array}{l}\$ 50.095+0.0019(\$ 50.095) \\
=\$ 50.19\end{array}$ & $\begin{array}{l}(\$ 50+0.0019(\$ 50))+ \\
0.0019(\$ 50+0.0019(\$ 50))= \\
\$ 50(1.0019)^{2}=\$ 50.19\end{array}$ \\
\hline$\ldots$ & $\ldots$ & $\ldots$ \\
\hline & & \\
\hline
\end{tabular}




\begin{tabular}{|l|l|l|}
\hline Money after 10 weeks & $\begin{array}{l}\$ 50.86+0.0019(\$ 50.86)= \\
\$ 50.96\end{array}$ & $\begin{array}{l}\$ 50(1.0019)^{9}+ \\
0.0019\left(\$ 50(1.0019)^{9}\right)= \\
\$ 50(1.0019)^{10}=\$ 50.96\end{array}$ \\
\hline$\ldots$ & & \\
\hline Money after 50 weeks & $\begin{array}{l}\$ 54.87+0.0019(\$ 54.87)= \\
\$ 54.97\end{array}$ & $\begin{array}{l}\$ 50(1.0019)^{49}+ \\
0.0019\left(\$ 50(1.0019)^{49}\right)= \\
\$ 50(1.0019)^{50}=\$ 54.98\end{array}$ \\
\hline$\ldots$ & $\ldots$ & $\ldots$ \\
\hline $\begin{array}{l}\text { Money after 1040 weeks } \\
\text { (about 20 years) }\end{array}$ & $\begin{array}{l}\$ 359.33+0.0019(\$ 359.33) \\
=\$ 360.02\end{array}$ & $\begin{array}{l}\$ 50(1.0019)^{1039}+ \\
0.0019\left(\$ 50(1.0019)^{1039}\right)= \\
\$ 50(1.0019)^{1040}=\$ 360.02\end{array}$ \\
\hline
\end{tabular}

Again, the middle column appears more intuitive. The third column shows the pattern for the algebraic formula if one were considering compounding interest weekly for 1040 weeks, i.e., $M=50(1.0019)^{t}$, where $\mathrm{t}=$ weeks.

The recursive formula for the middle column in table 9 is $\mathrm{M}_{\mathrm{t}}=\mathrm{M}_{\mathrm{t}-1}+0.0019 * \mathrm{M}_{\mathrm{t}-1}$. If we wanted to look at a picture that would follow the recursive thinking in column two of Table 9 for this interest bearing account, we might draw the diagram shown in Figure 7 , on the left.
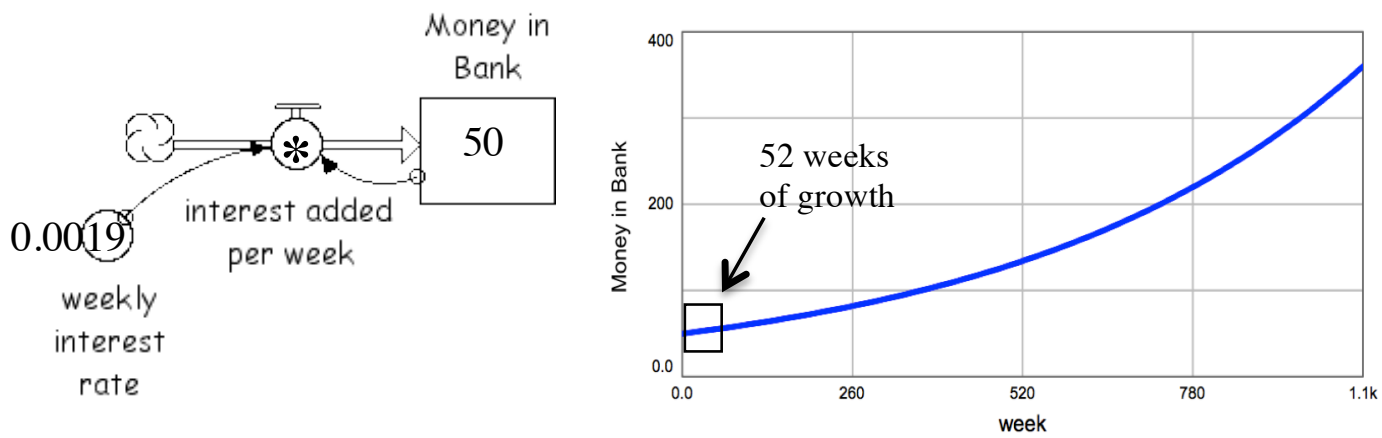

Figure 7: A picture showing how the interest on an interest bearing bank account might be calculated and added to the bank account. The graph shows the amount of money in the bank over 1040 weeks (20 years).

What the diagram in Figure 7 shows is that Demitre is starting with $\$ 50$ in the bank and is adding interest each week. The interest is calculated by taking the current amount of 
money that is in the bank and multiplying it by the weekly interest rate $(0.0019)$. The asterisk in the valve part of the inflow indicates that the software is multiplying the two factors that point to it. When the interest is added, in any given week, the Money in Bank is increased by the interest amount and is therefore larger when the subsequent interest calculation is made, just as is shown in the second column (recursive calculation) of Table 9.

Up to this point the equation and STELLA representations were both useful. Now, in the next lesson, we start to see how we can easily continue to expand the problem using SD but not when using an equation approach.

\section{The Third Lesson, Constant and Exponential Change: Adding Interest to Demitre's Original Savings Plan}

Demitre has been convinced by his sister that placing his money in the bank is a good idea. But he still wants to make his weekly deposits of $\$ 5$ and wants to be able to take out \$2 each week for incidentals. Demitre will probably not find a bank that will give him $10 \%$ interest, but we will keep this interest rate, for convenience. Let's see how we can calculate the weekly status of his money now.

Table 10: Calculating the money in the bank with $10 \%$ annual interest, compounded weekly, $\$ 5$ deposited per week and \$2 withdrawn per week.

\begin{tabular}{|l|l|l|}
\hline Week & $\begin{array}{l}\text { Money in bank } \\
\text { (recursive calculation) } \\
\text { decimals rounded for } \\
\text { convenience }\end{array}$ & $\begin{array}{l}\text { Money in bank } \\
\text { (calculation leading to } \\
\text { algebraic equation) }\end{array}$ \\
\hline $\begin{array}{l}\text { Starting amount of } \\
\text { money }\end{array}$ & $\$ 50$ & $\$ 50$ \\
\hline Money after 1 week & $\begin{array}{l}\$ 50+0.0019(\$ 50)+\$ 5- \\
\$ 2=\$ 53.095\end{array}$ & $\begin{array}{l}\$ 50(1.0019)+\$ 5-\$ 2= \\
\$ 53.095\end{array}$ \\
\hline Money after 2 weeks & $\begin{array}{l}\$ 53.095+0.0019(\$ 53.095) \\
+\$ 5-\$ 2=\$ 56.196\end{array}$ & $\begin{array}{l}\$ 53.095(1.0019)+\$ 5-\$ 2= \\
\$ 56.196\end{array}$ \\
\hline
\end{tabular}




\begin{tabular}{|l|l|l|}
\hline & & $\begin{array}{l}\text { there is no longer a convenient } \\
\text { pattern to follow when we } \\
\text { combine exponential and } \\
\text { constant change }\end{array}$ \\
\hline$\ldots$ & $\begin{array}{l}\$ 78.07+0.0019(\$ 78.07)+ \\
\$ 5-\$ 2=\$ 81.22\end{array}$ & \\
\hline Money after 10 weeks & $\begin{array}{l}\$ 195.26+0.0019(\$ 195.26) \\
+\$ 5-\$ 2=\$ 198.63\end{array}$ & $\begin{array}{l}\text { No simple closed form } \\
\text { equation }\end{array}$ \\
\hline Money after 46 weeks & \multicolumn{2}{|l}{} \\
\hline
\end{tabular}

The recursive formula used for column 2 of Table 10 is $\mathrm{M}_{\mathrm{t}}=\mathrm{M}_{\mathrm{t}-1}+\mathrm{M}_{\mathrm{t}-1} * 0.0019+$ 5 - 2. It shows he could make the purchase four weeks sooner, by placing his money in the bank. Eleven year old Demitre may not be able to follow all the calculations shown in column 2 of Table 10, but if we showed him the diagram in Figure 8 he would probably be able to understand the logic that is shown.
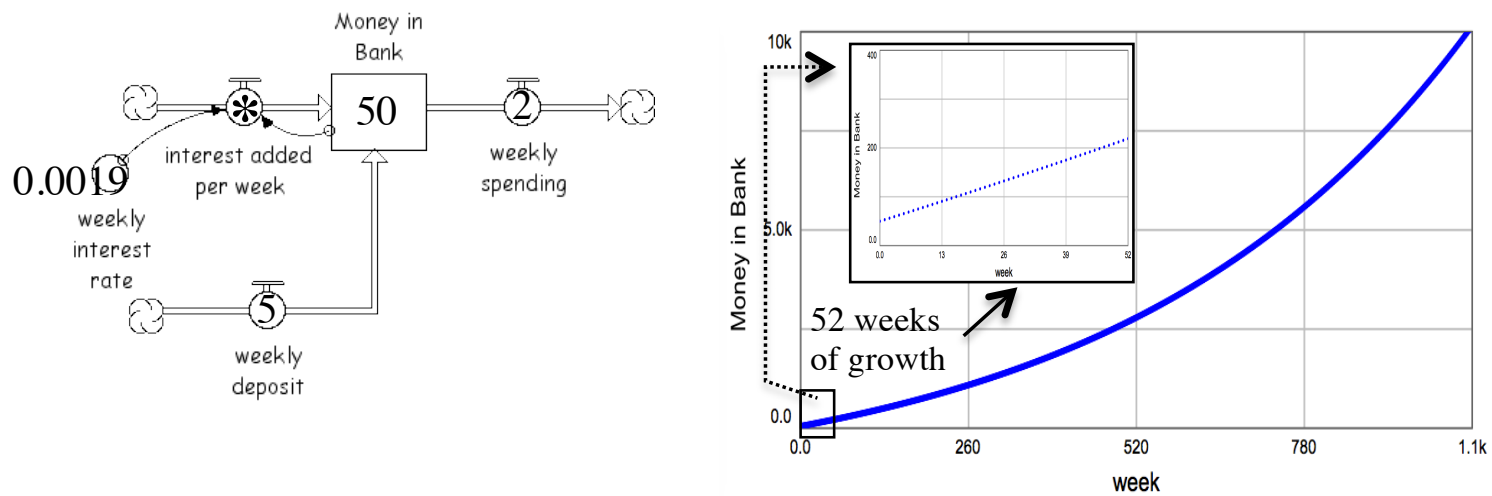

Figure 8: A picture of Demitre's savings plan, with interest added to his bank account each week, and a constant amount in weekly deposits and (constant) weekly spending. The (cut-out) graph shows the amount of money in the bank over 52 weeks.

\section{Extending Lesson 3}

Demitre's parents want him to develop good financial habits. They are willing to increase his allowance to $\$ 6$ per week if he will put $\$ 1$ per week in a savings account in the bank that will earn $12 \%$ annual interest (compounded weekly). If he were just to put 
this extra dollar in a savings shoebox he knows he would have saved $\$ 46$ in his shoebox at the end of 46 weeks (when he bought his bike and helmet). Placing the extra dollar in his checking account and having the bank automatically transfer $\$ 1$ to his savings account each week should work out better for him, since he is earning interest on his accounts. How much more money will he have in savings after 46 weeks, if he follows this plan? (\$2.47) A possible model diagram and graphical output are shown in Figure 9. There are many scenarios that could be tested with the model in Figure 9, different interest on checking and/or savings account, different savings amounts, different spending amounts, etc.
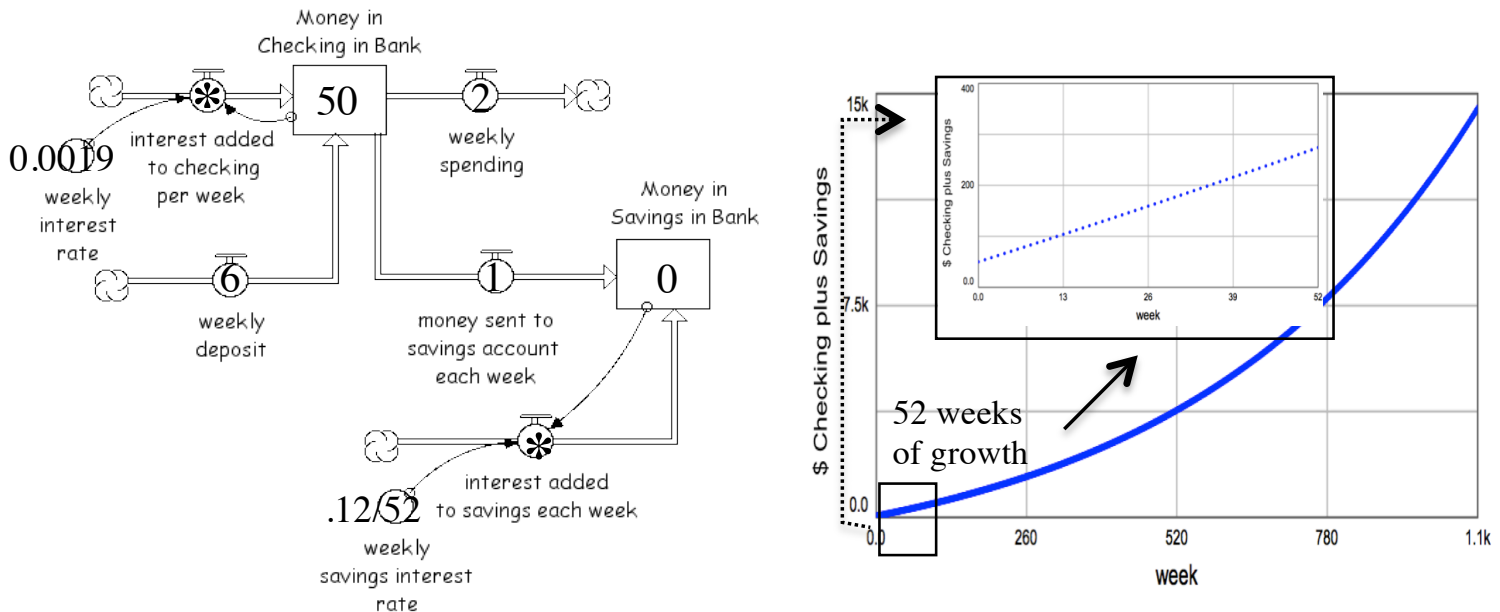

Figure 9: A picture (diagram) of Demitre's checking and savings account system. The graph shows the sum of both the checking and savings accounts.

\section{Other Considerations}

It is possible to design STELLA diagrams that will produce not only linear and exponential function behavior, as shown in the previous examples, but produce quadratic, convergent (goal-seeking), logistic, and sinusoidal function behavior, for example. It is 
then possible to combine these STELLA diagram segments to study larger problems in the same way that small Lego structures are combined to develop larger Lego systems.

STELLA has been used as a student model-building tool in some mathematics and science classes at the middle and high school level for over two decades. Curriculum has been developed for use in middle school and for use in high school mathematics and science classes (Creative Learning Exchange, ${ }^{23}$ 2015; Fisher, 2005, 2011a).

A detailed alignment of SD modeling and the CCSS-M Practices and Standards can be found at http://www.ccmodelingsystems.com/res-stds-skills-math.html.

\section{Discussion}

The first three examples (shown in lessons 1 and 2) in this article are exact models, simple enough to be expressed both by closed form equations and STELLA diagrams, but most real problems are more complex. Mathematizing with closed form equations typically requires simplifying the problem, sometimes extensively, to be able to bring the problem to an approachable level for students. The SD approach allows more complexity to be retained and is ideal to model natural phenomena that are not necessarily simple. It provides a vehicle more tuned to real-world analysis, giving students a tool that can grow with them throughout their educational instruction and into their professional lives.

Another benefit of the SD approach is that it more directly assesses student understanding, as the stock/flow diagrams bring to the surface, for analysis and discussion, the student's conception of how a problem is structured, surfacing their

\footnotetext{
${ }^{23}$ See http://www.clexchange.org/cleproducts/default.asp.
} 
"mental models." This visual mapping of the problem provides a vehicle for problem analysis that is inclusive of modeler and others, including students and teachers. The modeling acts both as a mathematization process and a communication process. As such, it allows students access to more sophisticated problems and gives them a vehicle for explaining their work that is more intuitive than using the closed form equation. Access to such dynamic problems, starting from closed form algebraic equations comes later, in calculus. Whereas learning the closed form equation in calculus helps only modestly, as most complex real world systems have no closed form solution of any type.

\section{Conclusion}

When we restrict our mathematical representation to closed form algebraic equations we limit the types of problems that students can study. In fact we also exclude students for whom the equation representation is not easy to understand nor easy to develop from a problem description. The System Dynamics modeling method is based on observing patterns of change over time for problems whose structure is laid out using icons that are identified using full words or phrases and depicting the dependencies between variables in the diagram.

We need to take advantage of the power that technology brings to our students: some using visual representations, some assisting with the tedious number crunching needed to determine long-term patterns, some possessing the ability to easily link different function structures together to capture complex behavior, and some possessing the ability for students to easily test "what-if" questions about the subject of interest. We 
need more adults (now and in the future) who can use newer analytical methods and technology to make informed decisions about complex problems. 


\section{Paper 3: Attempts to Enhance High School Algebra Through System Dynamics Modeling}

\section{Abstract}

In this paper I argue that there is a compelling need to provide secondary students with experiences that will allow them to begin to analyze complex systems problems. Dealing with the unintended consequences of complex systems problems present significant dilemmas for people locally, nationally, and globally. Technological advances have made access to the study of complex phenomenon accessible by pre-college students. This author has used System Dynamics modeling with students in grades 9-12, successfully, for over 20 years in mainstream mathematics classes, in both inner city and suburban high schools. What is missing is research to support the efficacy of this approach on a broader scale. An initial attempt to document differentiated learning outcomes from using SD modeling was undertaken with the help of two high school math teachers in a public high school. Multiple events led to compressing the time allotment for the classroom experiment, explained in this paper, to only 4 class periods. The experiment failed to differentiate learning outcomes for the experimental and control groups, as one might expect, but it did surface useful information about the teaching environment. The two participating teachers had used SD modeling in their algebra classes in the past, and found the experience valuable for their students. But a variety of technical, curricular, and scheduling issues, along with departmental dynamics conspired to present new barriers that were too difficult for these two teachers to overcome. An explanation of the 
design and results of the experiment, from both the student perspective and from the teacher perspective, is presented.

A. Introducing System Dynamics Modeling into K-12 Education

\section{System Dynamics Theory and its Importance}

"So if we want to bring about the thoroughgoing restructuring of systems that is necessary to solve the world's gravest problems - poverty, pollution, and war - the first step is to think differently. Everybody thinking differently" (Meadows, 1991, p. 3).

Mathematical analysis can play a part in offering insight into systemic problems, and its potential contribution has been greatly increased through new representational resources that allow access to the analysis to many more people (Kaput \& Rochelle, 2013).

In particular, System Dynamics modeling offers an analytical approach to the study of complex systemic problems (poverty, pollution, war, etc.) focusing on connections between components within the system, including feedback loops. Developed at Massachusetts Institute of Technology in the late 1950s by Jay Forrester, it has its roots in control theory. System Dynamics (SD) modeling has been successful at providing insight into difficult complex problems dealing with global warming (Sterman, 2011), kidney disease management at the Mayo Clinic (Gallaher, Steensma, Chrisope, Dingli, \& McCarthy, 2011), disaster planning (Hoard, Homer, Manley, Furbee, Haque, \& Helmkamp, 2005), health care policy reform (Homer \& Hirsch, 2006), and biodiversity loss, to name a few. In 1985, when one of Jay Forrester's students, Barry Richmond, developed an icon-based software (STELLA, described later in this article) that affords SD modelers a visual, intuitive interface for designing and running SD models, SD analysis became accessible to pre-college students.

The Case for Introducing SD Theory in Secondary Schools 
As teachers in K-12, with the potential to influence student thinking due to required student attendance for 13 years, we are called upon to prepare the younger generation with skills and analytic capabilities to help them when they are called upon to make decisions in their lives, in educational goals, in the world of work, and as participative citizens. To do this, teachers must continue to update their skills as new methods of analysis become available and accessible to their student populations. Jay Forrester has spent the past 25 years supporting efforts to bring SD modeling and analysis to the pre-college environment so that students would have the capability to address some of the pressing global problems of our times as they mature. If it is desirable to have "Everybody thinking differently" (i.e., more systemically), then K-12 teachers are in a unique position to facilitate that outcome.

Stigler and Hiebert (2009) completed two nationally representative studies of the instructional practices of junior high school mathematics and science teachers in the United States. The first study (in 1995) indicated that not much had changed in teacher instructional practice in the past 100 years. The second study (in 1999) still found no evidence that teacher practices had changed even though teachers were more aware of mathematics reform efforts. Stiegler and Hiebert stress that schools must become places where teachers as well as students are expected to learn.

Kaput et al. (2013) argue further that, within mathematics classrooms and many other contexts, representational access to mathematical concepts has not changed in (at least) the last 100 years. They indicate that the current symbolic representation of mathematics was developed for an intellectual elite who, at the time, were less than one 
percent of the population and for centuries only a very few people were ever expected to learn how to manipulate these symbols. Consequently, no effort was made to bring this symbolic mathematizing vehicle up-to-date, as was done with the automobile, airplane, and communication industries, each of which has become a common tool for living by the general public. Today we expect a very large, diverse population of students to learn algebra, but we have not developed an accessible style of reading and manipulating algebra (symbolically) that would be available to this population. Kaput et al. (2013) call for "dramatic new efficiencies across the entire K-12 curriculum... [if we are expected to] teach much more mathematics to many more people." They coined the phrase "democratizing mathematics" to describe this effort.

I assert that System Dynamics modeling provides a significant step forward, both in instructional methodology in mathematics and in student accessibility to reading and writing algebra (symbolically) (Fisher, 2005, 2011b). However, having students build small simulation models involves an instructional process that is very different from the traditional methods used by most US mathematics teachers. The visual, dynamic nature provided by the SD software (explained shortly) has been shown to make mathematics more accessible to students, as it has been successfully used for more than two decades by children as young as 11 years of age (Quaden et al., 2008, Waters Foundation, ${ }^{24} 2005$ ). So, how might we go about educating those teachers who are interested in modifying their instructional approach, to incorporate this new System Dynamics analytic method?

\section{Challenges to Teacher Change}

\footnotetext{
${ }^{24}$ See http://www.watersfoundation.org/about/history/ and http://watersfoundation.org/systemsthinking/systems-thinking-strategies/
} 


\section{Teachers' receptivity to change}

Most reformers believe that teachers are the key to change in the classroom (Wolf \& LeVasan, 2008). Important questions to consider for teachers when introducing innovation into education include:

- Is the innovation consistent with the teacher's beliefs about (a) his/her role in the classroom (e.g., teacher as the source of information versus facilitator of learning), and (b) what they think students should be learning and how they should learn it (e.g., will necessary content be covered versus will students discover and/or build their knowledge)? (Philipp, 2007)

- Have teachers had a role in the change (Rosenblatt, 2004)?

- Does the change consider the school culture, i.e. does it have administrative, parental, and community support?

- Have teachers been given extra time to implement the change; is professional development available to help teachers implement the change?

- Is there a method/incentive for recognizing teachers who implement the change well?

\section{Barriers to Teacher Change}

If any of the questions mentioned in the section above is answered in the negative, it can act as a barrier to change. Additional barriers to consider (Wolf et al., 2008) include:

- Teachers tend to be fearful of change.

- The demands of high stakes testing make teachers less inclined to try new ideas in the classroom that do not directly address performance on these tests [especially if their evaluations are partly based on student performance on these tests].

\section{Additional Barriers Related to the Use of Computer Technology}

Unfortunately, if the innovation involves using a technology the teacher has not yet incorporated into his/her instruction, and if that technology also involves modifying 
the teacher/student relationship (as can be the case when creating simulation models), there are additional barriers that can present themselves.

- Some teachers are fearful of losing control of their class, due to the change in their expected role (Skaza et al., 2013; Zbiek et al., 2008)

- Modeling can require teachers to have more domain knowledge (Hmelo-Silver et al., 2006; Roberts et al., 1988)

- If the innovation is new (as in the case of creating simulations) there may be a lack of appropriate curriculum (Ang, 2001; Zbiek et al., 2008)

- Teachers often lack the time to develop skill (using the theory, using technology, in developing curriculum, in reorganizing lessons, in developing new types of assessment) (Doerr, 1996; Zbiek et al., 2008)

- For an innovation to take hold there is a need for ongoing administrative and technology support. (Doerr, 1996; Otero et al, 2005; Roschelle et al., 2000)

Specific to building simulations that involve the study of complex systems (as is the case with more advanced System Dynamics modeling lessons for students), the following further barriers can emerge.

- Teachers who are linear thinkers find working with complex systems to be counterintuitive (Jacobson et al., 2006)

- The interdisciplinary nature of complex systems makes them hard to understand, especially because there is no right answer; validation of models can be difficult (Doerr et al., 2008; Jackson et al., 1994; Jacobson et al., 2006)

At this point the task of facilitating teacher receptiveness to including SD modelbuilding lessons in their instruction might seem insurmountable, but it is a challenge worth continued effort. High School students are capable of creating impressive original SD models and explaining the logic within the models (Fisher, 2011a), and appear to be quite receptive to this instructional approach even when used in more guided model-building lessons (Fisher, Gallaher, Macovsky, 2003). 


\section{Modeling with STELLA}

STELLA is one implementation of SD modeling software that has been used by professional modelers to study systemic problems. It is the SD software chosen by most K-12 teachers that have done SD modeling work with their students.

STELLA displays change over time, for each variable in the model, in graphs or tables. It does so by representing the state of the system at time zero, t, 2t, 3t, $4 \mathrm{t}$ and so on, where the time step t could be a minute, a year, etc., depending on the phenomenon being modeled. The state of the system at time $(n+1) t$ is computed by applying the model to the state at time nt.

There are four icons that form the foundation for building SD Amount of Money in a Bank Account models. A stock, represented by a labeled rectangle, is an accumulator and designates a variable whose value increases or decreases over time. An example of a stock variable might be the amount of money in a bank account. The modeler usually wants to track the value of the stock variable over time.

A flow (usually represented as an arrow with a wide shaft with a valve symbol at its center) represents a rate of change of a stock. If the flow arrowhead is pointing toward the stock, a

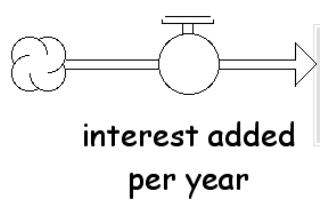
positive value (within the icon) designates the rate of increase in the stock value. If the flow arrowhead is pointing away from the stock, a positive value (within the icon) designates the rate of decrease in the stock value. For example, if the stock designates the Amount of Money in a Bank Account, a flow whose arrowhead points toward the 
stock could designate the interest added to the bank account each year. (For this paper the purpose of the "cloud" symbol need not be explained.)

Another icon is called a converter. It is represented as a circle and is used to hold parameter values or formulas for auxiliary variables

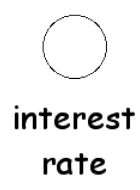
important to system logic. Continuing our example, a converter would designate the annual interest rate the bank uses to calculate interest to add to a bank account.

Finally, there is an icon called a connector. It is represented by a thinly shafted arrow that connects a converter to a flow, a converter to another converter, a stock to a flow or a stock to a converter. It acts like a telephone line, communicating numeric information between components so that formulas can be updated each time step. For an example of its use see Figure 11 below.

An example of a linear function stock/flow diagram is shown in Figure 10.

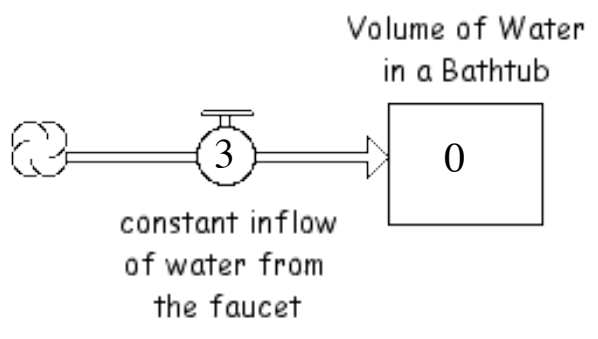

Figure 10: Linear function structure.

Here we want to track the volume of water in the bathtub over time, the time step being a minute. We will assume the bathtub is empty initially, and that the inflow of water from the faucet (the rate at which the bathtub water is changing) is a constant 3 gallons/minute. The volume of water in the bathtub (stock) will grow linearly because its rate (flow) is 
constant. This representation is built from an understanding of the differential equation concept of a linear function.

An example of an exponential function stock/flow diagram is shown in Figure 11. Here we want to track the amount of money in a bank account over time (in years). We will assume the bank account initially contains $\$ 100$ and that amount will grow at 5\% interest compounded yearly, over time..$^{25}$

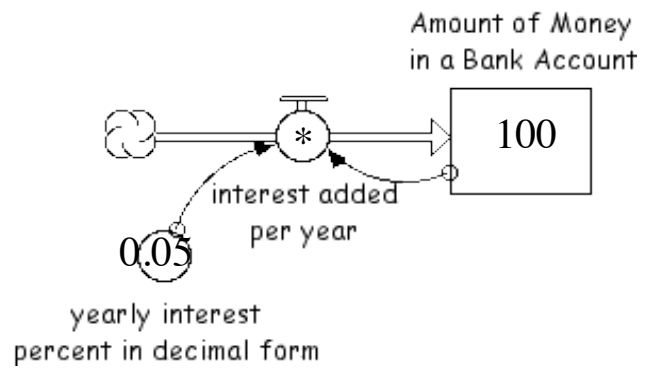

Figure 11: Exponential function structure.

The amount of the flow (the rate at which the bank account will grow) is not constant, but is calculated each year as the product of the amount of money currently in the bank account and the yearly interest rate of 5\%. The Amount of Money in the Bank Account (the stock) will grow exponentially because its rate of change (interest added per year) is proportional to the amount of money that is in the bank in any given year. This definition is built from an understanding of the differential equation for an exponential function.

\section{Beyond the Study of Functions to Modeling Complex Systems Using System Dynamics}

It is possible to design other simple function structures for quadratic, convergent, logistic, and sinusoidal functions that might be studied in a second year algebra course

\footnotetext{
${ }^{25}$ Note: STELLA can represent this graph using the scatter plot option, which will graph the bank account values as discrete points plotted just once per time unit (once per year, in this case).
} 
(all from their differential equation relationships). It is then possible for students to create more sophisticated stock/flow diagrams of scenarios that involve combinations of these functions, producing more realistic function structures and behaviors for problems that would have been out of their mathematical reach without this modeling approach (Blume et al., 2008; Doerr, 1996; Forrester, 1986; Heid et al., 2008a; Jacobson et al., 2006; Pea, 1987; Roschelle et al., 2000; Steed, 1992). A simple example is the following drug model that has been used in several algebra II classes,${ }^{26}$ after students have studied linear and exponential functions.

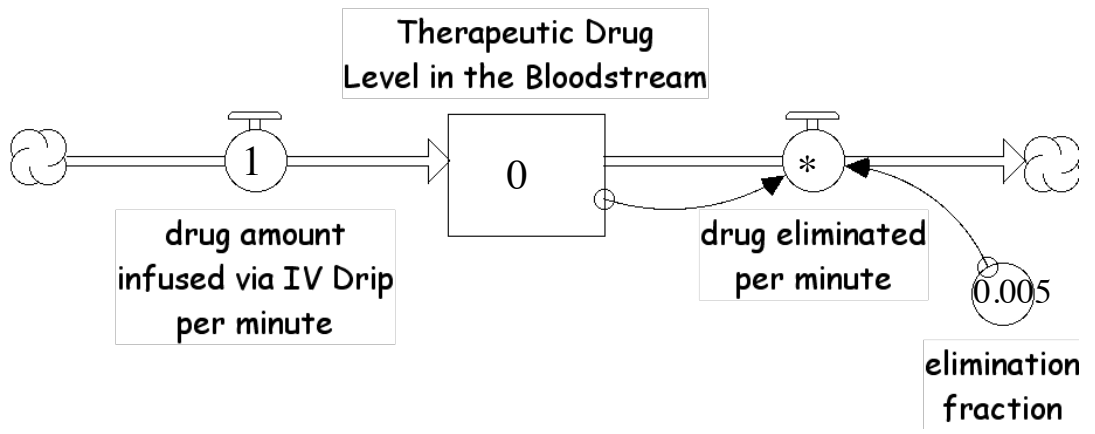

Figure 12: The IV drip Drug Model.

In the model shown above, a person is receiving a therapeutic drug via an intravenous (IV) drip. The inflow is constant. The outflow is exponential because the more drug there is in the body the more that is eliminated from the body per minute. The growth of the therapeutic drug level in the bloodstream is convergent to a level of around $200 \mathrm{mg}$, a point at which the inflow to the stock matches the outflow from the stock.

Model building is a student-centered activity with the teacher acting as a facilitator. To be able to do that the teacher must be comfortable with the process. To

\footnotetext{
${ }^{26}$ The classes include multiple algebra II classes taught each year for over 20 years by myself, by some of my colleagues, by high school math teachers I have trained, and by various math teachers who have purchased either of my two modeling books (both of which have been available for over 10 years).
} 
use the SD model-building approach the teacher will have to learn some basic principles of the SD theory, be comfortable using the computer and, in particular, the STELLA software.

SD theory is based on building computer models of dynamic systems and, using the structure of the model (including the feedback loops), explaining the behavior of the stock variables over time. In Figure 12, the feedback goes from the Therapeutic Drug Level in the Bloodstream to the drug elimination per minute and back to the Therapeutic Drug Level in the Bloodstream. Feedback analysis may not be part of initial modelbuilding activities in an algebra II class, but as models are built to capture the dynamics of more realistic applications feedback analysis become an essential part of understanding those dynamics. Feedback analysis will not, however, be incorporated in this introductory study as the student model-building lessons are quite basic.

In the second part of the paper, I describe both my own classroom experience introducing SD modeling into my mathematics classes and a classroom study introducing SD modeling into algebra II conducted with two interested high school algebra II teachers in a suburban school in the northwestern part of the United States.

B. Introducing SD Analysis in High School: Two Case Studies

\section{A 20-Year Action Research}

I have been a high school mathematics teacher for most of my career. I also taught computer programming, so was comfortable using technology in my mathematics instruction. In 1990 I saw the STELLA software for the first time and its influence on me during the next 20 years was significant. I experimented with the introduction of SD 
modeling in the high school mathematics classes that I taught in two ways. In the more traditional curriculum, algebra I, algebra II, pre-calculus, and calculus, I used SD modeling to reinforce elementary function structure and introduce new, slightly more sophisticated problems for my students to work with at various times throughout the year. I used SD modeling mostly in algebra II, as that was where I found it provided the greatest leverage for the concepts I wanted the students to understand. I only used 8 lessons throughout the year, but incorporating the SD approach changed the way I taught my courses. I focused more on general patterns of function behavior and their mathematical structure, especially using stock/flow diagrams. When dynamic problems only involved a single function I required students to move between the stock/flow diagram and the closed form equation. When the dynamic problems became more complicated, we mathematized the problems using only STELLA. Students were to build the correct structures, anticipate model behavior, explain discrepancies between predictions and simulation output, and modify the models correctly to incorporate new information. When students had a chance to become comfortable with the tool, I was able to introduce even more complicated problems. Even students who were typically not adept at algebra II indicated an appreciation for this approach. A student who was failing my algebra II class (the very first time I introduced STELLA in my class) said, "Why didn't we do this sooner. This I understand." Over the years, other comments from students who had difficulty with math were similar.

The second place I used SD modeling was in the design of a yearlong modeling course. I did not know formal SD modeling analysis when I started the class. I just liked 
the visual nature of the STELLA software, and began a 25-year study of the SD analytical approach. From the beginning the course culminated with students in teams of 2 building an original model and writing a technical paper explaining their models. Each year I would expand the benchmark for what I wanted students to do in the class. Each year students would jump over the benchmark and surprise me with the models they were able to build and explain. It was this yearly student progress that alerted me to the true potential of what SD offered for pre-college students.

When I started the modeling class I recruited students from my algebra II class, suggesting they take the modeling class. I looked for students who appeared to be somewhat curious about problems in the world, students who exhibited an ability to focus, and students who were at average or above ability in second year algebra. Students' ability to focus was very important because I never lectured in the modeling course. I would give students lesson packets that described story scenarios and they would work to build models for the scenarios. They talked to each other. We held the class in a computer lab. There were no tests and there was no homework. The packets contained questions about the story that students would use the model to answer. The course expanded so that students in grades $9-12$ were in the same modeling class. The younger students needed to have completed algebra I, and be more adept at math. Examples of some of the student models, student technical papers, and some short videos of students explaining their models can be found on the web. ${ }^{27}$

\footnotetext{
${ }^{27}$ www.ccmodelingsystems.com/student-projects-highlights.html, http://www.ccmodelingsystems.com/student-projects-videos.html, http://www.ccmodelingsystems.com/student-projects-other.html and https://www.youtube.com/user/CCModelingSystems
} 
I taught SD modeling for 20 years in the public school system in Portland, Oregon. For the first 10 years I used SD modeling in my math classes and taught the yearlong SD modeling course at an inner city high school that served a middle to lower socio-economic student population. We eventually had three sections of the first year SD modeling course and offered a second year SD modeling course for students. Only about $1 / 3$ of the student population attended four-year colleges. During the second 10 years I used SD in math and taught the yearlong SD modeling course at a suburban high school where $85 \%$ of the students attended four-year colleges. In both schools the students reacted very favorably to the use of SD modeling as part of the math curriculum.

I have attended and presented papers or workshops at both the International System Dynamics Conference and the K-12 Systems Thinking and Dynamic Modeling Conference since 1993. I wanted to share my initial experiences with teachers and so wrote two National Science Foundation grants that were funded. I was the lead principal investigator and directed the NSF projects: Cross-Curricular Systems Thinking and Dynamics Using STELLA (1993-1996) and Cross-Curricular Systems Using STELLA: Training and Inservice (1997-2001). In the NSF projects math, science, and social science teachers were taught to build small SD modeling lessons and then build a collaborative SD modeling lesson for their classes. Feeling a need to increase my formal training in System Dynamics modeling I earned a graduate certificate in System Dynamics from Worcester Polytechnic Institute in 2010 and have just completed my $\mathrm{PhD}$ in System Science at Portland State University. I currently sit on Policy Council of the International System Dynamics Society. My experience using SD modeling in the 
classroom, my collaboration with other professionals in the SD field, and my continued study of SD were the experiences that prompted me to try to continue to help other teachers who might be interested in using this SD modeling approach.

\section{A Design Experiment Infusing SD Modeling In the Algebra II Curriculum}

One of the main purposes of the experiment (to be explained in this paper) was to examine the specific components needed to support high school teachers as they taught initial SD model-building lessons in their algebra II classes. The second purpose of the experiment was to document previously observed improvements in students' ability to design and explain models of scenarios that were more complex than those typically presented in algebra II classes. Hence, an experiment was designed and executed in two algebra II classes at a public high school in Portland, Oregon during the 2015-2016 school year. The school serves a student population that would be considered slightly above average in its performance on statewide mathematics assessment (79\% proficient). It has a $22 \%$ minority population and receives no Title I funding.

Two algebra II teachers agreed to participate in the experiment. Each teacher taught at least two algebra II courses, so one class could be (randomly) designated as the experimental group and the other as a control group. The teachers were comfortable using technology in math instruction (beyond just graphing calculators) and were familiar with the STELLA software. One teacher had some training using SD in mathematics about 23 years ago, and the other had experimented with the software in his algebra II class about 5 years ago. Neither teacher was currently using SD modeling in his algebra classes. 
It is useful to know the math proficiency level of each of the four classes involved in this experiment. The math proficiency level of the students involved in this experiment was measured (only) by using the class mean scores of their first semester in algebra II. The results were: ${ }^{28}$

Table 11: Mean scores of the first semester algebra II grades for the classes in this experiment.

\begin{tabular}{|l|c|c|}
\hline & Teacher 1 & Teacher 2 \\
\hline Experimental & $83 \%$ & $69 \%$ \\
Class & $\mathrm{n}=21$ & $\mathrm{n}=22$ \\
\hline Control & $74 \%$ & $85 \%$ \\
Class & $\mathrm{n}=17$ & $\mathrm{n}=16$ \\
\hline
\end{tabular}

The teachers wanted the experiment to be done in the window of time between winter break and first semester exams, rather than spreading the lessons out over the first semester (as I had done in my own classes). To accommodate their wishes, that time slot was selected. Unfortunately, due to numerous scheduling difficulties, including unforeseen snow days that closed the school, it turned out we had to schedule the preand post-assessments and all 6 lessons into 4 class periods, only two of which were 93 minutes ${ }^{29}$ long. Students had enough time to complete the pre- and post-assessments, but each lesson had to be cut short and there was no time to go over student lessons before they had to work on the next lesson.

\section{The Student Experience}

A brief description of the assessments and lessons is appropriate at this point. The research question was: “Can System Dynamics model-building activities aid students

\footnotetext{
${ }^{28}$ The number of students, $\mathrm{n}$, designated for each class were those students, and parents who agreed that their student data could be used for the experiment (or who remembered to return the permission slips). The classes actually contained quite a few more students.

${ }^{29}$ The other two class periods, for this alternating block schedule, were either 75 minutes or 63 minutes long.
} 
in identifying and differentiating linear and exponential function behavior over time in the context of a real-world scenario?" The assessments asked conceptual questions about linear and exponential situations. In the control classes the teacher conducted a traditional review of linear and exponential functions.

Method: In the experimental classes there were six lessons: ${ }^{30}$

1. Students walked in front of a motion detector connected to a computer that displayed their motion graphically on an overhead screen. As a final problem, an original walking scenario was designed by each student and the student explained how one would walk to produce the graph they drew. This problem was "graded" by the researcher.

2. Students built linear STELLA models, on computers, from descriptions of linear scenarios, and then sketched the stock/flow diagram for an original linera model devising their own scenario. The original model was "graded" by the researcher.

3. Students walked into and out of a 5' $5^{\prime}$ ' rectangle (stock) taped to the classroom floor via large flows (also taped to the floor). The patterns of the inflow and outflow replicated linear and exponential patterns of change in the number of students in the stock.

4. Students graphed some of the scenarios from the motion detector and tape-walking experiments.

5. On the board the teacher used a bank account scenario to help students understand the design of the exponential STELLA structure that was used for the exponential modelbuilding lesson. Students then built exponential STELLA models, on computers, from descriptions of exponential scenarios. Finally, students sketched the stock/flow diagram for an original exponential model devising their own scenario. The original model was "graded" by the researcher.

6. Students built a drug model, on the computer, from a description that required a constant inflow of drug into the patient's blood system, and required an exponential outflow as the drug is metabolized. (See Figure 12.) At this time two students were randomly selected from each experimental class, removed from the class to another empty classroom, and videotaped as they used think-aloud protocol to build the drug

\footnotetext{
${ }^{30}$ More detail about the lessons, the learning theory upon which they are based, and the specific outcomes from the student experiment can be found in Fisher (2016) [Chapter 6 of this thesis.]
} 
model. The entire drug lesson packet (for both the extracted pairs of students and the students in the experimental classes) was "graded" by the researcher.

Analysis: The pre- and post-assessment did not show a significant difference in learning outcomes between the experimental and control groups. This is not surprising, given the extreme brevity of the duration of the experiment. However, some interesting results did occur on the linear and exponential modeling problems that were graded from the experimental lessons.

Table 12: Mean scores for each experimental class on the three graded problems from the experimental lessons: motion detector, sketch linear model, sketch exponential model.

\begin{tabular}{|l|c|c|c|}
\hline \multicolumn{4}{|c|}{$\begin{array}{c}\text { Experimental Groups } \\
\text { Student Original Work }\end{array}$} \\
\hline & $\begin{array}{c}\text { Motion } \\
\text { Problem }\end{array}$ & $\begin{array}{c}\text { Linear } \\
\text { Model }\end{array}$ & $\begin{array}{c}\text { Exponential } \\
\text { Model }\end{array}$ \\
\hline $\begin{array}{l}\text { Teacher 1 } \\
\mathrm{n}=20\end{array}$ & $89 \%$ & $80 \%$ & $75 \%$ \\
\hline $\begin{array}{l}\text { Teacher 2 } \\
\mathrm{n}=22\end{array}$ & $79 \%$ & $75 \%$ & $76 \%$ \\
\hline
\end{tabular}

It appears that the experimental group that was less proficient in traditional mathematics seemed to perform relatively well on the STELLA model-building lessons compared to the experimental group that was more proficient in traditional mathematics. One might be concerned with the decrease in mean score of the more proficient math group. I suggest, from experience, this is a temporary drop in performance, as the new approach requires different thinking, and these students would become proficient again in the new approach over time.

There were computer difficulties, using an old classroom set of netbooks, from the outset of this experiment. That difficulty climaxed during the drug lesson when a 
significant number of the classroom set of netbooks did not work. However, the student pairs (removed to a different, empty classroom for videotaping) from each experimental class did complete the drug lesson successfully, even though the pair from class 2 started with a wrong diagram. They realized their mistake as they were building the model on the computer and correctly modified their diagram.

\section{The Teacher Experience}

As was mentioned earlier, both participating teachers had used STELLA in their classes before, for a brief time, and then discontinued its use. They had each used it in a short self-contained one to two week unit, using either linear models exclusively, or linear and exponential models. No assessments were conducted on the modeling lessons during any subsequent assessments in their classes.

The research question for the teacher part of the experiment was: " What support is necessary to help interested algebra II teachers incorporate System Dynamics modeling in their algebra II curriculum?"

Method: The two participating teachers were videotaped teaching a statics lesson the week before the experiment started, each completed belief surveys, kept journals reflecting on their experiences during the execution of the student lessons, were videotaped teaching students how to develop the exponential stock/flow structure, completed a questionnaire at the end of the experiment, and were videotaped while being interviewed after the experiment.

Analysis: The videotape of each teacher teaching a statistics lesson indicated that the more senior teacher was also more traditional in his teaching style. His class involved 
less teacher/student interaction. He had students conduct an experiment and had them use calculators to produce the mean and standard deviation values for the experiment. The other (less senior) teacher was preparing students to conduct an original statistics experiment where they determined the question they were going to study, how they would collect data, what analysis they should try to conduct on the data and how they would present their findings. He brought up examples from the news and from experiences that students had in the past to give examples of confounding variables and issues that arise in data collection. Students interacted with him on a regular basis.

Both teachers completed a beliefs survey. The more senior teacher felt it was very important to lecture on new material and somewhat important to follow lesson approaches shown in the text. He also felt it was important to maintain a quiet classroom. The younger teacher felt lectures and textbook guidance and quiet classrooms were less important. The more senior teacher wanted students to be able to design a model for real world data in order to predict a future outcome. The younger teacher wanted students to develop a love of critical thinking and be able to communicate their thought processes and findings when problem solving. Both teachers felt it was okay for a teacher not to know the answers to some students' questions. The younger teacher felt that thoughtful students could always come up with challenging questions. The more senior teacher felt that he should often use "I don't know, let's figure it out," statements in class whether he knew the answer or not.

In the journals both teachers felt well prepared to lead the experimental lessons. They said they needed to brush up on their use of STELLA, but that it was not a problem 
to do so. Both teachers felt the students enjoyed and were engaged with the motion detector and model building lessons. The younger teacher really liked the tape-walking activity. He felt it helped students get a different perspective on linear versus exponential change. The senior teacher did not like that activity and said he thought the students felt that activity was beneath their dignity. The teacher of the group that was less proficient in math was quite concerned about the fact that there was not enough time for the students to complete the lessons. He was also concerned with the time it would take for these students to become comfortable with the software. He thought the frustration students felt building early models would not be balanced by potential positive learning outcomes unless the students used the software for more than two or three lessons. Both teachers complained about the computer issues that occurred during the drug model lesson. Both teachers said it would be important for a teacher to have a prior workshop in the use of the STELLA software to feel comfortable using the experimental lessons as part of their curriculum.

When introducing students to the exponential stock/flow diagram the younger teacher first reviewed the tape-walking exercise to set the stage for the new discussion. He focused on higher-level concepts - linear growth/decay is produced by a constant inflow/outflow, exponential growth/decay requires knowledge of the quantity in the stock as well as a rule indicating how much of that value should flow in or out. He often asked students for input. The more senior teacher merely put the linear structure and the exponential structure on the board and explained why the additional diagram parts were needed in the exponential structure. It was more of a lecture. 
Both teachers indicated, in their questionnaire, that they felt the lessons were worth doing. Both marked "essential" on the value of communicating with another teacher in their department when trying to use new software for the first time in their classes, to build their comfort level. Both complained about the difficulties using unreliable computers.

In the post-experiment interview the teachers mentioned again the difficulty of 8 math teachers trying to share one classroom set of netbooks that were slow and unreliable. Both teachers indicated that having reliable computers, having the software, having at least one other teacher who knew how to use the STELLA software, having predefined lessons to use, having a department that was looking for new ways of reaching students and presenting material were important considerations for starting to use SD in their algebra II classes. They indicated that all of these components were in place when they first used STELLA in their classes but were not in place now. It appears the choice of tools teachers are willing to use for instruction are fluid.

\section{Discussion of the Experiments}

There is very little research on the feasibility of using SD modeling in pre-college education. Mandinach et al. (2000) had conducted studies about the use of SD modeling in a some schools in the Northeast and in the Southwestern US where students were taught to build small SD models in science and math classes at the secondary school level (students ages $15-18$ years) and concluded, after years of work (STACI ${ }^{\mathrm{N}}$ Project), that large scale incorporation of SD modeling was not going to happen any time soon. They cite the increase in the cognitive load on students (and teachers) as more constructivist 
methods are incorporated into school lessons. They indicate (at the time of their analysis) computers were "a far cry from being used effectively." A statement that seems as true today as it was then. They go on to explain, "There is not one research method or design that will provide the definitive answer to the question of whether the innovation was successful in enhancing learning" (p. 381). One, of many, important points they make is the need to have data collected over an extended period of time. Another issue they mention is the difficulty of constructing assessments that can measure the learning that one hopes is occurring with the more "constructivist" approach recommended for high school math and science instruction. Finally, they mention the "zero-sum" game that must be played whenever attempting to introduce new curriculum. Something within the curriculum must be removed to make space for the new lessons. In spite of these, and other reservations, mentioned in the article, Mandinach et al. (2000) feel strongly (based on their own experience) that

"when appropriately implemented, computer-based curricular innovations can markedly improve cognitive performance and subsequently, achievement on standardized tests. Furthermore, we know from our own experiences that engaging and cognitively demanding computer-based curricula can promote academic achievement among many students who are currently not served well by our schools" (p. 392).

I would like to address several points about their observations and the experiment I conducted. Regarding the increased cognitive load that constructivist activities bring to the learning environment, the issue is more the willingness of the teacher to bear that load. If the teacher is not comfortable being put in situations that require them to "think on their feet" or that stimulate "deep thoughtful questions" they had not anticipated, they would not be attracted to the SD modeling approach. 
Teachers who are comfortable with this less formal environment can help scaffold the student learning experiences that require deeper analysis. This does, however, identify that the SD modeling approach will be quite uncomfortable for many math teachers. As such, it would be unwise to require a professional development for all members in a math department just because the SD approach is attractive, in the eyes of the administration. ${ }^{31}$ Rather, it should influence hiring decisions for new teachers in the department. Support and recognition should be provided for teachers who indicate an interest.

It is apparent from this brief experiment, the "special short unit" approach is not the way to introduce SD analysis into a curriculum. System Dynamics analysis is a way of thinking about complex problems. It is not a skill to be picked up in a few days just because the software makes building models relatively easy. The value of the approach is to have students begin to identify dynamics systems problems in the world they see and use the tool (STELLA) to begin to gain a deeper understanding of the structure of the system that causes it to produce the behavior they see. Using STELLA to represent the typical elementary functions they see in algebra II is just the first step in the process. It allows students to think about those functions from a dynamic structure perspective. Then those structures should be used as building blocks to access more sophisticated dynamics. It is necessary for the SD modeling lessons to extend long enough for students to start

\footnotetext{
${ }^{31}$ This, in no way, is intended to downplay the important role administrators have in helping influence integration of innovative instructional methods in the school. I suggest the more personal support of interested teachers to learn and implement innovative practice, by administrators, is more productive than a shotgun approach.
} 
working with problems they could not access using closed form equations. That is the value added, for both the students and the teacher. Short unit introductions do not allow this transition to occur.

In the short unit SD modeling approach previously used by each participating teacher, neither teacher assessed the unit learning outcomes directly. This may be due to the positioning of the unit just before the first semester exam (which was their habit), but it may be that they did not know how to assess the learning from the unit. (See the next paragraph for more about this issue). Whatever the reason, students place less importance on information/skills/concepts for which they are not held accountable. Teachers hear "Is this going to be on the test" often enough from students to reinforce the importance of developing some performance criteria for the concepts they consider essential for student learning.

The next obstacle is devising assessments that capture the essence of an SD modeling approach: more holistic thinking, identifying the connection between structure and behavior in the modeling process, enhancing the ability of students to explain their understanding of the problem, and enhancing their ability to communicate what they learned in the modeling process to an audience. These learning outcomes will not be captured on current standardized tests. But we need ways to publicize these outcomes, or there will always be roadblocks to scaling up the use of the SD modeling approach. The assessment used in the experiment explained in this paper was a beginning. It required students to think conceptually 
about linear and exponential functions. It was imperfect but holds promise that more appropriate assessment instruments can be developed.

Mandinach et al. (2000) mention that when one infuses a new curricular approach something else in the curriculum must be removed. I agree and disagree with this statement. I agree that, initially, there will be topics that will need to be removed to allow more modeling lessons to be added to the curriculum. This happened to me, when I started. But I started with only a few lessons and added more lessons each year as I found other places in the curriculum where modeling fit my overall goals better than the lessons I had been using in the past. Eventually, the SD modeling approach changed the way I taught. I looked at the algebra curriculum from a more holistic perspective. I did less procedural practice that I felt would be eventually relegated to using calculator or computer software, and concentrated on having students focus on patterns of change, where they occur, why they occur, and how we can capture the appropriate structures when looking at (slightly) more complicate scenarios. It allowed me to bring new problems into the classroom for analysis that the students found interesting. So finding the space, over time, changed the focus of the space in which I taught. I also found that the students in my algebra II course who were traditionally less adept at math felt relieved that there was another, less abstract vehicle to use to participate in the mathematics conversations that occurred. I believe that is what we are seeing with the improved performance of the second experimental group, compared to the first experimental group, on the first three lessons that were 
graded. That the first group of students who were more mathematically adept (traditionally) can learn to use STELLA well is exemplified by the projects the modeling class produced.

The two participating teachers liked the STELLA lessons they had used in their classes, but stopped short of realizing the true value of the SD modeling approach. The real reason they stopped was one they both mentioned and that I think is the primary barrier. The technology was just too much trouble to use. The one classroom set of netbooks were old, slow, and some did not work properly. The software on the netbooks had to be "pushed" to the laptops from the district office so if software programs were inadvertently deleted it was not a problem that had a quick solution. These problems beset the execution of the drug model in the experiment described above. There are 7 full computer labs in the high school where the experiment was conducted, but 6 of those labs are dedicated to testing, and one is dedicated to computer programming classes. Even teachers, who are comfortable with technology, and interested in using technology in their instruction eventually decide the problem is not worth fighting on a regular basis. Interestingly, this problem may be solved another way. By the end of 2016 isee systems, inc. (the developer of the STELLA software) will release a very basic, free, web-based version of the STELLA software. This will allow many beginning and intermediate SD model-building lessons to become accessible by tablets and smart phones. Another advantage of the free web version is that students would be able to finish model-building assignments at home. 
One teacher mentioned that the students who were less adept at math tended also to be less technically adept. He said it was difficult to convince those students to persevere with the modeling lessons. I believe this is an artifact of the short time allotted to the modeling unit approach that this teacher used. It may take students who are generally less comfortable with math concepts a longer time to develop skill with the technology, but it is possible for that to occur if the lessons are spread out throughout the year.

The other teacher mentioned that all the algebra II teachers collaborate on which topics to cover during the year and what schedule they would like to follow when covering those topics. This teacher indicated that it had been difficult to convince the other algebra II teachers that SD modeling should be incorporated into the collective list. While there are advantages to having teachers agree on a course scope and sequence it is not a binding agreement. One can introduce a lesson of one's choice here and there, as was evidenced by the videotaping of the two teachers classes before the experiment started. Each was conducting a lesson about statistics. One teacher was preparing students for a project they would complete during the next class period; the other was having students perform a scripted experiment. The second teacher did not have the students do the statistics project at all.

One of the teachers complained that with the new alternating block schedule there were a significant number of instructional class hours that had been lost. That is a problem. Teachers are held accountable, somewhat, for how their 
students perform on standardized state math exams. The school receives a report card indicating how well the students do on these tests. A teacher has a responsibility to be aware of the topics that are assessed and the types of questions students will be asked on these tests. But ultimately, the teacher is responsible for educating the student regarding the mathematics concepts that are to be studied in a given course. It is also important to make sure students are prepared to study the concepts they will experience in the next math course they take. But standardized tests have become a stranglehold on the curriculum, forcing attention to process questions rather than conceptual understanding. ${ }^{32}$ There was a gifted algebra I teacher at another high school who really felt SD modeling would help her students. Her students always performed well on the statewide math assessments. Her principal would not allow her to introduce SD modeling into her curriculum because he did not want her to change her class instruction in any way. The scores produced in her classes had elevated the scores for the entire math department. That was too important, to the principal, to tinker with.

\section{General Discussion}

System Dynamics modeling of elementary functions in algebra II can act as an avenue to an interesting and important next step in mathematical analysis of complex systems for teachers and students at the high school level. Such analytical skill is useful in helping one understand stories in the newspaper and is

\footnotetext{
${ }^{32}$ I understand the need for standardized assessments. But the current situation overemphasizes this method of assessment over more important assessments that do not lend themselves to this venue.
} 
even more important in preparing students to enter STEM related college disciplines and ultimately the professional workforce. Yet, new, innovative teaching approaches seem to be woefully absent in much of mathematics instruction today (Stiegler et al., 2009).

Kaput et al. (2000a) have argued for decades about the advantages of using computer software programs whose tools can be used to construct new representations for mathematizing problems when students work with core concepts in algebra and calculus. They claim the enhanced representations promote a "democratization of mathematics," a claim that this researcher has seen at work in the classroom. The computer can operate as a reorganizer of students' ability to think deeply about problems (Pea, 1985). Kaput, Bar-Yam, Jacobson, Jakobsson, Lemke, and Wilensky (2000b) make the case that new technologies are expanding access to the study of complex behaviors that, heretofore, had to be simplified to be analyzed. They recommend that such analysis become part of mainstream pre-college education, a promising recommendation.

What is causing the inertia in mathematics instruction at the high school level? My experience with the teaching experiment explained in this paper illustrate how difficult it is to change mathematics instruction. There are many barriers to teacher change. More barriers are evident when that change involves the use of new technologies. Even more barriers occur when the change involves new theoretical approaches, such as the inclusion of complex systems analysis. Still, there are teachers who are interested in experimenting with change involving 
technology and complex systems in their instruction, but the environmental conditions must support teachers who want to maintain use of new strategies and technologies in their classrooms. Changing the school environment is a complex systems problem. There are many factors needed to initiate change, teacher and administrative support being crucial. Continued effort on multiple fronts is needed to maintain new instructional approaches (Cobb \& Jackson, 2011).

Finally, it is important to remember that conducting research in the educational arena is difficult. It is not like conducting science experiments, where the researcher attempts to keep all conditions except the designated intervention constant. Berliner (2002) states, "Doing science and implementing scientific findings are so difficult in education because humans in schools are embedded in complex and changing networks of social interaction." This should not dissuade us from attempting to do statistically controlled studies that could provide illuminating answers to important research questions. And we should not be discouraged when we find that the statistical approach did not provide significant differentiation between student learning outcomes. Rather, such findings indicate that most educational research should include multiple research instruments and approaches so that a more heterogeneous analysis can be done to help illuminate other important events/findings beyond just looking at the statistical results.

\section{E. Conclusion}

In this paper I present an argument for incorporating SD modeling activities into mainstream pre-college classes. The considerable list of potential 
barriers to teacher change indicates the inertia that will need to be overcome to make this happen. But more young people are comfortable with technology, so it would seem that more young teachers would be open to its use in the classroom.

A 20-year action research study using SD modeling in high school mathematics classes provides evidence that students at the secondary school level are quite capable of using the SD modeling approach (Fisher, 2011b). Moreover, the 20-year experiment with the yearlong modeling course suggests students are quite adept at building sophisticated models of complex systems, and explaining how they operate. This further strengthens the value of bringing the SD modeling approach to pre-college mainstream education.

The classroom experiment conducted in January 2016 did not provide statistically significant differentiation between the experimental groups using SD modeling and the control groups using traditional lessons regarding student ability to differentiate linear from exponential patterns of behavior. The teachers who participated in the experiment described the changing school environment that adversely impacted their efforts to maintain the inclusion of SD modeling lessons in their classes over multiple years. Nonetheless, I think there is room for optimism. The next study should repeat the experiment, implementing the SD modeling lessons over a semester, with the lessons infused into the regular algebra II curriculum. 


\title{
VI. Paper 4: Details of Student Component of Classroom Experiment Presented in Paper 3
}

\author{
Lessons Learned From a Classroom ${ }^{33}$ Experiment: \\ A Very Brief Introduction of System Dynamics Modeling in \\ Two Algebra II Classes ${ }^{34}$
}

\begin{abstract}
\end{abstract}
The purpose of this paper is to present the results of an experiment conducted at a secondary school in the US in which two mathematics teachers were enlisted to teach a series of 6 lessons introducing System Dynamics modeling as a method to help students better understand the difference between the structures that produce linear versus exponential change over time in real world scenarios. There are very few formal research studies attempting to document learning outcomes from using System Dynamics modeling in mathematics classes at the secondary school level. Four algebra II classes were involved in the study, an experimental and control class for each of the two participating teachers. The teachers administered pre- and post- assessments to each of the four classes and taught 6 experimental lessons to their classes that were designated as experimental. Due to a number of difficulties that contributed to a very limited time to conduct the assessments and lessons the pre- and post assessments did not produce significant differences between the experimental and control groups. However the results collected on some of the lessons indicated that SD modeling might potentially reduce the

\footnotetext{
${ }^{33}$ The paper was submitted using "Failed" experiment. But the suggestion by some on the dissertation committee was that "failed" was inaccurate. Hence the name was changed for this document.

${ }^{34}$ Accepted for presentation at the $34^{\text {th }}$ International System Dynamics Conference, Delft, The Netherlands, $7 / 2016$.
} 
gap in performance between students who are more adept at math and those who are not.

Videotaped think-aloud protocols used with two pairs of students, one from each

experimental group indicated that, even with such a brief introduction, students can build

correct SD models and correctly analyze the behavior for a problem that is slightly

beyond the typical problem studied an algebra II. The experiment should be repeated

over a longer period of time and incorporated into the regular curriculum to overcome

most of the problems that arose with the execution of this experiment. This paper

includes a great deal of information about the experiment that could be used by others

interested in improving the method described here. It is hoped future experiments will be

conducted to add to the literature documenting the learning outcomes that SD modeling

and analysis provides.

\section{A. Introduction}

"Concepts and methods enabled by rapid advances of information technologies are enabling us to understand aspects of the real world where events and actions have multiple causes and consequences, and where order and structure co-exist at many different scales of time, space and organization. Within this complexity framework, critical behaviors that were systematically ignored by classical science can now be included as essential elements that account for many observed aspects of our world-for example, global phenomena that require multiple physical, biological, social, and mathematical perspectives" (Kaput, et al., 2000b, p 1).

The literature indicates a pressing need for adults to become better at understanding complex systemic behavior (Homer et al., 2006; Hung, 2008; Sterman, 2000, 2011). If understanding complex systemic behavior is so important for adults, it seems reasonable to expect mainstream K-12 education to begin to incorporate activities that give students experience working with "wicked" problems. The importance of 
including the study of complex systems in mainstream education is increasingly appearing in research articles within the last decade, even for elementary school students (English, 2007). Jacobson et al. (2006) state,

"The conceptual basis of complex systems ideas reflects a dramatic change in perspective that is increasingly important for students to develop as it opens new intellectual horizons, new explanatory frameworks, and new methodologies that are becoming of central importance in scientific and professional environments" (p. 12).

Although there are a variety of analytical methods that can be applied to the study of complex systems problems, the focus of this paper is on the system dynamics method.

\section{Some Current Efforts in K-12 Education in the US}

The Waters Foundation has had success working with elementary and middle school teachers, training them to use behavior over time graphs, their "Habits of a Systems Thinker" cards, and Iceberg and Ladder of Inference analysis techniques to get teachers to begin using more holistic approaches to their content. Their goal is to help "build systems thinking capacity" in the teachers they train. This effort is scaling up.

The Creative Learning Exchange has increased curricular offerings for K-12 teachers by commissioning curriculum development of models and lessons based on Forrester's statements regarding the nature of systems (Forrester, 2009). These lessons can be accessed on their website. Quaden et al. (2008) have developed the Connection Circle to help elementary and middle school teachers and students analyze feedback loops in scenarios involving more than two components. These two gifted teachers have developed simple System Dynamics (SD) modeling lessons that help students in grades 5 - 8 (ages 11- 14 years) understand the importance of feedback in certain real-world 
scenarios highlighting the difference between linear and exponential patterns of change over time. CC Modeling Systems also offers online courses for math and science teachers who want to learn how to create small SD models to use in their curriculum.

What is missing? Research on the efficacy of the SD modeling approach for K-12 education is missing. Mandinach et al. (1993) conducted quite a few studies working with over 32 secondary school math, science, and social studies teachers incorporating SD into their curriculum. They discussed three levels of modeling using the STELLA software with high school students (ages 15 - 18 years). The first they called parameter manipulation and referred to this as the least cognitively demanding. Next they describe what they call constrained modeling, where students build a model to solve a specifically assigned problem. Finally, they describe "epitome" modeling, the most cognitively demanding, where students build original models for an idea they conceive. The needed modeling expertise of the teacher, as well as the student, increases significantly from the first to the third type of modeling, as does the amount of time that must be dedicated to the modeling activity in the curriculum. In a later article, Mandinach et al. (2000) discuss the many difficulties that they encountered in trying to conduct their research and why they felt that this innovative approach was not destined to appear in mainstream education any time soon.

Yet, the need to document the value of the SD approach to learning about complex systems is reaching a critical stage. Those who are familiar with the approach appreciate what SD modeling can offer, but without the strength of research support to document what, heretofore, have been mostly anecdotal success stories, it will not be 
possible to convince educational decision-makers that efforts should be made to include this "new” approach in classrooms.

So this author undertook the design and execution of a classroom experiment to determine if the use of SD modeling might show an improvement in understanding a concept that is already in the algebra II curriculum, the difference between the underlying process that produces linear versus exponential change over time. This effort was to stay close to the current curriculum as a bridge to moving students toward the study of a slightly more difficult problem that would be outside their normal algebra II curriculum. It was hoped this might indicate a more immediate way to begin incorporating SD modeling into a traditional algebra II course without requiring much modification on the part of the teacher.

The rest of this paper describes the learning theory supporting the design of the experimental lessons, the importance of having students understand the function concept in mathematics, the school environment in which the experiment was conducted, the research question, the method used to conduct the experiment, the various data collected and analyzed, and a discussion of some of the results and lessons learned.

\section{B. The Experiment}

The study comprises an account of the student experience and the learning of the students as an introductory sequence of lessons was used to prepare students to build (in their final lesson) a model of a problem involving a combination of linear and exponential change over time (a situation not covered in algebra II). Design of the experimental lesson sequence and classroom environment were guided, in broad terms, 
by the learning theories developed by Lev Vygotsky and Jerome Bruner, as described below.

\section{Theoretical Foundations}

\section{Learning Theory}

Lev Vygotsky suggested that learning should be a socially active endeavor, where students are expressing their thinking, and the teacher is facilitating the process. This interaction should be cooperative and collaborative (i.e., the teacher uses demonstrations and leading questions) to be effective. Teachers do not transmit concepts. "If concept development is to be effective in the formation of scientific concepts [those new ideas learned in school] instruction must be designed to foster conscious awareness of concept form and structure and thereby allow for individual access and control over acquired scientific concepts" (Vygotsky in Daniels et al., 2007, p. 312).

One of Vygotsky's major contributions to learning theory he called the "Zone of Proximal Development" (ZPD). The ZPD is conceived of as a gap between what the student could learn by him/herself and what he/she could learn with the help of more knowledgeable peers and/or the teacher. Vygotsky indicated that the trajectories for individual student learning in this zone are quite open and will follow dynamic and divergent paths. The objective of the "instruction" is, however, to help the student eventually internalize the new knowledge. Vygotsky (1978) indicated that essential (good) learning should create a ZPD (“awaken a variety of internal developmental processes in the child that are activated by working cooperatively with peers and other people in his/her environment", p. 90) that is forward looking, developmentally, rather 
than testing, which is backward (ineffective) looking. In this way, Vygotsky said, once the processes within the child become internalized they lead to independent developmental achievement (Vygotsky, 1997, italics added).

Jerome Bruner is an important interpreter of Vygotsky, developing Vygotsky's theory in certain directions. Still relevant today is his early book "Toward a Theory of Instruction" (Bruner, 1966) in which he presented three modes of representation that are needed to help students acquire new ideas with understanding. The first mode is enactive, wherein students manipulate concrete objects to gain an understanding of the elements in the system and how they might be related. The second mode is iconic. In this mode students use some pictorial representation of the system they experienced in the enactive mode, to capture the structure or behavior that was present in the activity. Creating and reading graphs are examples within this mode, as is the construction of various diagrams. This mode is still quite concrete - the iconic representation is directly connected to a physical activity. The final mode is symbolic, wherein students use symbols, such as numbers, computational symbols, or words to start to abstract the ideas from the concrete to other similar patterns existing in problems they do not physically experience. STELLA modeling, with pre-activities involving physical simulation, constitutes part of a learning experience that exploits all three of Bruner's modes.

The team method of building System Dynamics models, used consistently in K12 , is well grounded in these learning theories as an effective learning strategy. Students work collaboratively with each other (and with teacher facilitation) to determine what components to include in the model, how they should be connected, whether the 
simulation results are reasonable, how modifications to the values or to the structure modify the system behavior, and recommend possible "solutions" or policies that might transform the system to produce more desirable behavior. This focused, active interaction with the modeling process aligns well with Vygotsky's description of lessons that would produce effective concept development.

The experimental lessons focus on strengthening student conceptual understanding of linear and exponential functions, the concept of function being foundational in algebra.

\section{The Importance of the Function Concept in Mathematics}

"The concept of function is central to undergraduate mathematics, foundational to modern mathematics, and essential in related areas of the sciences. A strong understanding of the function concept is also essential for any student hoping to understand calculus - a critical course for the development of future scientists, engineers, and mathematicians" (Oehrtman et al., 2008, p. 27).

Many mathematics education researchers present studies attempting to determine whether students understand the abstract definition of function, i.e., that a function is a special relationship between two variables whereby each value of one (the independent variable) within a specified range maps to at most one value of the other (the dependent variable). System Dynamics fits into a broader, more dynamic, more applications oriented view of a function. Using the stock/flow diagramming structure of SD many of the continuous elementary functions used in an algebra classroom can be constructed. Those stock/flow structures can serve as an alternate, two-dimensional symbolic representation for the elementary functions. The connection between different representations of functions is 
essential in helping student build a stronger understanding of the function concept (Leinhardt et al., 1990; Keller \& Hirsh, 1998; Yerushalmy, 1991).

The elementary functions that are studied in most second year algebra classes in secondary school represent different patterns of change over time that occur often enough that mathematics educators think students should be able to recognize them whenever they arise in class, whether by viewing the graph or by solving a story problem. But story problems tend to be simplified due to the limitations students have in understanding closed form equations.

"What makes teaching (and learning) of the translation skills so difficult is that behind them there are many unarticulated mental processes that guide one in constructing a new equation on paper. These processes are not identical with the symbols: in fact, the symbols themselves, as they appear on the blackboard or in a book, communicate to the student very little about the processes used to produce them" (Clement, Lockhead, \& Monk, 1981, p. 289).

These functions are generally only called to represent change in one direction (increase or decrease, never both). But systems are not so restricted. So for students to be able to study problems involving systems, it should not be expected that they jump from the graph or story description directly to a "correct" symbolic representation immediately. Kaput (1999) indicated that functions are used to build mathematical systems through successive approximations, where each iteration tries to improve the structure built in an attempt to understand a problem under study. This process involves modeling and some researchers argue that modeling problems/phenomena is the primary reason to study algebra. 
The SD stock/flow function diagram is built with a focus on how the structure produces the function's characteristic pattern of change over time. This structure opens up a representation that has been used successfully to provide a conceptual introduction to elementary calculus concepts within algebra classes. It also can provide a vehicle for enabling students to use the elementary function structures as building blocks that will allow them to study more realistic applications by having them build models that combine these elementary function structures, as small Lego structures can be used to build larger Lego systems.

The lessons for this study focus on increasing student understanding of linear and exponential change over time. Two lessons are devoted to introducing and then enhancing student understanding of the behavior of each function. The first of these two lessons uses a kinesthetic activity to introduce the primary dynamic characteristic of the function, that is, coupling the behavior with a specific type of rate of change (constant for linear, proportional to current value for exponential).

[The primary framework ${ }^{35}$ guiding analysis of student learning in this study will be APOS Theory $(\mathrm{A}=$ action, $\mathrm{P}=$ process, $\mathrm{O}=$ object, $\mathrm{S}=$ schema $)$ developed by $\mathrm{Ed}$ Dubinsky (Dubinsky \& McDonald 2002). At the Action level students are following a plan of action prescribed by the teacher. They merely try to follow the instructions correctly. To move to the Process level students need to reflect on what they have done in the action stage and be able to internalize the process enough to complete related

\footnotetext{
${ }^{35}$ Formal APOS Theory wording was not introduced, as such, in the paper submitted to the International System Dynamics Conference. Instead, a more general vocabulary, "follow directions, create your own, transfer to a new situation," was substituted to indicate the stages in the APOS framework used for analyzing the lessons.
} 
problems without a set of step-by-step directions. At the Object level students can understand the process sufficiently to apply the process concepts to other situations. At

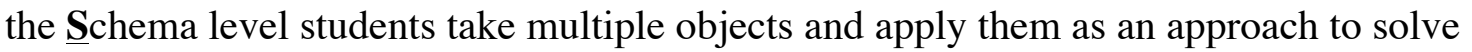
a more sophisticated problem. (Asaila et al, 2004; Dubinsky et al., 2002)] Students follow specific directions in these kinesthetic lessons initially, then are expected to produce their own actions to generate the same function behavior emphasized in the lesson. The attempt is to move students from a "following directions" [action] mode of thinking to a "create your own" [process] understanding of the function. The second function lesson (for each function) has students build an SD model that produces the characteristic function behavior (with focus on rate of change), following directions given in the lesson. Students experiment with the models and explain the reason the model output changed. Students, again, are expected to create an original model that produces the function behavior under study. Modifying the models gives students more experience with each function's behavior. Finally, students are given one problem that involves both a constant and a proportional rate of change and students, it is hoped, understand the type of function structure needed to capture these dynamics as they create one model structure to mathematize the problem. This lesson is designed to move students from the :create your own" [process] understanding on a single function type to the :transfer to a new situation" [object] concept of function where they recognize, from the description, the types of functions that must be used to solve the new, more complicated problem (involving more than one function type). 
In addition to doing the tasks, students will also be expected to explain what they create as a culminating activity in each stage of the experimental/intervention instruction. Explaining one's creations has been shown to "enhance learning and understanding of new knowledge" (Chi et al., 1994, p. 469). Students will be working in teams on most of the activities. Team problem solving is considered a positive learning environment, improving student attitude toward mathematics, and fostering more student engagement in lessons and with each other (Davidson, 1990; Springer, Stanne, \& Donovan, 1999).

\section{The Teachers and School Environment}

This study was conducted in partnership with the curriculum vice-principal and two algebra II teachers at a local high school in Portland, Oregon. This school serves primarily a middle socio-economic population that is $22 \%$ minority, and about $24 \%$ of its students are considered disadvantaged. It has 56 teachers who serve about 1250 students. The school has no Title I funding. The students enter the school generally at normal grade level in mathematics. Reporting on state mathematics tests indicate that $79 \%$ of the students are proficient in mathematics.

The two teachers are experienced secondary mathematics teachers with between 14 and 32 years of experience, respectively, teaching at their current high school. Each has taught algebra II between 10 and 15 years, respectively, each is quite comfortable with technology, and each has used STELLA model-building briefly in their algebra II classes in the past, and then quit using the STELLA software.

The student segment of this study attempted to determine how well students understood an extension of the elementary functions (linear and exponential) as they 
designed a new function that combined the change dynamics associated with the two initial functions.

\section{The Research Question:}

Can System Dynamics model-building activities aid students in identifying and differentiating linear and exponential function behavior over time in the context of a realworld scenario?

Method 


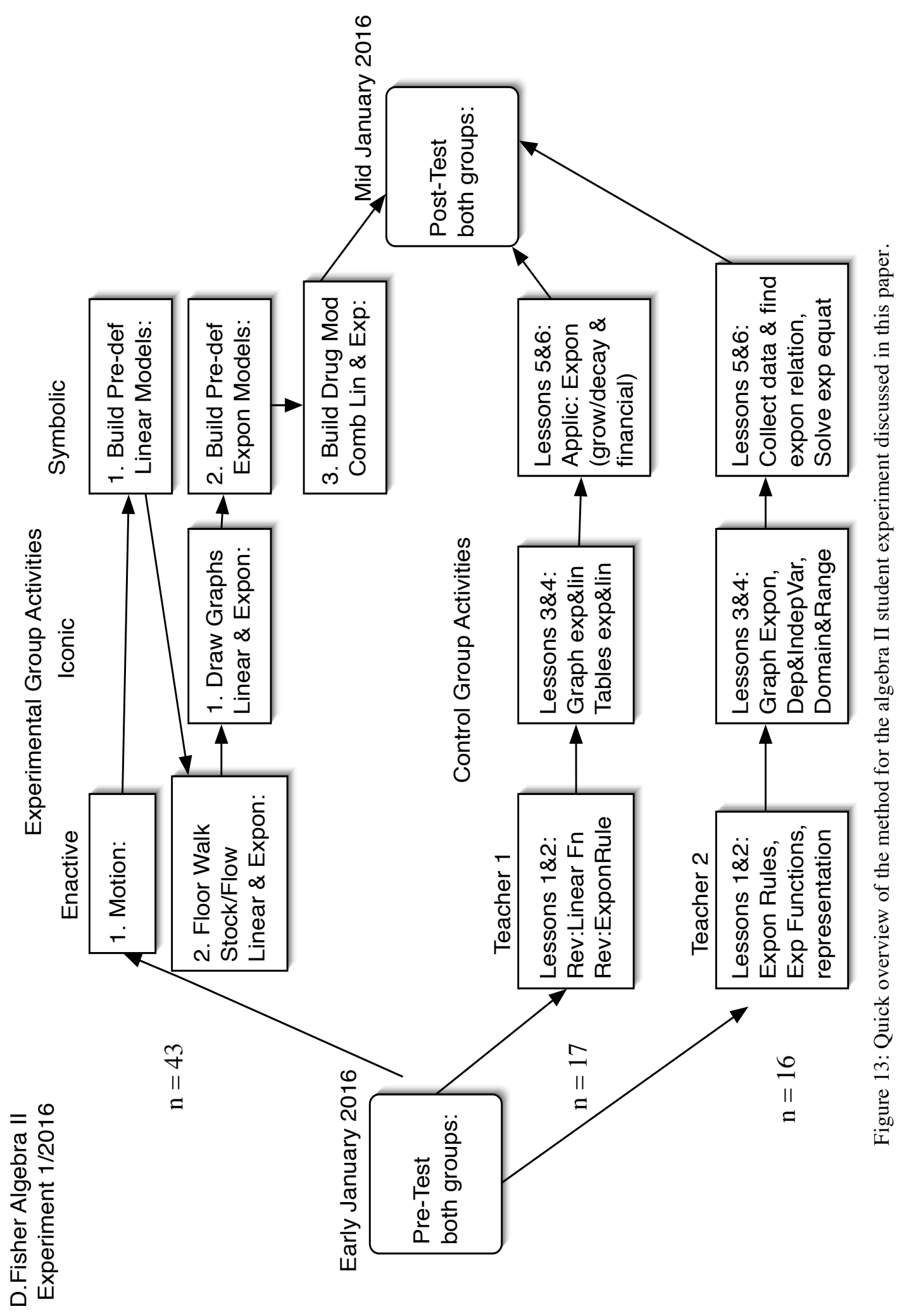


Figure 13 displays a quick overview of the method for the student experiment. There were 6 lessons for the experimental algebra II class. Two of these lessons fall into the "enactive" mode of Bruner's learning theory, two in the "iconic" mode, and two in the "symbolic" mode. (See Appendix A.) All lessons require students to work with the topic for the lesson and three of the six require the creation of original scenarios and explanations dealing with the focus topics. The enactive mode lessons are intended to determine if students have moved from "following directions" mode to the "create your own" thinking about linear and exponential functions. The iconic and symbolic lessons are intended to determine if students have moved from "create your own" thinking to being able to "transfer" the function concept to a new situation involving more than one function type.

A quick overview of the lessons to be used with students will be described below, with a more detailed explanation of the lessons in Appendix A.

1. (Motion) As a full-class activity the teacher had students move, to produce different types of linear motion, in front of a motion detector connected to a computer that projected the motion graph on the overhead screen. As a final problem, an original walking scenario was designed by each student and the students explained how one would walk to produce the graph they drew. This problem was "graded" by the researcher.

2. (Linear Models) Using the STELLA software on a classroom set of netbooks students (in teams of two) built linear models matching scenario descriptions given on a handout. A final assignment asked students to sketch the stock/flow diagram for an original linear model devising their own scenario. The original model was "graded" by the researcher.

3. (Floor stock/flow activity: Linear functions and exponential functions) The teacher created a large stock/flow structure on the floor of the classroom and had the students enter and leave the stock in different linear and exponential patterns. A table of values (number of students in the stock) was recorded for each different pattern. 
4. (Graphs) Students graphed the values that were recorded in the tables that were produced in activity 3 above.

5. (Exponential Models) After the teacher built a stock/flow bank account with simple interest model in class (to remind students about the process of building models using STELLA) students used the classroom set of netbooks to build (in teams of two) various exponential models based on problem descriptions given in their handout. A final assignment asked students to sketch the stock/flow diagram for an original exponential model devising their own scenario. The original model was "graded" by the researcher.

The following day the teacher built a stock/flow bank account model with interest added (inflow) and constant withdrawals (outflow) with the aid of students in the class, asking students how to build the model and asking them to predict behavior based on changing values in the model.

6. (Combine Functions) A random selection of two pairs ${ }^{35}$ of students were removed from the experimental classes when the rest of the experimental classes were working (in teams of two students each) on the drug model lesson. Each randomly selected pair of students built a drug model requiring a constant inflow from an IV drip and exponential outflow simulating the body metabolizing and eliminating the drug. These students were videotaped by the researcher. The rest of the class built the same model, while the two pairs of students were being videotaped. The teacher "graded" the entire drug packet for all of the experimental students.

\section{Data and Analysis}

Originally it was intended to conduct these lessons throughout the first semester of the year, but the teachers indicated that the curriculum structure of the algebra II course had changed recently and they no longer taught linear and exponential functions as separate units in algebra II. So they wanted to conduct the experiment in a brief 3week unit review just before the first semester exam. The 3-week period was to occur directly after winter break. Another situation occurred that pushed the semester exam forward by a week. So now there would be only two weeks between winter break and

\footnotetext{
35 Student names were placed in pairs on small papers and selected at random from a container. The pairing was designed to maintain student comfort in working with another student they usually choose to work with, if possible, on the task for activity 6 .
} 
semester exams. Yet another situation occurred in that the school changed from a modified block schedule ( 3 - 50 minute class periods and $1-90$ minute class period per week) to alternating block schedule, (either 3 - 93 minute classes per week or $2-93$ minute classes per week. Moreover, there was not a guarantee of 93 minutes, since days involving early dismissal, late arrival, tutor times, or assembly schedules changed class periods to either 63 or 75 minutes instead of 93 minutes.)

Due to circumstances beyond the control of the teachers and researcher 2 snow days occurred immediately after winter break. The 6 lessons and the pre- and postassessments had to be executed in 4 class periods of between 63 and 93 minutes each. Consequently, students were able to complete only the first 3 (of 4) exercises in the linear and exponential modeling lessons. For one teacher the graphing lesson had to be eliminated due to a very shortened class period. In the drug model lesson there were significant difficulties with the computers and many students were only able to complete $1 / 4$ of the lesson).

It is useful to know the math proficiency level of each of the four classes involved in this experiment. The math proficiency level of the students involved in this experiment was measured (only) by using the class mean scores of their first semester assessments in algebra II. The results were:

Table 13: Class mean scores, first semester 2015-2016, for each for the four classes in this experiment.

\begin{tabular}{|l|c|c|}
\hline & Teacher 1 & Teacher 2 \\
\hline Experimental & $83 \%$ & $69 \%$ \\
Class & $\mathrm{n}=21$ & $\mathrm{n}=22$ \\
\hline Control & $74 \%$ & $85 \%$ \\
Class & $\mathrm{n}=17$ & $\mathrm{n}=16$ \\
\hline
\end{tabular}




\section{The Pre- and Post-Assessments}

The pre- and post-assessment structures were almost identical in that they contained the same types of questions, only differing in numeric values or in slight modification of question asked (i.e., growth questions changed to decay questions, etc.) The assessments were identified as form A or form B and half of the students in each class received form A and half form B for pre-assessment. Students received the other form for their post-assessment. There were 12 questions on each assessment form. Since the same assessments were to be used for both the experimental and control group students there were some traditional questions (questions 5 and $11^{36}$ ) as well as some more conceptual questions regarding linear and exponential function behavior, although no questions required the use of mathematical equations, to answer. More detail about the assessment questions can be found in Appendix B.

Results: The following tables show the results on the pre- and post-assessments as coordinates on a grid. The first coordinate of each point represents the pre-assessment score. The second coordinate represents the post-assessment score. Students above the y $=\mathrm{x}$ diagonal line indicate an improvement in their performance from the pre- to the postassessment. Each of the four classes, two experimental and two control, has its own plot.

\footnotetext{
${ }^{36}$ Questions 4, 7, and 9 favored the experimental group. The rest of the questions 1, 2, 3, 6, 8, 10, and 12 were intended to be neutral.
} 

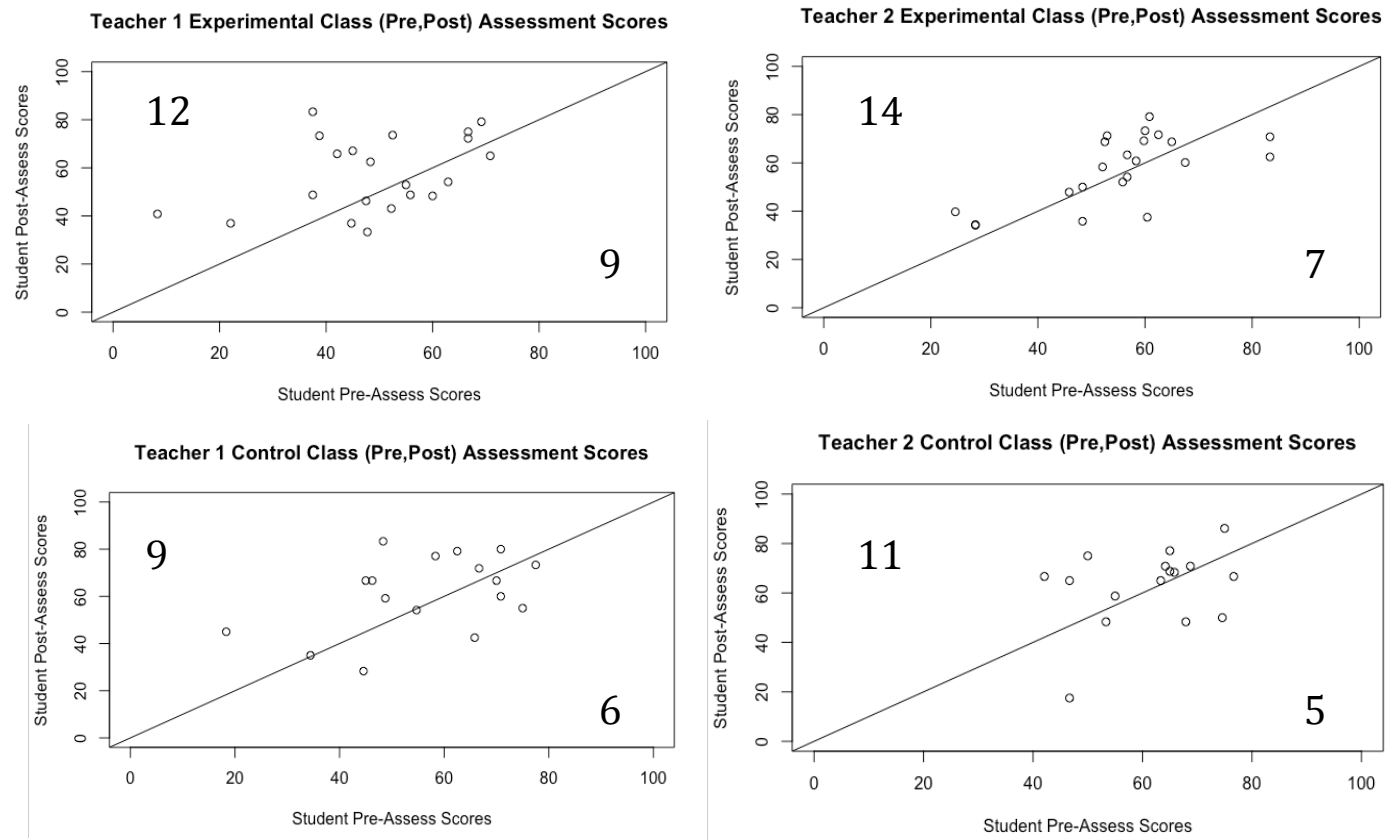

Figure 14: (Pre, Post) assessments plots for each student in each of the four classes involved in this experiment.

If we combine the two experimental groups and the two control groups and analyze individual questions, there was interesting information:

Table 14: Improvement in scores from pre- to post-assessments for the combined experimental and combined control groups, and then the improvement of the experimental over the control group on each question.

\begin{tabular}{|l|c|c|c|c|c|c|c|c|c|c|c|c|}
\hline & $\mathrm{Q} 1$ & $\mathrm{Q} 2$ & $\mathrm{Q} 3$ & $\mathrm{Q} 4$ & $\mathrm{Q} 5$ & $\mathrm{Q} 6$ & $\mathrm{Q} 7$ & $\mathrm{Q} 8$ & $\mathrm{Q} 9$ & $\mathrm{Q} 10$ & $\mathrm{Q} 11$ & $\mathrm{Q} 12$ \\
\hline $\begin{array}{l}\text { Post-Pre } \\
\begin{array}{l}\text { Experimental } \\
\text { Group n }=43\end{array}\end{array}$ & 2.3 & -1 & -1.7 & 2.3 & -8.1 & 18.6 & -8.1 & 15.4 & 14.9 & 3.8 & 4.1 & 21.4 \\
\hline $\begin{array}{l}\text { Post-Pre } \\
\text { Control } \\
\text { Group n=31 }\end{array}$ & 6.1 & 5 & 5.5 & -1.5 & 6.1 & -3.0 & 0 & 7.5 & 1.5 & 8.5 & -1.8 & 6.1 \\
\hline $\begin{array}{l}\text { Experimental- } \\
\text { Control }\end{array}$ & -3.8 & -6 & -7.2 & 3.8 & -14.2 & 21.6 & -8.1 & 7.9 & 13.4 & -4.7 & 5.9 & 15.3 \\
\hline
\end{tabular}


Table 14 showed promising results on a few questions, 6, 9, and 12. Yet Looking at each experimental group compared to its control group the findings tell a slightly different story.

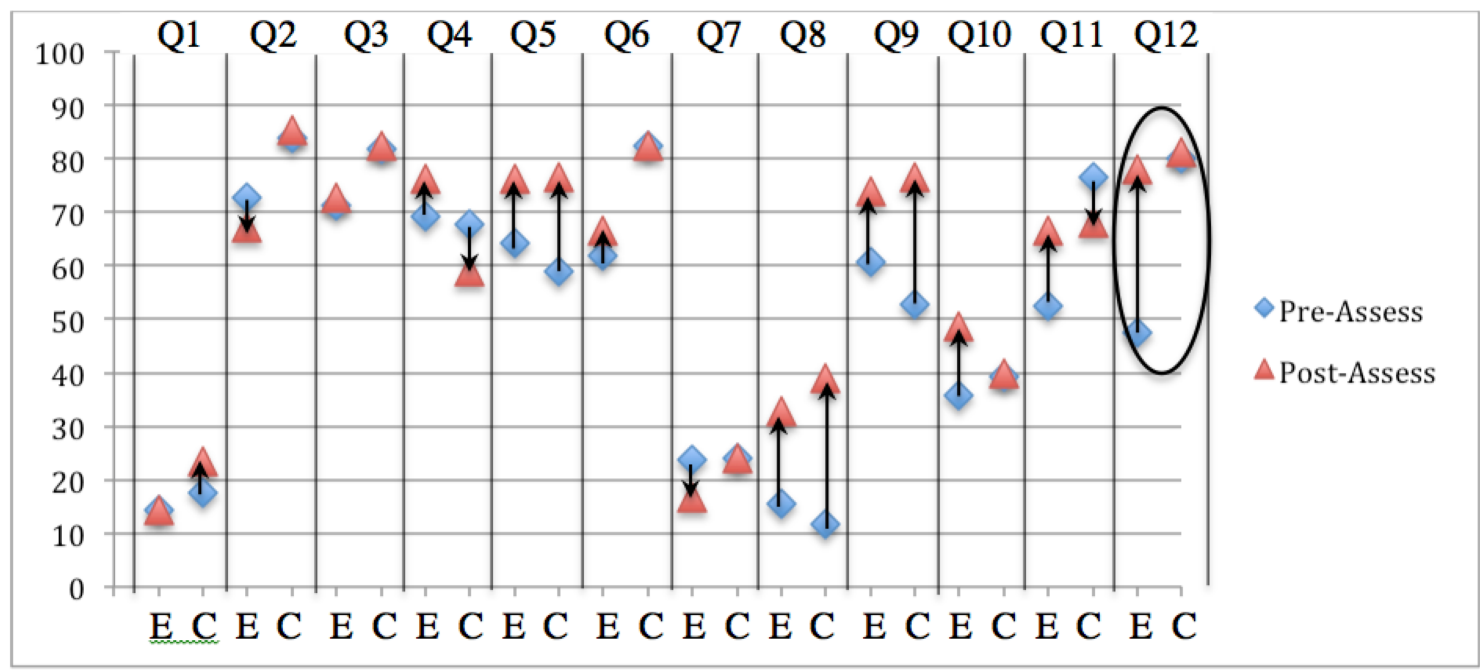

Figure 15: Teacher 1: Experimental pre \& post-assessment scores compared to control pre \& postassessment scores.

Note: question 12 has significant improvement for the experimental group but the control group performance was already high and remained high.

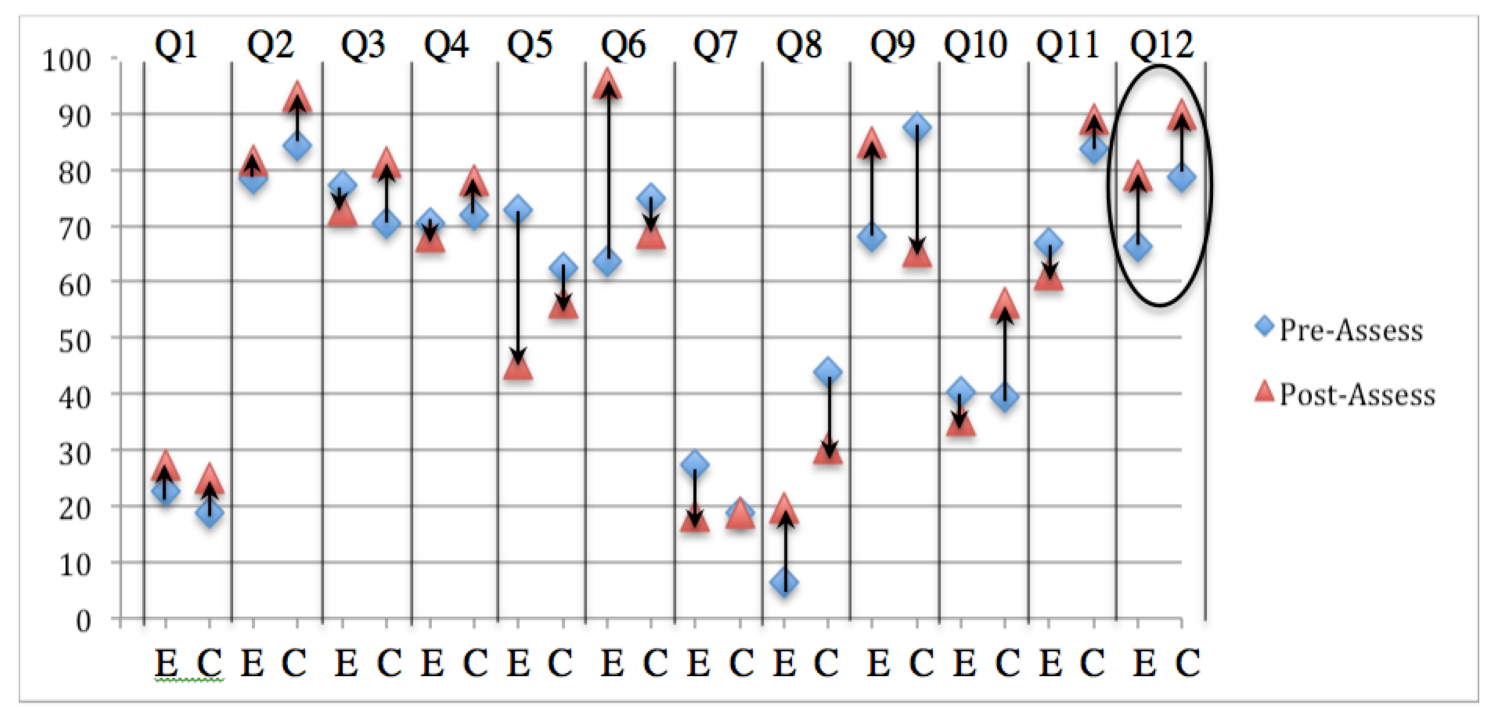

Figure 16: Teacher 2: Experimental pre \& post-assessment scores compared to control pre \& postassessment scores.

Note: question 12 shows experimental and control groups improving by about the same amount. 
It is apparent from both graphs (Figures 15 and 16) that it is not possible to draw conclusions about any overall success of the experimental groups over the control groups on any particular question.

On the given assessment questions 2, 4, 6, 8, 9,10, and 12 fell into the category directly relating to an understanding of linear vs exponential change over time.

- The scores on question 2, draw the graph of the water level in a container when someone is filling (emptying) a container at a steady constant pace for 5 seconds, then stopping for 5 seconds, were pretty high. There is no reason the experimental group should have done more poorly than the control group. In point of fact, the experimental group for teacher 2 (with a lower semester 1 algebra II average) performed better on this question than the other experimental group (with the higher class average). Most of the errors involved students drawing a diagonal line up instead of down (or vice versa) and/or continuing the diagonal line for the second 5 seconds instead of drawing a horizontal segment. All students did, however draw linear segments and not exponential ones. So, for the purposes of the research question, the students did choose the correct function (linear) representation for their curves.

- Question 4 gave students a description of a person walking and asked them to select the correct distance versus time graph (given 4 choices). Most of the errors involved not paying close attention to the time duration associated with a specific walking strategy. So this question did not really differentiate between linear and exponential behavior, since all the choices were linear. It would have been better to include an exponential curve as part of one graph choice.

- Question 6 involved describing the value of the slope of an exponential graph over time. This was a good question for differentiating between linear and exponential functions, but, there was not significant improvement by the experimental group compared to both control groups on this question.

- Question 9 involved using a labeled linear STELLA model diagram and asking students if the stock value would increase or decrease, and then asked them to select one of 3 graphical patterns to represent the increase or decrease. This was a good question differentiating linear and exponential change for the experimental group, but was not really a fair question for the control group. The experimental groups improved, as was expected, but one of the control groups improved even more. 
- Since students had insufficient time to complete all of the problems for the linear and exponential model lessons. Some important relationships (assessed, for example, in questions 8 - does doubling the growth rate double the growth amount in 5 years - or question 10 - will a linear payment plan or an exponential payment plan pay off a loan faster) were not experienced.

- Question 12 held great promise. It asked students to identify each of 5 short scenarios as representing linear or exponential change over time. Both experimental groups improved, one significantly (over 30\%), but one control group had high scores already (and remained high) and the other control group improved almost as much as the experimental group for that same teacher.

- Questions 3 and 7 tried to assess how a quantity would change based on relative size of inflow versus outflow and so were not directly useful for the research question. With the problems that occurred on the drug lesson (the only lesson that contained both an inflow and an outflow that all students were required to complete) there was insufficient time to practice, and so to develop an intuition for that concept.

\section{Data from The Lessons}

Motion Detector: The graded question involved giving each student a graph containing two points, asking the students to connect the two points using between 2 and 4 linear segments, and then to explain the walking motion a person would have to complete to produce the graph drawn. 3 points were awarded for drawing a correct graph and 4 points were awarded for describing the walking motion correctly. The results of this assessment are shown below.

Table 15: Mean scores for each experimental class on the motion detector problem.

\begin{tabular}{|l|c|}
\hline \multicolumn{2}{|c|}{ Experimental Groups } \\
\hline $\begin{array}{l}\text { Teacher } 1 \\
\mathrm{n}=20\end{array}$ & $89 \%$ \\
\hline $\begin{array}{l}\text { Teacher } 2 \\
\mathrm{n}=22\end{array}$ & $79 \%$ \\
\hline
\end{tabular}

Constructing an original linear STELLA model: The graded question required that students select a scenario that increased or decreased in a linear fashion over time. They were to 
sketch the appropriate STELLA diagram and label it (3 points), indicate the values and units for the stock and the flow ( 3 points), indicate whether the stock value would increase or decrease over time and how they could tell from the diagram (2 points), and how they knew the stock would change linearly (2 points). Note: students did not actually build this model on the computer.

Table 16: Mean scores for each experiental class on the linear modeling problem.

\begin{tabular}{|l|c|}
\hline \multicolumn{2}{|c|}{ Experimental Groups } \\
\hline $\begin{array}{l}\text { Teacher } 1 \\
\mathrm{n}=20\end{array}$ & $75 \%$ \\
\hline $\begin{array}{l}\text { Teacher } 2 \\
\mathrm{n}=22\end{array}$ & $76 \%$ \\
\hline
\end{tabular}

Constructing an original exponential STELLA model: The graded question required that students select a scenario that increased or decreased in an exponential fashion over time. They were to sketch the appropriate STELLA diagram and label it (3 points), indicate the values/formula and units for the stock and the flow (3 points), value for the converter (1 point), indicate whether the stock value would increase or decrease over time and how they could tell from the diagram ( 2 points), and how they knew the stock would change exponentially (2 points). Note: students did not actually build this model on the computer.

Table 17: Mean scores for each experimental class on the exponential modeling problem.

\begin{tabular}{|l|c|}
\hline \multicolumn{2}{|c|}{ Experimental Groups } \\
\hline $\begin{array}{l}\text { Teacher } 1 \\
\mathrm{n}=20\end{array}$ & $80 \%$ \\
\hline $\begin{array}{l}\text { Teacher } 2 \\
\mathrm{n}=22\end{array}$ & $75 \%$ \\
\hline
\end{tabular}


Students worked on the first 2 models for the linear and exponential lessons in pairs. That work would be considered at the "following directions" stage of the learning framework. The $3^{\text {rd }}$ problem in each lesson, however, was to design an original growth or decay model of their choosing, label the model, indicate how the model should be defined (i.e., the values or formulas needed) and explain why the model would show growth/decay and why the stock should increase/decrease in a linear/exponential fashion. Success on these exercises would demonstrate that those students had progressed to the "create your own" stage of the learning framework, since they are transferring their understanding of linear and/or exponential structure to a new situation, defining the model correctly, and correctly indicating why the model should produce the desired pattern of growth/decay over time.

Building the drug model: Due to technical problems only the first 2 questions on the student packets were graded. The first question required that students read the description of the scenario and sketch the STELLA diagram that would capture the details of the scenario. (The scenario required a constant inflow and an exponential outflow for the stock.) The diagram was graded (4 points) as indicated in the table below ( 1 point for a diagram that contained an inflow and an outflow, 1 point if the inflow was constant and the outflow was exponential, 1 point if the diagram was labeled correctly, and 1 point if the correct values were indicated for each icon). Students were then to predict what they thought the graph of the stock value would be over time. Then students were to build the model on the computer and copy the simulation results on the same grid as the prediction graph. The 2 graphs were given a total of 1 point. 
Table 18: Mean scores for each experimental call on the sub-parts of the first and second problem of the drug model lesson.

\begin{tabular}{|l|c|c|c|c|c|}
\hline \multicolumn{7}{|c|}{ Experimental Groups } \\
\hline & $\begin{array}{l}\text { Stock, } \\
\text { In/outf }\end{array}$ & $\begin{array}{l}\text { Con in, } \\
\text { ExpOu }\end{array}$ & labels & values & $\begin{array}{c}\text { Pred } \\
\text { Run }\end{array}$ \\
\hline $\begin{array}{l}\text { Teacher 1 } \\
\mathrm{n}=21\end{array}$ & $97 \%$ & $80 \%$ & $34 \%$ & $39 \%$ & $57 \%$ \\
\hline $\begin{array}{l}\text { Teacher 2 } \\
\mathrm{n}=17\end{array}$ & $68 \%$ & $62 \%$ & $26 \%$ & $32 \%$ & $44 \%$ \\
\hline
\end{tabular}

Theoretically, those students who correctly designed the drug model and simulated it would have moved to the "transfer" stage of the learning framework because they demonstrated that they understood linear and exponential behavior sufficiently to create a diagram that contains a constant flow (and linear behavior in the stock, if there were no outflow) and an exponential flow. Moreover, they understood that the outflow had to be exponential and the inflow constant. This would satisfy the "transfer" stage since students are applying their understanding of linear and exponential behavior to a completely new scenario involving both functions, something they had not dealt with in the past.

Results of Videotape of two pairs of students from each experimental class

Additionally, for the drug model, two pairs of students (one from each experimental class) were videotaped, separately, using a think-aloud task-structured protocol to determine how they thought about the model as they were creating it. The videotapes were transcribed and analyzed using Lesh and Lehrer's (2000) videotaping analysis framework to determine if students understood the difference between linear and exponential functions and could interpret a more sophisticated problem involving both types of functions. 
The pair was working on the drug lesson (and being videotaped by the researcher)

at the same time their algebra II class was working on the same lesson with their algebra

II teacher. Each student had a "Drug Model Lesson" packet to read and work from for

this exercise. Students were to build and exercise the drug model while using think-

aloud-protocol.

1. Overall Purpose 1: To capture the thinking of the students as they decided how to construct the stock/flow diagram to capture the behavior of the following problem:

"You are continuing your work as a medical resident at a local hospital. You are again working in the emergency room when a patient arrives and needs medical attention. For this patient you decide you must insert an IV drip into the person's arm in order to administer a therapeutic drug. You set the IV drip so it will allow a constant inflow of $1 \mathrm{~g} / \mathrm{min}$ of the drug into the person's blood system. The patient, you estimate, will eliminate $0.55 \%$ of the drug in his system each minute. (Be careful, $0.55 \%$ is less than $1 \%$ )."

a. A subordinate purpose was to determine if the students could construct a stock/flow diagram that had the students select a stock and identify it as the amount of drug in the body, and construct a constant inflow toward the stock and an exponential outflow from the stock. Note that the generic exponential growth and exponential decay stock/flow diagrams were shown in a boxed display at the top of the paper, for student reference.

- Team 1 produced a correct stock/flow structure on their initial attempt.

- Team 2 started out with an incorrect inflow structure (exponential instead of constant), but realized since the inflow was a constant they need to remove the exponential inflow structure and replace it with a constant flow structure. (They redrew the inflow correctly.) They also defined the model components correctly.

2. Overall Purpose 2: To determine if students can explain what is happening with the dynamics of the problem that causes the shape of the stock graph to be produced when the model is simulated? That is, can the students interpret the model output, relating it to the real world problem?

a. It is typical in System Dynamics modeling lessons to request that students anticipate model behavior before simulation runs are executed. Most students, 
initially, have a great deal of trouble doing this, as it is not something that is typically asked of them in their math classes. This situation was no different.

- The first pair of students drew an exponential growth curve. The curve was incorrect.

- The second pair created a linear graph where they moved by blocks, in time, and increased the next point vertically by 1 block but then subtracted .5 of a block from that, creating a line that had essentially a slope of .5 of a block. This curve was incorrect on many levels. (Note: The default STELLA graph pad is divided into 16 grid blocks. See Figure 5, for example.)

b. Students were then asked to explain the result the simulation produced (whose appearance showed an exponential convergence upward from 0 to about $173 \mathrm{~g}$, reaching steady state about $1 / 3$ the way through the simulation).

- The first pair of students reached a reasonable conclusion. In the packet the students wrote: "The medicine being eliminated slowly approaches the value of the medicine entering but never will reach the same value or decrease. " Unfortunately, they did not explain why the medicine level should not decrease. But it is a valuable insight that they did consider this option.

- The second pair, after exclaiming how different the simulation graph was from their prediction, came to a reasonable explanation for the shape of the simulation graph. The students observed the graph, then set up a table with the drug in the system, the inflow value and the outflow value. In the packet the students wrote: "The inflow is constant but the outflow is exponential so as more drugs enter the system the outflow at a rate of $.55 \%$ the outflow will grow to be the same as the inflow."

3. Overall Purpose 3: The final objective was to determine if the students were becoming comfortable enough understanding the model dynamics that they could correctly predict what would happen to the graphical model output if a modification of the model was made. The following description was given to the students:

"A complication occurs with this patient about 8 hours after the IV is administered. One of his kidneys quits functioning, causing the elimination rate to reduce to half. Predict what you think will happen to the drug level in the patient's body, recording your prediction on the grid below." 
Both pairs correctly predicted the new behavior and were able to identify where the model needed to be modified, and how the definition of the selected component needed to be modified.

- Team 1: [The students ran out of time. They did not have time to see the simulation run, so they could check their prediction. Both students drew prediction graphs in their lesson packet that indicated an initial jump upward at 8 hours followed by a leveling off of the drug at a higher equilibrium. This is the correct behavior the model would have produced.]

- Team 2: These students drew both the prediction (using a dotted curve) and the actual simulation run (using a solid curve). The dotted curve increased in a more gradual fashion, indicating a smoother upward transition at 8 hours, than the simulation graph that made a more pronounced upward jump at 8 hours.

The transcripts ${ }^{37}$ indicate that the students were able to mathematize the problem without much difficulty, even after a faulty start with the second pair. They were able to use the software to explain the dynamic behavior represented in the simulation graph of the initial model. That was a key point. Once they had an understanding of the cause of the dynamic behavior pattern of the original model they were able to modify the model and were reasonably successful predicting the new behavior of the modified model. All of this work was on a model whose behavior was not typical of functions they had seen in class at that point.

The student problem solving scenario captured in these two videotapes supports the claim that students are able to mathematize new scenarios that are combinations of behaviors they already know and are able to analyze and modify and reanalyze the problem with relative ease. The videotaping lasted about 33 minutes for each pair of students.

\footnotetext{
${ }^{37}$ Conversation clips from the transcripts can be found in Appendix C.
} 
This analysis was done comparing three problems across both student pairs (horizontal analysis) and also analyzing the improvement in thinking over the full time frame (vertical analysis) for each pair of students.

Algebra Questionnaire

Table 19: LIkert scale results, student opinions about the lessons.

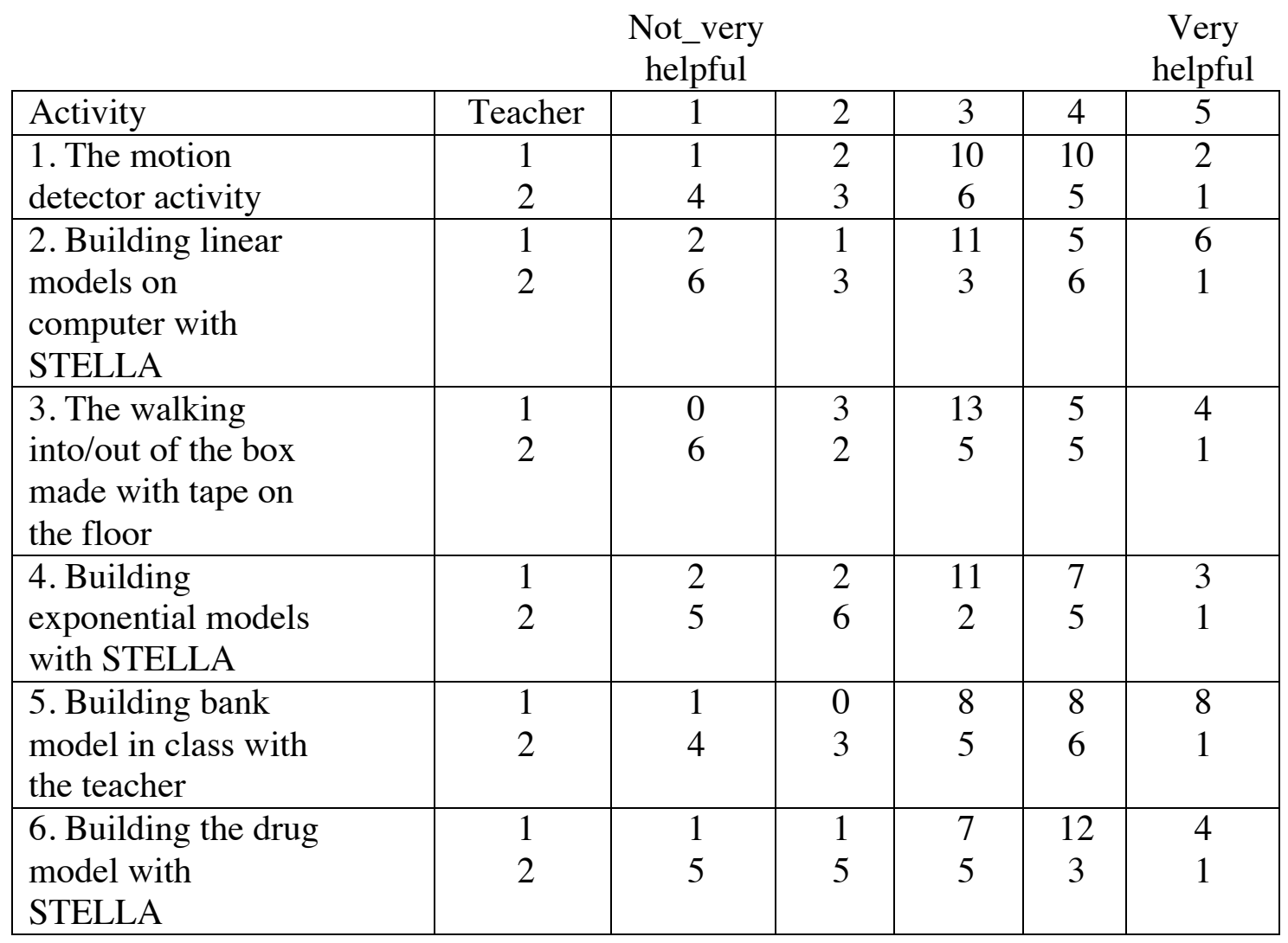

A Likert scale was used to give students in the experimental groups an opportunity to express how useful they felt the lessons were in helping them understand the concept of linear and exponential functions. The lowest indicator was labeled "Not very helpful" and the highest indicator was labeled "Very helpful." There were five points on the scale. Students were to choose one of the five points to assess each lesson 
(motion detector, building linear STELLA models, tape-walking floor activity, building exponential STELLA models, building a STELLA bank model with the teacher, building a STELLA drug model).

Students were then asked to make comments about the lessons in general.

Table 20: Student comments about their impression of the usefulness of the experimental lessons.

\begin{tabular}{|l|c|c|c|c|}
\hline Statement & Teacher & Negative & Neutral & Positive \\
\hline Comments about items 1-6 & 1 & 3 & 2 & 9 \\
& 2 & 5 & 0 & 3 \\
\hline 7. From these six lessons, did you feel & 1 & 5 & 6 & 14 \\
$\begin{array}{l}\text { you learned important/useful information } \\
\text { about linear and exponential functions? }\end{array}$ & 2 & 12 & 2 & 5 \\
\hline $\begin{array}{l}\text { 8. Do you think the STELLA models } \\
\text { helped you understand why the graphs of } \\
\text { the situation you built models for had a }\end{array}$ & 2 & 3 & 1 & 19 \\
linear or exponential shape? & & 7 & 3 & 8 \\
\hline 9. Do you think this activity (all 6 & 1 & 8 & 3 & 14 \\
lessons) were worth doing? & 2 & 12 & 1 & 6 \\
\hline Additional Comments & 2 & 0 & 0 & 4 \\
& & 3 & 0 & 0 \\
\hline
\end{tabular}

Of the comments made regarding question 1-6: $55 \%$ were positive comments (enjoyed, liked, fun, helpful), 9\% were neutral (wanted more interaction with the teacher, depends on the person), and $36 \%$ were negative (took more time than it was worth, didn't understand, confusing).

Of the comments made regarding question 7: $43 \%$ were positive (yes: reasons varied from gained better understanding because I am a visual learner, liked the problems, it was hands-on). $18 \%$ were neutral (I already knew linear and exponential, 
learned a little). 39\% were negative (no: I already knew this, confusing, not taught well, easier to just use numbers).

Of the comments made regarding question 8: $66 \%$ responded in the affirmative (it was visual so easier to understand, the models were interactive, I could see what was going on, I already understood the concept but now I know it from a different perspective), $10 \%$ were neutral (I already understood the concept), and 24\% were negative (it was confusing, I still don't understand them, it was unclear).

Of the comments made regarding question 9: $45 \%$ said yes (fun, it definitely improved my understanding, they all tied together, because I learned something that actually might be useful in my life), $16 \%$ were neutral (timing was bad - right before finals, useful now but probably not in the future), and $45 \%$ were negative (no impact on my learning, hard to understand, felt like we were rushing, not practical, confusing).

\section{Validity}

This procedure (the six lessons) is assumed to have content and face validity because the lessons deal specifically with linear and exponential function concepts and have been used successfully with algebra II students in the past. The procedure is also assumed to have construct validity, hoping to support a more conceptual understanding of linear and exponential functions. The definition used to support evidence of conceptual understanding is 1) whether students can extend the models built in class to include a combination of those functions (linear and exponential), 2) whether students can comfortably transfer the linear and exponential scenarios they studied in the modelbuilding activities 2 and 5 to a drug model scenario, and 3) whether students can correctly 
modify the initial drug model they create at the beginning of activity 6 to solve additional problems presented later in the drug lesson. Note: The pre- and post-assessment is assumed to have reliability due to the use of the cross-balancing ${ }^{38}$ process for distributing the two forms of the assessment.

\section{Discussion and Lessons Learned}

\section{The Assessment}

- The extreme compression of time for the six lessons (one of which - the graphing lesson - was not able to be executed in the experimental group for teacher 2) impacted the overall results of the post assessment, as students did not have time to complete any lesson and there was no time to provide feedback to the students on their work before moving on to another lesson. Also, students who missed a class did not have an opportunity to make up the lesson due to the very short time frame for the experiment. Consequently, the full post-assessment scores, do not represent a reasonable assessment of overall progress toward shedding light on the research question.

- For any possible meaningful results from the total scores the experiment would have to be conducted over a longer period of time.

- It was a mistake to do this experiment as a short unit (even if we had been able to dedicate a full three weeks to the unit) rather than infusing it into the regular curriculum. It seemed as if most students did not place much value on the new approach because they knew they would not see it again after the experiment concluded. Also, a short unit experiment, while easier to design and implement, gives short shrift to the fact that SD analysis is a way of thinking about problems. It needs incubation time to be fully realized.

- To perform statistical test item confidence analysis it is important to ask questions that have at least 5 different possible scores. This was not considered in advance of the execution of the experiment.

- It is important to view the data using multiple perspectives. Combining the experimental classes and control classes in order to achieve a larger " $n$ " value to

\footnotetext{
${ }^{38}$ Half the students received form A and half form B for the pre-assessment. Then the form was reversed to use for the post-assessment for each student.
} 
assist statistical analysis actually hid important relationships that ultimately negated the assumptions that the collective data seemed to present.

\section{The Lessons}

- STELLA linear and exponential model building seems to narrow the gap in performance between students who traditionally perform well compared to students who traditionally perform more poorly in algebra II. Evidence for this statement was based upon comparing the class averages on the linear and exponential graded assignments for the two experimental groups whose performance on their first semester algebra II course was different by 14 percentage points.

- The results of the drug model lesson completed by the two randomly selected student teams who were videotaped were quite positive. Even the students who created an incorrect model initially were able to correct their mistake themselves as they built the model. Those results provide promise that, had the two classroom attempts to complete the drug model lesson not succumb to so many technical problems, ${ }^{39}$ there might have been an opportunity to determine whether more students were able to transfer what they learned in the linear and exponential modeling lessons to a new, more complicated scenario.

\section{The Questionnaire}

- Students who generally had more success with math evaluated this very quick experiment in a more positive light than the students who were generally less successful. This does not mean the lessons could not have altered the negative view had the students been given more time to work with the software. The experiment was rushed and did not provide time for students to complete lessons, nor was there time to provide feedback about their work to the students, both situations that are felt more strongly by students who are already uncomfortable with regard to course content.

- Although the teachers chose the placement of the experiment in the school calendar, some of the students indicated that they were not pleased that the experiment was conducted just before semester final exams. They wanted to work on lessons that specifically prepared them for the final. The students knew their course grades would not be impacted by their performance on any of the experiment assessments.

\section{Other}

\footnotetext{
${ }^{39}$ The netbooks were old. Quite a few of the computers did not function properly. By the end of the experiment, the STELLA software, whose image had to be "pushed" onto the computers from the central district office, was missing from a significant number of the computers that were still operational.
} 
- There are other issues that should be researched. Another article by this author documenting this experiment from the perspective of the teacher is currently in the review process with a mathematics education journal. It includes an analysis of teacher beliefs, teacher reflections during the experiment and also clarifies why the two teachers, both of whom have found SD modeling useful for their students, no longer use it in their curriculum.

D. Conclusion

It is becoming abundantly clear that adults need to gain facility dealing with complex systems scenarios as informed citizens or even when making decisions about social interactions. It is becoming clear that some educational leaders also feel that educating people about complex systems should start in mainstream education, with students in K-12. Progress has been made in K-12, but research supporting the improvement in learning outcomes for students at this level is sorely lacking. The experiment described in this paper encountered some of the problems mentioned by researchers who have conducted classroom experiments with SD in the past. The difficulty with the technology and the extremely compressed time frame for executing the experimental lessons led to results showing no statistical difference between the experimental and control groups on the pre- and post-assessments. However, there were promising results from data gathered on the lessons themselves, indicating SD modeling may provide a useful method of closing the gap somewhat between students who are adept at math and those who are less adept, when analyzing dynamic problems. The results of the videotaped think-aloud protocol used with a pair of students, randomly selected from each of the experimental classes, as they built a drug model indicate that students are able to successfully build and analyze a model that is slightly 
more difficult than the typical problems studied in algebra II. The experiment should be repeated over a more extended time frame where the experimental lessons are infused into the mainstream curriculum. The experiment was intended to suggest a path from the current topics covered in algebra toward those topics that are more illustrative of complex systems. In this vein, the current experiment can add value to the current literature.

The student work produced in classrooms where teachers are already using Systems Thinking and System Dynamics modeling is impressive. This work will be largely ignored until documentation can be provided showing an improvement in learning outcomes. This improvement will probably not be captured by current standardized tests. Further work needs to devise appropriate assessment instruments to capture the more holistic thinking, attention to feedback analysis, structure/behavior connections, and increased depth of understanding evidenced in student explanations when they are using systems tools. We should have a discussion about what behaviors we hope to see in students studying systems that sets them apart from students in other more traditional classes. We should have a discussion about how to structure experiments to guide our studies to give them the best chance to produce results that we can document. I invite those researchers who are interested in pursuing this path to build from the mistakes of this experiment and then tell us how much further they were able to progress, than I have. We can do this. It is, after all, a complex systems problem. 


\section{Synthesis}

\section{A. Overall Aims}

For over 20 years I have used System Dynamics modeling in my teaching, first as a new representation (stock/flow diagrams) for mathematizing simple dynamic problems that exemplified the behavior of the elementary functions found in the algebra II curriculum, second as a vehicle to expand the type of (multi-function) dynamic problems students in algebra II could analyze, and finally to have students build original System Dynamics models of complex systems problems that they subsequently explained in technical papers and presented to audiences. Each of these avenues raised my appreciation for what students were capable of understanding using this "new" representation and analytical approach. In my $30+$ years of teaching mathematics at the high school level I had never encountered an approach whose benefits to student learning were as dramatic as using SD modeling.

SD modeling has been around for 60 years, almost exclusively at the graduate university level. I wondered why I had not been exposed to this approach nor seen any application of this method at the high school level. I wanted to find research about the efficacy of SD modeling in mathematics. The research was scant. Mandinach and her colleagues had done research in high schools and, although they were impressed by what they saw, were discouraged by the systemic barriers the pre-college environment presented with regard to implementing this innovation. Yet, I felt I was not unique in my ability to apply SD modeling concepts in my high school courses. I had not been trained 
in SD analysis but still managed to find useful applications in the algebra II curriculum and found consistently positive reception by my students to this approach.

The STELLA software was developed in 1985, still early enough that there should have been plenty of opportunity for experimentation before I started my research work. But it did not happen, and I wondered why. Why was this approach invisible to the pre-college educational environment? It turned out that there were pockets of precollege work going on. Systems thinking work was happening as early as 1989 at Orange Grove Middle School in Tucson, Arizona. It started when a retired MIT professor, Dr. Gordon Brown, who had mentored Jay Forrester at MIT, walked into the middle school and had a conversation with the principal. Lola Piper, a computer science teacher, was using STELLA in her computer science classes at Blair Magnet Program in Silver Spring, Maryland around that same time and was trying to get some of the other teachers at her school interested. Reports indicated that students were enthusiastic. Mandinach and colleagues were conducting experiments on infusing systems thinking and dynamic modeling in a high school in Brattleboro, Vermont, four high schools and two middle schools in the San Francisco Bay area and a high school in Tucson, Arizona $1986-1993$ (STACI and STACI ${ }^{\mathrm{N}}$ Projects). It is hard to know what happened to the efforts to bring systems thinking to the schools involved in the $\mathrm{STACI}^{\mathrm{N}}$ research, as none of the teachers involved have attended the K-12 Systems Thinking/Dynamic Modeling biannual conference for the past 20 years. Save Mandinach's work, there seemed to be very little empirical research since that time. 
One of my aims for this dissertation was to review literature in mathematical education and system dynamics education relevant to using modeling to teach mathematics at the pre-college level. Secondly, I wanted to write three research papers about the use of SD modeling in algebra classes to submit to math education journals. It is no trivial task to write research papers that have the potential to be published. I needed guidance in this area. Thirdly, I wanted to design and execute a formal classroom experiment, learning all the requirements and procedures that this entailed.

This dissertation documents my efforts and how they will influence my future research.

\section{B. Findings/Contributions to Knowledge}

From the literature review I found that, although there was scant empirical evidence with regard to the use of SD modeling in secondary school classrooms, there was significant empirical evidence with regard to modeling activities and modeling using technology in math education research. Many of these findings, though not using SD modeling directly, were applicable to the use of SD in secondary school mathematics. The greatest find was the work of the late James Kaput, who had been writing for decades about his efforts to use technology to (at first) make calculus meaningful to everyone, then to make core concepts in algebra meaningful to everyone using a collection of interconnected representations that start with an analysis of motion. He coined the term "democratization of mathematics," as the underlying impetus of his efforts to improve mathematics instruction. In 2000 he worked on a national initiative with like-minded mathematics and science educators to support the inclusion of complex 
systems analysis in mainstream K-16 education. My work and vision presented in this paper, for the use of SD modeling in algebra are very closely related to Kaput's vision.

A second valuable finding that occurred from the literature review was the documentation of the many positive learning outcomes that occur from having students create models. The initial expectation was to show that students, through modeling (and SD modeling), gained a deeper, more conceptual understanding of the problem with which they were working. This is a significant claim, borne out by the work of Heid et al (2008b), Hung (2008), Jackson et al (1994), Mandinach et al (1988, 1993, 1994), and Stratford et al (1998). The other positive outcomes were so numerous that a section of this dissertation, More Background Research, was created to record the positive learning outcomes.

A third valuable finding from the literature review was the indication that understanding functions and covariational reasoning were essential skills for success in calculus and for students' future work in the sciences. This fact indicates that starting SD modeling efforts focused on elementary functions, in the path toward inclusion of complex systems analysis in algebra as proposed in this paper, is on the right track. Gaining a deeper, more conceptual understanding of elementary functions, then understanding how multiple functions interact when studying slightly more complex problems is a useful trajectory to enhance mathematical thinking starting in algebra classes.

When deciding about the topics the three research papers should address, it became clear that it would be necessary to "educate" the mathematics education research 
community and the secondary mathematics teacher community about SD modeling, both to introduce/reacquaint them with the approach and to set a stage for a possible increase in research articles on this topic. Essentially, it was necessary to raise the visibility of the SD modeling approach in the mathematics education research and practitioner communities To do that the articles had to provide not only a connection of SD modeling to traditional algebra, but provide a clear path that could be traversed by educators who were interested in order to help them gain experience and begin experimentation in the classroom. The first two papers in this dissertation strive to do that.

The classroom experiment, presented in papers 3 and 4, was key in providing a foundation for future classroom experiments, indicating both pitfalls to avoid and experiences to replicate. The main finding was to note that a short one to two-week unit introducing SD modeling lessons into an algebra II class will not provide enough experiences for students to demonstrate statistically significant improved learning outcomes compared to students given traditional instruction over the same concepts. Students need time to develop skill with the software. They need feedback on their initial model-building efforts. They need to progress enough with the SD modeling approach to start working with problems that move them beyond the typical problems found in the algebra II curriculum. This cannot happen in one to two weeks.

Two technology-savvy teachers recruited for the study who had used the STELLA software to introduce SD modeling in algebra II in the past, had discontinued its use due to the following departmental and environmental barriers:

- the only set of computer netbooks available for math department instruction were old, slow, and only partially functional; 
- the software used on the netbooks had to be "pushed" to the computers from the district office, making the turn-around time for dealing with technology issues (especially the disappearance of software icons) unmanageable;

- the new alternating block class schedule had reduced the number of instructional hours per year and placed significant pressure on teachers to cover topics that are assessed on state standardized tests, reducing time for implementing more innovative topics and instructional techniques.

- all algebra II teachers had to collectively agree on the topics to cover in the course and when to cover them, and most teachers have not been trained to use STELLA, do not know its value and have indicated no interest in using it;

For the two participating algebra II teachers involved in the classroom experiment (described in chapters 5 and 6 of this dissertation) these barriers had not been present during their initial experimentation with SD modeling lessons (in the past).

In preparation for the experiment, original pre- and post-assessments had to be created. It is necessary to give considerable thought to the construction of pre- and postassessment instruments when conducting research aimed at accessing improvement in conceptual understanding of a topic (i.e., linear and exponential function structure and behavior, in this case). These types of assessments are not readily available, yet are essential for capturing the different type of learning that one hopes to document when students are expected to think more deeply about concepts and applications.

Other considerations came to light, after the fact, when trying to analyze the student pre- and post-assessment results. Creating pre- and post-assessment questions that have less than 5 possible different numeric scores (i.e., multiple choice questions) make statistical confidence analysis on those questions impossible. This has implications 
for how one might try to capture student thinking on a short assessment instrument, and warrants further study.

Conducting statistical analysis on data is an art as well as a science. It is important to look at pre- and post-assessment results from multiple perspectives to ascertain whether there is a reasonable indication that statistical confidence analysis is warranted. In the classroom experiment conducted for papers 3 and 4, when combining the results of the two experimental groups, combining the results of the two control groups, and then comparing the experimental group pre/post-assessment gains with the control group gains, it appeared there were 3 out of 12 questions where the experimental group significantly outperformed the control group. On further analysis, graphing the experimental and control group pre/post-assessment results for teacher 1 separately from the pre/post-assessment results for teacher 2 , those comparative performance improvements disappeared.

Hidden agendas can impact innovation in schools. Grading schools on student performance on standardized state mathematics tests has had the unintended consequence of placing a stranglehold on innovation in the classroom. There was a gifted Algebra I teacher at another high school who really felt SD modeling would help her students. Her students always performed well on the statewide math assessments. She wanted to conduct an experiment with her students in collaboration with this researcher to document her efforts introducing simulation modeling into her Algebra I class. Her principal would not allow her to introduce SD modeling in her curriculum because he did not want her to change her class instruction in any way. The scores produced in her 
classes had elevated the scores for the entire math department at her school. That was too important to the principal to be tinkered with.

\section{Implications/Significance}

\section{For Researchers}

Kaput et al. (2013) present a compelling argument regarding the approach teachers take toward traditional mathematics instruction. They indicate that at about the time the Gutenberg printing press was invented, the symbolic representation for expressing algebraic relationships was emerging. This representation was intended for an elite few intellectuals who were expected to use this method of communicating with each other. It was never intended for the general public. They continue by expressing the impressive transformation that the transportation industry has undergone since the early days of the automobile and airplane, making travel easily accessible to the general public. A similar transformation has occurred in communication since the emergence of the printing press. The general public is quite comfortable with many forms of communication. But, Kaput et al. (2013), lament, no real effort has been made to develop "an equally accessible style of reading and writing algebra for everyday use by the general public"(p. 15), although we expect all high school students to understand this language. The SD method and the STELLA software, in particular, provides an alternative, visual, symbolic representation for mathematizing dynamic problems. The two-dimensional stock/flow structures displaying variable connections, and using naming conventions that are more like everyday conversation, can move us toward a more accessible communication of algebraic concepts. After having my algebra II class build 
and test a simple population model using STELLA, a student who was failing my class said, "Why didn't we do this sooner? This I understand." In the short term, using the STELLA software as a vehicle for mathematizing dynamic scenarios for students in algebra, pre-calculus, and calculus classes would be a worthwhile endeavor.

If one agrees that the alternate symbolic representation provided by the STELLA software can enhance a traditional curriculum by reinforcing function concepts that are already part of the curriculum, then we automatically gain additional benefit from its use. We gain many of the desirable outcomes for learning experiences that were listed in the "More Background Research" section of this dissertation. The SD modeling approach has the potential to support:

- $\quad$ an increased motivation to learn (Jackson et al, 1994);

- a student-centered, active instructional approach (Mandinach et al, 1988, 1993, 1994; Spector et al, 2001; Stratford et al, 1998);

- lowering the level of abstraction when trying to model problems (Hung, 2008; Tinker,1990);

- $\quad$ an opportunity for students to

- practice inquiry (Confrey et al, 1994);

- take control of their knowledge (Confrey et al, 1994);

- have access to real-world problems (Stratford et al, 1998, Tinker, 1990), that have the potential to take them beyond what they would normally study (Tinker, 1990);

- increase conceptual understanding (Mandinach et al, 1988, 1993, 1994);

- have a vehicle to help them reflect more upon their work (Confrey et al, 1994);

- better communicate their "mental model" of how a problem is structured (Jackson et al, 1994; Stratford et al, 1998);

- express and experiment with their own ideas (Hung, 2008; Jackson et al, 1994);

- formulate and test hypotheses (Jackson et al, 1994; Mandinach et al, 1988; Stratford et al, 1998);

- enhance their intuition about how the world works (Hung, 2008; Jackson et al, 1994; Mandinach et al; 1988; Roberts et al, 1988; Stratford et al, 1998).

While the advantages listed in the previous two paragraphs regarding the use of the STELLA software to enhance the traditional curriculum and the learning environment 
are noteworthy, they don't tell the whole story. The real message is that the full power of the System Dynamics modeling approach can be a game changer for mathematics instruction. It provides:

- accessibility by a wide range of students to core ideas about complex systems (Tinker, 1990);

- $\quad$ an opportunity for students to:

- $\quad$ understand the importance of feedback and interconnections (Hung, 2008; Spector et al, 2001; Spector, 2009);

- understand a problem more deeply (Hung, 2008; Jackson et al, 1994; Stratford et al, 1998);

- understand the process of change in the world (Spector, 2009; Stratford et al, 1998);

- gain cross-discipline exposure to concepts (Hmleo-Silver et al, 2006);

- gain insight into how complex systems work (Hung, 2008; Jackson et al, 1994; Mandinach et al, 1993; Roberts et al, 1988; Spector et al, 2001; Stave, 2012; Stratford et al, 1988).

Using the SD method has the power to change the way our students think about the world. STELLA is just a vehicle, providing access to a "cognitive enhancement" (Pea, 1985) in one's ability to analyze complex, non-linear dynamic systems. In the long term, teachers have a chance to take a quantum leap in helping students gain skill in analyzing problems that the current, traditional method of instruction cannot provide. The SD approach has been used by professional problem-solvers in industry, government, academia, and non-profit organizations since the 1950 s. So we know it has powerful application. When the STELLA software made the modeling interface graphical and elegantly simple, that power became available to pre-college students. Precollege students have shown that they can build relatively sophisticated models of dynamic, complex systems, and explain their reasoning. This is documented in: a) the 20 years this author has had students in grades 9 through 12 doing just that, b) in SD 
modeling activities/courses offered in other high schools, and c) in the student

SymBowl, ${ }^{40}$ SymFest, and DynamiQuest expositions of student SD modeling work that has occurred over the past 20 years.

Most of the previous discussion has been about using STELLA to enhance an algebra curriculum. That is where most math teachers interested in this approach will start and stay. But some of the work that students in grades $9-12$ produced during a year-long course in SD modeling is available for anyone to view. Some of their models, technical papers explaining their reasoning, and some short student video clip presentations can be found on the web. ${ }^{41}$ Although their work has not been assessed on any standardized national or state exam, there has not been one parent, administrator, or other professional adult (in the 20+ years these SD modeling classes were offered) who has looked at these models and papers and not been impressed by the student work. The student work itself serves as an assessment of the method and of the student's thinking. It is the student's portfolio of what they learned to accomplish by using the SD modeling approach. As a teacher, it gives me hope that our students will be better prepared to face the future with more powerful tools than good (traditional) mathematics training alone. I want to believe I have provided my students a tool that can help them understand how to think about some of the difficult problems they will face (collectively) as adults. A high

\footnotetext{
${ }^{40}$ SymBowl, SymFest, and DynamiQuest were/are gatherings that have been held annually, the first two in Portland, Oregon and the third in Massachusetts, that are similar to science fairs, where students display and explain their SD models for judges, parents, and other interested adults. SymBowl and SymFest are no longer active.

${ }^{41}$ See pages http://www.ccmodelingsystems.com/student-projects-highlights.html, http://www.ccmodelingsystems.com/student-projects-videos.html, https://www.youtube.com/user/CCModelingSystems, and http://www.ccmodelingsystems.com/studentprojects-other.html.
} 
school student recently attended a conference on global warming. When the keynote speaker finished telling the audience about all the dire predictions, the student rose and asked "Is there no hope?" Thankfully the speaker said, "in the words of Donella Meadows [a great system dynamicist], I believe there is just enough time.” Complex systems abound. We must provide our students with the tools, and the hope, that they will in fact be able to address complex problems - or allow the desperation of thoughtful students to go unattended.

\section{Implications/Significance For Practitioners}

Some recommendations for educational decision-makers who want to introduce SD modeling in the pre-college curriculum are outlined below.

Educate the principal and/or curriculum vice-principal of the school where a teacher wants to implement the SD model-building activities. Show them how the SD modeling approach opens up new possibilities for students. Show them what students can do with SD modeling that cannot be done with traditional symbolic representations. Show them how the visual nature of the software provides an opportunity for less successful math students to access algebra concepts. What you will not have is evidence that SD modeling improves student outcomes on standardized tests (although it probably will).

Once the appropriate administrators have agreed to allow implementation of SD model-building activities in math classes it will be important to ask for a commitment from them to maintain the computers available for math instruction. A working computer lab is essential to the success of this instructional approach, not just providing computer 
access initially but maintaining the lab so it teachers can depend upon that technology over time. Chapters 5 and 6 indicated the importance of this part of the plan.

Moreover, it would be necessary to request support for training at least two (or more) algebra II teachers, initially, so they can learn the SD instructional approach together and would be more willing to incorporate SD into the general curriculum scope and sequence document that guides the algebra II instructional goals. It would be useful to ask if it is possible invite other teachers to the SD modeling training (perhaps from environmental science, biology, physics, global studies, and/or health) who might be willing to coordinate topics into their classes that are amenable to SD analysis.

Educate parents. This can be done by creating a one-page handout that highlights the main virtues of the SD approach for supporting mathematics concepts and having that handout available at parent-teacher conferences. Often schools have a "back to school" night in September where parents follow their child's school schedule and meet the teachers. In this venue teachers, formally or informally, tell the parents about the expectations of the course. This is a good time to introduce the idea that students will be doing computer assisted model-building activities to enhance conceptual understanding of mathematics via the use of a visual interface. It is important that parents are informed of new techniques used in instructing their children, especially if they are not familiar with the approach. Parent can be quite supportive if they feel a new instructional strategy will give their child an opportunity to understand mathematics in a deeper, clearer way. They can also be useful allies in helping to convince the appropriate 
administrators (and other parents) of the value of an experiment regarding the infusion of SD model-building activities in mathematics classes.

Highlight student work both at school and in the larger community if possible. It is important to show parents and administrators what students can do using SD modeling that they could not do before. SD modeling gives students tools that can be applied to community problems (traffic congestion, homelessness, recycling projects, etc.) and if students choose local problems as modeling topics it can improve community/school relations to have students display and explain their models and the policy implications.

Use alternate assessments to document understanding that highlight the systems approach. Do not expect necessarily to see a difference on state math assessments. Standardized assessment mathematics questions do not test understanding of behavior and dynamics (in math). So innovators must develop other ways to capture what the students are learning that demonstrates their improved understanding. This can include exams that ask students to 1) build stock/flow diagrams for short descriptive, dynamic problem scenarios (mathematizing a problem), or 2) explain what multiple graphs (e.g., a population graph and its births and death graphs on the same grid) are telling the viewer about the pattern of population change over time and why that change is happening (covariational reasoning), or 3) sketch the graph of a scenario studied in class in which a new problem occurs part way through the simulation and changes the dynamics (hypothesis creation/testing, estimation/prediction), or 4) sketch (on a stock/flow diagram that is provided) an enhancement of the given diagram to include a new idea (extend mathematical understanding), etc. 
Ask students to articulate what they learned, how the SD approach has helped them understand specific math concepts better, and why. It is always good to listen to how the students feel the new approach has helped (or hindered) them. Recall, however, it is not sufficient to introduce SD modeling lessons in a short, isolated one to two week unit. While it is useful to have students use the STELLA software to build very small models of dynamic problems, this experience does not allow students to see this approach in a broader perspective, as an actual tool that can enhance their ability to think about difficult, dynamic problems. Until students have an opportunity to work with problems that are beyond the scope of the typical problems included in most algebra II textbooks (i.e., simple multi-function problems like the drug model) students may not see the value in the SD approach and question if learning it is worthwhile. It is important to note that if a teacher only uses one or two STELLA lessons the frustration level indicated in the comments might outweigh the virtues, so it would be best to allow students to gain some comfort with the software to get a more balanced view of their opinions. It will also make a difference if students have been able to study problems that are more sophisticated than typical (e.g., resource depletion scenarios, predator/prey scenarios, etc.) before asking them about the value of the approach. It takes extra time to reach this point when SD modeling has been introduced in a mathematics class. Allowing that extra time is essential. Student comments can make powerful statements about the value of teaching differently.

Try to find a colleague to work with. Most teachers need to have a safety net when trying something new in their classes, especially if it involves technology. That 
safety net is another person, ideally another teacher who is using the same technology (or idea) in the same type of class, with whom a teacher can speak when problems arise. And they will arise. Teachers can discuss the theory behind the new approach that may not be clear, or how to use certain features of the software. They can also share ideas on how best to introduce a new approach, share curriculum materials created to implement the new approach, and discuss issues that arose with classroom management and/or computer access.

Moreover, it is important that the SD modeling approach be seen as an important value-added topic, supported by multiple teachers teaching the same course so the instructional approach can be included in the scope and sequence document for the course, if such a schedule controls what can be covered in the course. Having multiple teachers argue for the inclusion of SD modeling activities within a given course curriculum makes its inclusion more probable.

Emphasize the value SD modeling has for reinforcing the concept of function. The concept of "function" is foundational to mathematics, is very important for applications in the sciences, and necessary for understanding calculus (Oehrtman et al, 2008). Using SD modeling to reinforce the function concept in algebra II could be used, and has been used, as an entry point for SD modeling lessons.

Provide time for cross-disciplinary SD teaching, or at least coordination between the math teachers and science or social science or health teachers via topics covered for subgroups of students in their given year. Systems thinking has not typically been emphasized in math instruction at the pre-college level. But this is not the case for other 
disciplines. In science, the Next Generation Science Standards (NGSS) specify as a cross-cutting goal (across all the sciences) "Systems and Systems Modeling." Additional cross-cutting concepts specified in the NGSS that are directly related to SD modeling are Patterns, Cause and Effect, Structure and Function, and Stability and Change. ${ }^{42}$ Population models and the many scenarios to which they can be applied make it ideal for studying cultural challenges faced in many parts of the world (e.g., water shortages, arable land, deforestation, etc.) that are taught in global studies classes. Drug models, such as an alcohol consumption model, and how alcohol affects the human body are ideal for discussions in health classes. These models have been used in the pre-college classroom, usually in algebra classes. This is a great way for students to see the benefits of learning mathematics. Moreover, these models can be relatively small models. Insight can be gleaned from even simple models (Ghaffarzadegan, Lyneis, \& Richardson, 2011).

Unfortunately, traditional high school schedules do not easily provide opportunities for teachers from different disciplines the chance to discuss potential curricular coordination. For this option to occur the administration has to work diligently and innovatively to foster such team collaboration.

D. Strengths and Limitations

\section{Strengths}

\footnotetext{
42 A more complete alignment of SD modeling and the NGSS cross-cutting concepts can be found at: http://www.ccmodelingsystems.com/res-stds-skills-science.html
} 
In this dissertation I document the need for including a method of analyzing complex systemic problems that is accessible by pre-college students. Some researchers within the mathematics and science communities have already indicated that infusing complex systems analysis in mainstream pre-college education is important (Kaput et al, 2000b). System Dynamics modeling is a powerful method of analyzing complex, nonlinear, systems problems (Forrester, 1987; Sterman, 2000) that is accessible by precollege students (Creative Learning Exchange; Waters Foundation; Fisher, 2011b), due to the graphical human interface provided by the STELLA software. As such, it affords mathematics teachers a vehicle to initiate the infusion of complex systems analysis in algebra courses.

In paper 2 included in this dissertation, a connection between the traditional closed-form equation approach, the traditional recursive equation approach, and the STELLA modeling approach to mathematizing a simple bank account problem is given. That paper forms a simple explanation illustrating the mathematics engine (recursive solution of differential equations) driving the STELLA software, in a manner that is easy for a mathematical audience to understand. Paper 2 can help create more of a glass box view of the SD modeling approach, to mathematics practitioners.

Paper 2 also illustrates, using a typical bank account scenario, how easy it is to move problem analysis beyond access via the traditional closed-form equation representation, yet still allow even quite young students an avenue (using STELLA) for further mathematical investigation. Moreover, the problem described uses only linear and exponential functions, topics included in most introductory algebra courses. 
Although not presented in this dissertation, additional SD stock/flow structures can be designed to represent quadratic, convergent, logistic, and sinusoidal functions as well.

All three papers in this dissertation contain examples of simple SD models that have been used in algebra classes by a broad range of students to mathematize dynamic problems, allowing them access to investigation. This access is afforded by the visual nature of the software, STELLA in this case. Tinker (1990) documents that a broad range of students have access to complex systems analysis using SD modeling.

Having students explain their solutions to problems is an important component of learning with understanding (Chi et al., 1994). SD stock/flow diagrams can serve as a tool for helping students display and explain their "mental model" for how a dynamic problem is structured. SD modeling can help a person surface his/her mental model (Forrester, 2009). In paper 3, I present the 20-year action research conducted by this researcher. An illustration of students using SD modeling and stock/flow diagrams to explain their mental models is evident in the technical papers written by high school students who have had an SD modeling course and can be found at the website listed in footnote 41 .

In all three papers I explain that the STELLA stock icon represents a variable that is an accumulator and the flow icon represents a variable that is a rate of change. Moreover, the manner in which the simple SD models are presented in each paper uses a differential equations frame of reference. SD modeling provides a vehicle for introducing a dynamic perspective for many of the elementary functions that are part of the standard algebra II curriculum, enabling a conceptual introduction to calculus 
principles before students reach a traditional calculus course. This statement is supported in research done by Tinker (1990).

In papers 2 and 3, I present a multi-staged path that can be used whereby high school teachers could successfully implement the study of complex systems in their algebra II classes. The path could start with introducing stock/flow diagrams for mathematizing simple, dynamic, single-function problems, then expand by introducing applications using multi-function dynamics not typically studied in algebra II. The path mentioned in the previous sentence has been successfully implemented by this researcher and other math teachers (notably those who participated in the NSF CC-STADUS and CC-SUSTAIN projects mentioned in the 20 -year action research section of paper 3 ) in dozens of algebra II classes in the past.

Determining how to assess a new instructional approach that is quite different from a traditional approach can be difficult. However, multiple strategies for designing classroom assessments have been presented in the Implications/Significance for Practitioners sub-section, of chapter 7 of this dissertation.

In this dissertation I differentiate those studies that provide empirical results with regard to enhanced learning outcomes from modeling from those that merely provide thoughtful reflection and conjecture on the part of the researchers. The differentiated references to the articles can be found in tables 1,2, and 3, displayed in the "More Background Research" section of this dissertation.

\section{Limitations}


The classroom experiment designed and executed for this dissertation (papers 3 and 4) did not involve many students, only a total of 43 for the experimental group and 33 for the control group. Such small numbers do not support findings that could be generalized. The experiment did, however, yield valuable insight into the mechanisms that were needed to conduct an experiment on a larger scale. It is necessary to take into consideration the large number of students who do not return permission slips, and the few parents or students who did return permission slips but decided not to participate.

Originally, the design experiment was to include both algebra I and algebra II teachers, but the two algebra I teachers who had agreed to participate encountered impediments to their participation. One teacher's school did not have a site license of the STELLA software, nor could she obtain permission from her administrator to participate. The other was given a teaching assignment that included new courses during the year the experiment was to be conducted that required extra time; consequently, she felt unable to participate due to lack of time to prepare for the experiment. As a result, the experiment was conducted with only two teachers, both of whom taught algebra II. Although this narrowed the scope of the experiment, all of the lessons and design for the algebra I segment of the experiment have been constructed and can still be used in an experiment at a future time.

The two experimental student groups were of significantly different ability in mathematics (algebra II semester mean of $69 \%$ for one group and $83 \%$ for the other). This created a problem when combining the students into a larger experimental group, for analysis, and trying to draw conclusions based on the performance of the larger group. 
Additional confounding influences would possibly have been introduced by such divergent group ability. Having two student groups with quite different math ability, however, did produce results that suggest SD modeling might support students who are less adept at traditional mathematics in their effort to mathematize and analyze dynamic problems. This point is mentioned in the section on topics that warrant further study.

The classroom experiment (see paper 4) did not result in differentiating learning outcomes in the experimental algebra II classes compared to the control algebra II classes. What I learned from this experiment was the need to perform experiments that extend over longer time frames to allow students to gain a comfort level using the STELLA software, to receive feedback on their early model-building experiences, and to develop their ability to anticipate and explain the behavior of the model based on its structure. These skills do not develop in two weeks.

Both the short experiment time-frame and the technical problems hindering students' ability to build the important last model (the drug model) may have adversely affected the value students placed on the SD modeling approach. Students need to see problems that extend beyond those typically covered in an algebra II class to be able to experience the value afforded by the SD approach to help them learn mathematics. Developing the foundational skills needed to introduce such problems takes longer that the 1.5 weeks that were allotted to the experiment conducted for the study presented in chapters 5 and 6 of this dissertation. Furthermore, the fact that many of the netbooks lost the STELLA icon by the last lesson meant many students were unable to construct the drug model (the extended problem for this experiment), a lesson that had been popular 
with students in previous years. The abbreviated model-building process and computer problems did not allow sufficient time to execute the extended problem.

A longitudinal study was not incorporated into the design of the experiment for this dissertation. Longitudinal studies over several years within the secondary school timeframe would be ideal for testing the claim that SD modeling has the potential to change how students think about the world, a claim that is made by many teachers who teach systems thinking and dynamic modeling. It was not practical to conduct a longitudinal study as part of this dissertation experiment, but such a component is very important for any future research involving SD modeling.

The pre- and post-assessment instruments were not optimally constructed to allow statistical confidence analysis on individual questions. Future assessment instruments should contain more questions that are open-ended and/or require student responses that can be scored over a range of at least 5 different possible numeric values.

Moreover, students should have been interviewed about the pre- and postassessment instrument after the classroom experiment was over to determine if they found any questions confusing, so the assessment instrument could be improved.

An experiment with regard to teacher training, for teachers who have never used SD modeling, was not conducted. This researcher has pursued several avenues for such training and it would be useful to conduct such a study to fine-tune a training approach that would allow teachers to implement and retain SD analysis as part of their algebra II curriculum. 
The STELLA software is only available commercially, at this time. This adds a barrier to its use at the high school level, a barrier that becomes apparent when a teacher becomes trained in SD modeling and wants to implement SD model-building lessons in his/her class. For example, when a teacher who had attended a short training in SD modeling and was interested in implementing SD modeling in her algebra class, asked her administrator to purchase the software, he refused. The teacher wanted to conduct some experiments with her students and this researcher. Only schools with a site license of the STELLA software are candidates for experiments based on infusing SD modeling over an extended period of time in the classroom. Lack of software access could be one reason teachers have been reluctant to experiment with SD modeling. However a free, web-based basic version of STELLA should be available by the end of the 2016 calendar year.

E. Indications for Future Research

\section{Reflections}

To move forward in the effort to incorporate more model-building activities as part of infusing analysis of complex systems into the precollege classroom, more research is needed. In fact, without more research, it may be difficult to gain administrative support for efforts by teachers interested in incorporating complex systems analysis in their curriculum, as administrators control professional development for teachers, time allocated for experimenting with new concepts and instructional strategies, assessment of teachers who use new strategies, and the accessibility of technology for instructional (as opposed to statewide assessment) use. 
It is my intention to continue to conduct classroom experiments using SD modeling in mathematics and science pre-college classes. Based on lessons learned conducting research for this dissertation I will be following some guidelines that I now share with the reader. For future research I plan firstly, to insure experimental modeling lessons be infused in the regular curriculum. The number of lessons should be sufficient for students to consider SD modeling as a viable tool for studying dynamic problems. This may require a minimum of one SD modeling lesson per month. Secondly, it is important to avoid short "unit" length introductions of SD modeling of a few weeks, and where the approach is never used again during the class. SD is an analytical approach for thinking differently about dynamic problems. The "unit" instructional method shortcircuits the intention of the SD approach. Thirdly, it is important to design part of the experiment to include pre/post-assessments using control and experimental groups whenever feasible, in order to try to perform statistical confidence analysis, as results of such experiments are still held in high regard in the research community. While it is true that obtaining statistically significant results from instructional intervention is quite difficult in educational research (Berliner, 2000), it does not mean it should be abandoned, rather that it should be honed. Fourthly, it is still important to designate part of the experiment to include design experiment instruments such as videotaping students/teachers as they work, interviewing teachers and students, etc., as valuable information is obtained by these analytical methods that cannot be obtained by statistical analysis using control and experimental groups. I believe the previous recommendations can be useful in designing experiments to address recommendations for further research. 
Some readers might notice that I have not made any mention of gender issues with regard to SD modeling. The reason is that I found the girls just as interested and just as capable as the boys using the SD approach in my algebra II classes. A better indicator might be that the number of girls who signed up for, and successfully completed the yearlong modeling course (an elective math course) was in balance with the boys who signed up for and successfully completed the course. ${ }^{43}$ Of note, the girls tended to select for their final original models topics dealing with health issues. One of my female students said, "I wanted to study how cocaine works in the human body because a member of my family is addicted to cocaine." I think the female students felt the SD approach allowed them to study topics that were very interesting to them. This is especially important with the emphasis on STEM related courses for both girls and boys. A colleague who is a retired NASA engineer and who is familiar with SD and the STELLA software said that SD models allow students to do design engineering. So SD modeling addresses STEM topics as they directly apply to all four areas: Science, Technology, Engineering, and Mathematics.

Another consideration arises from the fact that many of the recommendations for further research mentioned below have had some research attention in the past. While that research has been useful, much of it is dated, and the research that exists is minimal. SD analysis of complex systems is a timely topic for pre-college education. The recommendations for further research highlighted here identify some of the most

\footnotetext{
${ }^{43}$ As a matter of fact the drop-out rate for the year-long modeling course for both girls and boys was near zero.
} 
important claims (regarding SD modeling) that are promising and sorely in need of more analysis.

\section{Suggestions}

Research is needed to determine whether students who are less adept at traditional mathematics (using closed form equations) can mathematize dynamic problems and explain their reasoning more easily than using traditional closed-form equations. (See Tinker, 1990.) Experiments could be conducted whereby modeling activities are analyzed with respect to the success of subgroups using different representations. Moreover, the teacher could allow students a choice of representation method to mathematize certain dynamic problems and see which representations are selected by different subgroups.

Following the previous recommendation, it would be useful to use the stock/flow diagramming approach to identify areas of common mistakes and misconceptions that occur during model building, and how often these mistakes occur (Van Borkulo, van Joolingen, Saelsbergh, \& de Jong, 2009). Part of identifying and correcting areas of common mistakes and misconceptions requires that students be able to identify those parts of the model structure that produce the behavior exhibited by the model. Without understanding the connection between structure (stock/flow diagram) and behavior (graphical output) students will likely not be able to correct their mistakes (Hmelo-Silver et al., 2007). Determining how well students are able to understand the connection between structure and behavior is another area for future research (Doerr, 1996) that will 
likely need to be developed on a continuum, where the problems gradually become more complicated so that the quality of student explanations could be analyzed.

As students become more comfortable using SD modeling to capture their "mental models" by creating the stock/flow diagram and validate that the behavior of the model is reasonable by explaining how and why their model produced the behavior demonstrated, the question remains, does this enhance their understanding of key concepts at the foundation of the lesson? This question requires some agreement about what conceptual understanding means. One might suggest that it could mean, can students extend models to capture additional facets of a problem (e.g., can they include a carrying capacity component in a population model that is growing exponentially) or can they transfer a model structure to another scenario that has similar behavior (e.g., taking the spread of an epidemic structure and apply it to the spread of a rumor or marketing a new product)? Determining whether most students who use SD modeling are able to adapt models and/or transfer structure to a new context requires further study (HmeloSilver, et al., 2006; Jacobson et al., 2006). Mandinach et al., 1987) suggests this transfer is not automatic and needs scaffolding by the teacher before it can occur.

Since SD modeling software uses variables that represent accumulations and rates of change it is claimed that SD modeling can be used to introduce students to basic calculus concepts in courses that occur in the mathematics sequence prior to a formal calculus course (Roschelle et al., 2000; Tinker, 1990). It would useful to know exactly how much students understand about accumulations and rates of change after working with SD modeling and whether they can explain what they know by using other, say, 
more physical or pictorial examples. Some researchers have identified the need to research whether students really understand the difference between stocks and flows (Mandinach, et al., 1988). If students cannot differentiate between variables that should be represented as stocks versus flows, it would certainly call into question whether students understand the most fundamental concepts in calculus.

Researching claims by teachers that SD analysis has changed how some of their students view local, national, and/or global issues requires more than a few classroom experiments with a few teachers. Mandinach et al. (2000) suggest that longitudinal studies should be designed over several years and should include interviews with students, teachers, and administrators and incorporate observations of the classroom and multiple assessment criteria. They suggest that student information should be collected, including grade point average, types of classes taken, attendance, disciplinary actions, and dropout rate, among others, to give a more complete picture of the effect SD modeling has on subgroups of students. Expanding on Mandinach's recommendation, even more extensive longitudinal studies focused on the value of SD modeling to prepare students for college and/or the workforce could provide valuable insights regarding whether SD training affects the educational path students choose for college and/or their choice of profession. I would strongly recommend that any future research should include components that do follow-up studies in later years with the students who have been trained in SD modeling.

As suggested in previous sections, further research is needed to devise new assessment instruments to capture the enhanced student learning outcomes that SD 
educators claim are a product of using SD modeling (Doerr, 1996; Roschelle, et al, 2000). Documenting student explanations provides some of this data, but such documentation is not easily summarized. It may be useful to investigate how science teachers assess systems thinking (ST) concepts, as considerable focus has been placed on ST in science education in the past decade.

Students will not have an opportunity to use SD modeling unless their teachers are interested and willing to take the risks associated with using an instructional approach that is quite different from the traditional one (Mandinach et al., 1988). Research should explore the new role of the teacher as a facilitator rather than a person who imparts knowledge to the student. It is important to determine the teacher's belief about the value of modeling when analyzing the effectiveness of student modeling activities. Continued research is needed to determine whether newly trained teachers are more open to the facilitator role and the use of technology in the classroom.

Online professional development for teachers can be tailored to individual teacher needs and interest, differentiating in-service professional growth opportunities. System Dynamics modeling training is already available online. It would be useful to determine if those opportunities provide what teachers need to begin using SD modeling in their classrooms. An administrator could experiment, allowing a small group of teachers to determine the direction for their professional development, and then could visit their classrooms in subsequent months/years to see if the teachers are applying what they learned. Conversations between the teacher and administrator would be needed to define the expectations for this mode of professional development. 


\section{F. Concluding Comments}

Secondary school mathematics education in the US is in dire need of an overhaul. Math scores on state and national assessments are very low, yet classroom instruction has not changed in decades. The current system does not serve significant subgroups of students, nor does it serve the teachers who are expected to differentiate instruction but are not given adequate training on new technological approaches nor given adequate technology to use in the classroom.

Technology use, in the form of computer modeling and simulation can serve as a reorganizer of algebraic thinking and as such, can be a game changer for mathematics instruction. Students at the secondary school level have shown that they are capable of creating SD models to study complex systems problems, explaining their models in technical papers, and highlighting the insights gained from model building to others. An important need is to present evidence about the value that SD modeling provides to enhance mathematics learning outcomes for students. To do so will require researchers to devise assessments that capture the differences that teachers who use SD modelbuilding lessons claim they see in their students after using the SD approach. A multistage path has been identified in this dissertation to guide teachers who want to begin to incorporate SD modeling in their algebra classes. Not all teachers will want to follow the entire path, but following any part of the path could provide value for students.

In this dissertation I have presented the empirical research of others supporting the value computer modeling brings to student learning. I have identified efforts within the mathematics research community to bring complex systems analysis into mainstream 
pre-college education. I have reinforced the importance of the focus on understanding functions as a high leverage point in early SD modeling lessons in mathematics. I have identified the lessons learned from a classroom experiment whereby two algebra II teachers introduced SD modeling lessons into their classes. The lessons were: infuse SD modeling into the curriculum over an extended time period, allow students to see SD modeling as a tool that supports mathematizing and analysis of problems that are beyond those they would typically be able to study, and provide an environment for teachers that allows them to focus on their teaching - including reliable, available computers, another SD teacher to talk to, a class schedule that provides needed instructional hours for core content as well as time for innovation by students, and a reduction in the stress to "teach to the standardized state/national tests."

Online instruction in SD modeling and analysis is available through various universities and online SD instruction for math and science teachers is available through Portland State University. Curriculum materials appropriate for K-12 Systems Thinking (ST) and SD modeling are available through the Creative Learning Exchange and isee systems, inc. A bi-annual K-12 Systems Thinking and Dynamic Modeling conference is held in Massachusetts (organized by the Creative Learning Exchange) for teachers who want to learn and/or share their systems thinking and SD work.

Mathematical analysis of complex systems problems is becoming increasingly important. We have powerful analytical methods with elegant graphical interfaces that make these methods accessible to pre-college students. We teachers have a responsibility 
to equip our students as we prepare them to deal with a world that has not prospered under our care, with the best available tools for thinking. 


\section{References:}

Akkoç, H., \& Tall, D. (2003). The function concept: Comprehension and complication. Proceedings of the British Society for Research into Learning Mathematic, 23(1), 1-6.

Alessi, S. (2000). Designing educational support in system-dynamics-based interactive learning environments. Simulation Gaming, 31, 178-196.

Alessi, S. (2009) Modeling a system and teaching a system: Enhancing what students learn from modeling. In P. Blumschein, W. Hung, D. Jonassen, \& J. Strobel. (Eds.) Model-Based Approaches to Learning: Using Systems Models and Simulations to Improve Understanding and Problem Solving in Complex Domains (pp. 199-214). Rotterdam, The Netherlands: Sense Publishers.

Ang, K.C. (2001) Teaching mathematical modeling in Singapore schools. The Mathematics Educator, 6 (1). 63-75.

Arcavi, A. (2003). The role of visual representations in the learning of mathematics. Educational Studies in Mathematics, 52(3), 215-241.

Ben-Hur, M. (2006). Concept-rich mathematics instruction: Building a strong foundation for reasoning and problem solving. Alexandria, VA: Association for Supervision and Curriculum Development.

Ben-Zvi-Assaraf, O, \& Orion, N. (2010). Four case studies, six years later: Developing system thinking skills in junior high school and sustaining them over time. Journal of Research in Science Teaching, 47 (10). 1253-1280.

Berliner, D. C. (2002). Comment: Educational research: The hardest science of all. Educational Researcher, 31(8), 18-20.

Blume, G. W., Heid, M. K. (2008). The role of research and theory in the integration of technology in mathematics teaching and learning. . In M. K. Heid, \& G. W. Blume (Eds.) Research on Technology and the Teaching and Learning of Mathematics: Vol 2. Research Syntheses (449-464). Charlotte, NC: Information Age Publishing, Inc.

Booth-Sweeney, L., \& Meadows, D. (2001). The systems thinking playbook. White River Junction, VT: Chelsea Green Publishing, Inc. 
Bransford, J., Brown, A., Cocking, R., Donovan, M. S., \& Pellegrino, J. W. (Eds.) (2000). Expanded Edition. How People Learn: Brain, Mind, Experience and School. Washington, D.C.: National Academy Press.

Bruner, J. S. (1966). Toward a theory of instruction (Vol. 59). Cambridge, MA: Harvard University Press.

Bruner, J. S. (2009a). The process of education. Cambridge, MA: Harvard University Press.

Bruner, J. (2009b). Culture, mind, and education. In K. Illeris (Ed.) Contemporary Theories of Learning: Learning Theorists... in Their Own Words (pp. 159-168). London: Routledge.

Carlson, M., Jacobs, S., Coe, E., Larsen, S . \& Hsu, E. (2002). Applying covariational reasoning while modeling dynamic events: A framework and a study. Journal for Research in Mathematics Education, 33(5), 352-378.

Carney, K., Forbus, K. D., Ureel II, L. C., \& Fisher, D. (2009) Can modeling foster analogical reasoning? In P. Blumschein, W. Hung, D. Jonassen, \& J. Strobel. (Eds.) Model-Based Approaches to Learning: Using Systems Models and Simulations to Improve Understanding and Problem Solving in Complex Domains (pp. 73-109). Rotterdam, The Netherlands: Sense Publishers.

Chen, D., \& Stroup, W., (1993). General system theory: Toward a conceptual framework for science and technology education for all. Journal of Science Education and Technology, 2 (3), 447-459.

Chi, M. T., DeLeeuw, N., Chiu, M. H., \& LaVancher, C. (1994). Eliciting selfexplanations improves understanding. Cognitive science, 18(3), 439-477.

Clement, J., Lochhead, J., \& Monk, G. S. (1981). Translation difficulties in learning mathematics. The American Mathematical Monthly, 88(4), 286-290.

Clement, L. L. (2001). What do students really know about functions. Mathematics teacher, 94(9), 745-748.

Cobb, P., \& Jackson, K. (2011). Towards an Empirically Grounded Theory of Action for Improving the Quality of Mathematics Teaching at Scale. Mathematics Teacher Education and Development, 13(1), 6-33.

Confrey, J., \& Doerr, H. M. (1994). Student Modelers. Interactive Learning Environments, 4 (3). 199-217. 
Daniels, H., Cole, M., \& Wertsch, J. V. (2007). The Cambridge companion to Vygotsky. Cambridge, NY: Cambridge University Press.

Davidson, N. (1990). Small-group cooperative learning in mathematics. In T. J. Cooney \& C. R. Hirsh (Eds.) Teaching and Learning Mathematics, 1990, Yearbook of the National Council of Teachers of Mathematics (pp. 52-61). Reston, VA: National Council of Teachers of Mathematics.

Davidsen, P. I. (2000). Issues in the design and use of system-dynamics-based interactive learning environments. Simulation Gaming. 31, 170-177.

Doerr, H. M. (1996). Stella ten years later: A review of the literature. International Journal of Computers for Mathematical Learning, 1, 201-224.

Doerr, H. M., \& Pratt, D. (2008). The learning of mathematics and mathematical modeling. In M. K. Heid, \& G. W. Blume (Eds.) Research on Technology and the Teaching and Learning of Mathematics: Vol 1. Research Syntheses (259-285). Charlotte, NC: Information Age Publishing, Inc.

Dörner, D. (1996). The Logic of Failure: Recognizing and Avoiding Error in Complex Situations. Cambridge, MA: Basic Books.

Dubinsky, E., \& McDonald, M. A. (2002). APOS: A constructivist theory of learning in undergraduate mathematics education research. In D. A. Holton (Ed.) The Teaching and Learning of Mathematics at University Level: An International Commission on Mathematical Instruction Study (pp. 273-280). Dordrecht, Netherlands: Kluwer Academic Publishers.

Dubinsky, E., \& Wilson, R. T. (2013). High school students' understanding of the function concept. The Journal of Mathematical Behavior, 32(1), 83-101.

English, L. D. (2007). Complex systems in the elementary and middle school mathematics curriculum: A focus on modeling. In B. Sriraman (Ed.) The Montana Mathematics Enthusiast Monograph: Vol. 3. Festschrift in Honor of Gunter Torner (pp. 139-156). Charlotte, NC: Information Age Publishing.

Fey, J. T. (1989). Technology and mathematics education: A survey of recent developments and important problems. Educational Studies in Mathematics, 20(3), 237-272.

Fisher, D. M. (2005). Lessons in mathematics: A dynamic approach with applications across the sciences: Teacher's guide. Lebanon, $\mathrm{NH}$ : isee systems, inc. 
Fisher, D. M. (2010). Modeling for high school students: Teaching critical thinking through system dynamics. In J. Richmond, L. Stuntz, K. Richmond, \& J. Egner (Eds.) Tracing Connections. (pp. 81 - 91). Lebanon, NH: isee systems, inc.

Fisher, D. M. (2011a). Modeling Dynamic Systems: Lessons for a First Course: Teacher's Guide. Lebanon, NH: isee systems, inc.

Fisher, D. M. (2011b). "Everybody thinking differently": K-12 is a leverage point. System Dynamics Review, 27(4), 394 - 411.

Fisher, D. M. (2015). Learn system dynamics modeling to address national standards in math and science: An online professional development opportunity.". Retrieved from http://www.ccmodelingsystems.com/news-overview-intro.html.

Fisher, D. M. (2016). Lessons learned from a failed experiment: A very brief introduction of system dynamics modeling in two algebra II classes. Proceedings of the $34^{\text {th }}$ International System Dynamics Conference. Delft, The Netherlands.

Fisher, D. M., Gallaher, E. J., \& Macovsky, L. (2003). How Drugs Work in the Human Body Analysis of a Modeling Unit Used in a Second Year Algebra Class. Proceedings of 21st International System Dynamics Conference. New York: NY.

Forrester, J. (1986). System dynamics as an organizing framework for pre-college education. System Dynamics Review, 3 (, 183-194.

Forrester, J. (1987). Lessons from system dynamics modeling. System Dynamics Review,3 (2), 136-149.

Forrester, J. W. (1995). Counterintuitive behavior of social systems. Retrieved from http://www.exponentialimprovement.com/cms/uploads/1/CounterintuitiveBehavio rOfSocialSystems.pdf

Forrester J. (1996). System Dynamics and K-12 Teachers. Lecture at the University of Virginia School of Education: Charlottesville, VA. Retrieved from http://static.clexchange.org/ftp/documents/roadmaps/RM1/D-4665-5.pdf

Forrester, J.W. (June, 2009). Learning through system dynamics as preparation for the 21 st century. Paper presented at the K-12 Systems Thinking and Dynamic Modeling Conference. Retrieved from http://static.clexchange.org/ftp/documents/whyk12sd/Y_2009-02LearningThroughSD.pdf

Fuson, K. C., Kalchman, M., \& Bransford, J. D. (2005). Mathematical understanding: An introduction. In M. S. Donovan \& J. D. Bransford (Eds.) How Students Learn: 
Mathematics in the Classroom (pp. 217 - 256). Washington, D.C.: The National Academies Press.

Gallaher, E. J., Steensma, D. P., Chrisope, T. R., Dingli, D., \& McCarthy, J. T. (2011). Individualized Medicine and Biophysical System Dynamics: An Example from Clinical Practice in End Stage Renal Disease. Retrieved from http://www.systemdynamics.org/conferences/2011/proceed/papers/P1299.pdf

Ghaffarzadegan, N., Lyneis, J., \& Richardson, G. P. (2011). How small system dynamics models can help the public policy process. System Dynamics Review, 27(1), 22-44.

Gordon, F. S., \& Gordon, S. P. (2006) "What does conceptual understanding mean." The American Mathematics Association of Two-Year Colleges Review, 28(1), 57-74.

Greer, B, \& Mukhopadhyay, S. (2012).“The hegemony of mathematics.” In O. Skovsmose \& B. Greer (Eds.) Opening the Cage (pp. 229-248). Rotterdam, The Netherlands: Sense Publishers.

Grotzer, Tina, 1999, Math/Science Matter: Resource Booklets on Research in Math and Science Learning: Booklet 1: Cognitive Issues that Affect Math and Science Learning: Understanding Counts: Teaching Depth in Math and Science, Project Zero, Harvard Graduate School of Education.

Heid, M. K., \& Blume, G. W. (2008a). Technology and the development of algebraic understanding. . In M. K. Heid, \& G. W. Blume (Eds.) Research on Technology and the Teaching and Learning of Mathematics: Vol 1. Research Syntheses (pp. 55-108). Charlotte, NC: Information Age Publishing, Inc.

Heid, M. K., \& Blume, G. W. (2008b). Technology and the teaching and learning of mathematics: Cross content implications. In M. K. Heid, \& G. W. Blume (Eds.) Research on Technology and the Teaching and Learning of Mathematics: Vol 1. Research Syntheses (pp. 419-431). Charlotte, NC: Information Age Publishing, Inc.

Hillen, S., \& Gonzalez, J. (2009) Generating dynamic stories from complex simulation models: a learning approach applied in information security. In P. Blumschein, W. Hung, D. Jonassen, \& J. Strobel. (Eds.) Model-Based Approaches to Learning: Using Systems Models and Simulations to Improve Understanding and Problem Solving in Complex Domains (pp. 149-162). Rotterdam, The Netherlands: Sense Publishers.

Hirsch, G. B. (2006). Packaged Simulators and Simulation-Based Learning Environments: An Alternative to Model-Building that Can Expand the Audience for System Dynamics. The Creative Learning Exchange, 15(2), 1-8. 
Hmelo-Silver, C. E., \& Azevedo, R. (2006) Understanding complex systems: Some core challenges. The Journal of the Learning Sciences, 15 (1). 53-61.

Hmelo-Silver, C. E., Marathe, S., \& Liu, L. (2007). Fish swim, rocks sit, and lungs breathe: Expert-novice understanding of complex systems. Journal of the Learning Sciences, 16 (3), 307-331

Hoard, M., Homer, J., Manley, W., Furbee, P., Haque, A., \& Helmkamp, J. (2005). Systems modeling in support of evidence-based disaster planning for rural areas. International journal of hygiene and environmental health, 208(1), 117-125.

Hollar, J. C., \& Norwood, K. (1999). The effects of a graphing-approach intermediate algebra curriculum on students' understanding of function. Journal for Research in Mathematics Education, 30(2), 220-226.

Homer, J. B., \& Hirsch, G. B. (2006). System dynamics modeling for public health: Background and opportunities. American Journal of Public Health, 96(3), 452458.

Hung, W. (2008) Enhancing systems thinking skills with modeling. British Journal of Educational Technology, 39 (6), 1099-1120.

Hung, W. (2009) Utilizing system modeling to enhance students' construction of problem representations in problem solving. In P. Blumschein, W. Hung, D. Jonassen, \& J. Strobel. (Eds.) Model-Based Approaches to Learning: Using Systems Models and Simulations to Improve Understanding and Problem Solving in Complex Domains (pp. 41-57). Rotterdam, The Netherlands: Sense Publishers.

Hung, W., \& Blumschein, P. (2009) After ward: where do we go from here? In P. Blumschein, W. Hung, D. Jonassen, \& J. Strobel. (Eds.) Model-Based Approaches to Learning: Using Systems Models and Simulations to Improve Understanding and Problem Solving in Complex Domains (pp. 319-329). Rotterdam, The Netherlands: Sense Publishers.

Jackson, S. L., Stratford, S. J., Krajcik, J., \& Soloway, E. (1994). Making dynamic modeling accessible to precollege science students. Interactive Learning Environments, 4 (3). 233-257.

Jacobson, M., \& Wilensky, U. (2006) Complex systems in education: Scientific and educational importance and implications for the learning sciences. The Journal of the Learning Sciences, 15 (1). 11-34. 
Johnson, T., Bryden, J. M. \& Refsgaard, K. (2009). Modeling rural, social, economic and environmental interactions of EU agricultural policy. In P. Blumschein, W. Hung, D. Jonassen, \& J. Strobel. (Eds.) Model-Based Approaches to Learning: Using Systems Models and Simulations to Improve Understanding and Problem Solving in Complex Domains (pp. 293-303). Rotterdam, The Netherlands: Sense Publishers.

Jonassen, D.H. (2004). Model building for conceptual change: Using computers as cognitive tools. Proceedings from 4th Conference of the Hellenic Scientific Association of Information and Communication Technologies in Education. Athens, Greece.

Jonassen, D. (2006). Modeling with technology: mindtools for conceptual change ( $3^{\text {rd }}$ $E d$.). New Jersey: Pearson, Merril/Prentice Hall.

Jonassen, D. H. (2009) Modeling thinking processes by building cognitive simulations. In P. Blumschein, W. Hung, D. Jonassen, \& J. Strobel. (Eds.) Model-Based Approaches to Learning: Using Systems Models and Simulations to Improve Understanding and Problem Solving in Complex Domains (pp. 61-71). Rotterdam, The Netherlands: Sense Publishers.

Jonassen, D. H., Carr, C., \& Yueh, H. P. (1998). Computers as mindtools for engaging learners in critical thinking. Tech Trends, 43, (2), 24-32.

Jonassen, D. H., \& Strobel, J. (2006). Modeling for meaningful learning. In D. Hung, \& M. S. Khine (Eds.), Engaged Learning With Emerging Technologies (pp. 1-27). The Netherlands: Springer.

Jonassen, D.H., \& Hung, W. (2008) All problems are not equal: implications for problem-based learning. Interdisciplinary Journal of Problem-Based Learning, 2 (2), 6-28.

Kaput, J. J. (1999). Teaching and learning a new algebra. In E. Fennema \& T. A. Romberg (Eds.) Mathematics Classrooms that Promote Understanding. Mahwah, New Jersey: Lawrence Erlaum Associates, Publishers.

Kaput, J., \& Roschelle, J. (1997) Deepening the impact of technology beyond assistance with traditional formalisms in order to democratize access to ideas underlying calculus. In E. Pehkonen (Ed.). Proceedings of the 21st Conference of the International Group for the Psychology of Mathematics Education, Vol. 1, (pp. 105-112). Lahti, Finland: University of Helsinki.

Kaput, J., \& Roschelle, J. (2000a). Shifting representational infrastructures and reconstituting content to democratize access to the math of change and variation: Impacts on cognition, curriculum, learning and teaching. In NSF Workshop to 
Integrate Computer-based Modeling and Scientific Visualization into K-12 Teacher Education Programs. Reston, VA: National Science Foundation.

Kaput, J., Bar-Yam, Y., Jacobson, M., Jakobsson, E., Lemke, J., \& Wilensky, U. (2000b). Two roles for complex systems in education: mainstream content and means for understanding the education system itself. Planning documents for a national initiative on complex systems in $\mathrm{K}$-16 education. Retrieved from http://www.necsi.edu/events/cxedk16/cxedk16_0.html.

Kaput, J. J., \& Roschelle, J. (2013). The mathematics of change and variation from a millennial perspective: New content, new context. In S.J. Hegedus, \& J. Roschelle (Eds.), The SimCalc Vision and Contributions, Advances in Mathematics Education (pp. 13-26). DOI 10.1007/978-94-007-5696-0_2. The Netherlands: Springer .

Keller, B. A., \& Hirsch, C. R. (1998). Student preferences for representations of functions. International Journal of Mathematical Education in Science and Technology, 29(1), 1-17.

Kelly, A. E., Baek, J. Y., Lesh, R. A., \& Bannan-Ritland, B. (2008). Enabling Innovations in Education and Systemizing their Impact. In A. E. Kelly, R. A. Lesh, \& J. Y. Baek, Handbook of Design Research Methods in Education (pp. 318). New York: Routledge.

Leinhardt, G., Zaslavsky, O., \& Stein, M. K. (1990). Functions, graphs, and graphing: Tasks, learning, and teaching. Review of educational research, 60(1), 1-64.

Lesh, R., \& Lehrer, R. (2000). Iterative refinement cycles for videotape analyses of conceptual change. In R. Lesh (Ed.), Handbook of research data design in mathematics and science education (pp. 665-708). Mahwah, NJ: Lawrence Erblaum Associates.

Lesh, R., \& English, L. D. (2005). Trends in the evolution of models \& modeling perspectives on mathematical learning and problem solving. Zentralblat für Didaktik der Mathematik, 37(6), 487-489.

Lesh, R. (2006) Modeling students modeling abilities: The teaching and learning of complex systems in education. The Journal of the Learning Sciences, 15 (1). 45 52 .

Lesh, R., Kelly, A., \& Yoon, C. (2008). Multi-tier design experiments in mathematics, science, and technology education. In A. E. Kelly, J. Y. Baek, \& R. A. Lesh (Eds.), Handbook of design research methods in education: Innovations in 
science, technology, engineering, and mathematics (pp. 131-148). New York: Routledge.

Mandinach, E. B. (1987). The use of simulations in learning and transfer of higher-order cognitive skills. Paper presented at the American Educational Research Association. Retrieved from ERIC database. (ED 282 915).

Mandinach, E. B., Thorpe, M. E., \& Lahart, C. M. (1988). The impact of the systems thinking approach on teaching and learning activities. Retrieved from ERIC database. (ED 305 928).

Mandinach, E. B., \& Cline, H. F. (1993). Systems, Science, and Schools. System Dynamics Review, 9 (2), 195-206.

Mandinach, E. B., \& Cline, H. F. (1994). Classroom Dynamics. Hillsdale, NJ: Lawrence Erlbaum Associates.

Mandinach, E. B., \& Cline, H. F. (2000) It won't happen soon: Practical, curricular, and methodological problems in implementing technology-based constructivist approaches in classrooms. In A. P. Lajoie (Ed.) Computers as Cognitive Tools, Vol II, (377-395). Mahwah, NJ: Lawrence Erlbaum Associates, Publishers.

Mansilla, V. B., Jackson, A. (2011). Educating for global competence: Preparing our youth to engage the world. Asia Society. Retrieved from http://www.pz.harvard.edu/sites/default/files/book-globalcompetence.pdf.

Meadows D. H. (1991). The Global Citizen. Washington, D.C.: Island Press.

Meadows, D. H. (2008). Thinking in Systems: A Primer. White River Junction, Vermont: Chelsea Green Publishing.

Milrad, M., Spector, J. M., \& Davidsen, P. I. (2003) Model facilitated learning. In S. Naidu (Ed.) Learning \& Teaching with Technology: Principles and Practices (pp. 13-27). London: Kogan Page.

National Council of Teachers of Mathematics. (2000). Principles and standards for school mathematics. Reston, VA: National Council of Teachers of Mathematics.

Newman, F., \& Holzman, L. (2005). Lev Vygotsky: Revoltn Scientist. New York, NY: Routledge.

Nicolaou, C. T., Nicolaidou, I. A., \& Constantinou, C. P. (2009) Scientific model construction by pre-service teachers using stagecast creator. In P. Blumschein, W. Hung, D. Jonassen, \& J. Strobel. (Eds.) Model-Based Approaches to Learning: Using Systems Models and Simulations to Improve Understanding and Problem 
Solving in Complex Domains (pp. 215-236). Rotterdam, The Netherlands: Sense Publishers.

Oehrtman, M. C., Carlson, M. P., \& Thompson, P. W. (2008). Foundational reasoning abilities that promote coherence in students' understandings of function. In M. P. Carlson \& C. Rasmussen (Eds.), Making the Connection: Research and Practice in Undergraduate Mathematics (pp. 27-42). Washington, DC: Mathematical Association of America.

Organization for Economic Cooperation and Development. (2008). 21st Century Learning: Research, Innovation and Policy. In the Proceeding of Organization for Economic Cooperation and Development/Centre for Educational Research and Innovation International Conference. Retrieved from http://www.oecd.org/site/educeri21st/40554299.pdf

Organization for Economic Cooperation and Development. (2014). PISA 2012 Results: Creative Problem Solving (Volume V): Students'Skills in Tackling Real-Life Problems. Program for International Student Assessment, Organization for Economic Cooperation and Development Publishing. DOI: 10.1787/9789264208070-en.

Otero, V., Peressini, D., Meymaris, K. A., Ford, P., Garvin, T. Harlow, D. Reidel, M., Waite, B., \& Mears, C. (2005). Integrating technology into teacher education: A critical framework for implementing reform. Journal of Teacher Education, 56 (1). 8-23.

Papert, S. (1980) Mindstorms (2 ${ }^{\text {nd }}$ Ed.). Cambridge, MA: Basic Books.

Pea, R. D. (1985) Beyond amplification: using the computer to reorganize mental functioning. Educational Psychologist, 20 (4). 167-182.

Pea, R. D. (1987) Cognitive technologies for mathematics education. In A. Schoenfeld (Ed.) Cognitive Science and Mathematics Education (89-122). Hillsdale, NJ: Lawrence Erlbaum Associates, Inc.

Philipp, R. A. (2007). Mathematics Teacher's Beliefs and Affect. In F. K. Lester (Ed.), Second Handbook of Research on Mathematics Teaching and Learning (pp. 257315). Charlotte, NC: Information Age Publishing.

Quaden, R., Ticotsky, A., \& Lyneis, D. (2008). The Shape of Change and The Shape of Change: Stocks and Flows. Acton, MA: The Creative Learning Exchange.

Reimann, P., \& Thompson, K. (2009) Ecosystem modeling for environmental education: from stocks and flows to behavior and interactions. In P. Blumschein, W. Hung, 
D. Jonassen, \& J. Strobel. (Eds.) Model-Based Approaches to Learning: Using Systems Models and Simulations to Improve Understanding and Problem Solving in Complex Domains (pp. 111-148). Rotterdam, The Netherlands: Sense Publishers.

Richmond, B. (1993). Systems thinking: Critical thinking skills for the 1990s and beyond. The System Dynamics Review, 9 (2), 113-133.

Richmond, B. (2004). Introduction to Systems Thinking. Lebanon, NH: isee systems, inc.

Riley, D. (1990). Learning about systems by making models. Computers \& Education, 15 (1-3), 255-263.

Roberts, N. (1978). Teaching dynamic feedback systems thinking: An elementary view. Management Science, 24 (8), 836-843.

Roberts, N., \& Barclay, T. (1988) Teaching model building to high school students: Theory and reality. Journal of Computers in Mathematics and Science Teaching, 8, 13-16.

Roschelle, J. M., Pea, R. D., Hoadley, C M., Gordin, D. N., \& Means, B. M. (2000). Changing how and what children learn in school with computer-based technologies. Children and Computer Technology, 10 (2), 76-101.

Rosenblatt, Z. (2004). Skill flexibility and school change: A multinational study. Journal of Educational Change, 5, 1-30.

Schwartz, J. L., \& Yerushalmy, M. (1995). On the need for a bridging language for mathematical modeling. For the Learning of Mathematics, 15(2), 29-35.

Seel, N. M., \& Blumschein, P. (2009) Modeling and simulation learning and instruction: a theoretical perspective. In P. Blumschein, W. Hung, D. Jonassen, \& J. Strobel. (Eds.) Model-Based Approaches to Learning: Using Systems Models and Simulations to Improve Understanding and Problem Solving in Complex Domains (pp. 3-15). Rotterdam, The Netherlands: Sense Publishers.

Senge, P. M. (2006). The fifth discipline: The art and practice of the learning organization. New York: Currency Doubleday.

Simon, H. A. (1996). The sciences of the artificial (3rd ed.). Cambridge, MA: Massachusetts Institute of Technology Press.

Skaza, H.J., \& Stave, K.A. (2009). A test of the relative effectiveness of using systems simulations to increase student understanding of environmental issues. 
Proceedings of the 27th International Conference of the System Dynamics Society. Albuquerque, NM.

Skaza, H., Crippen, K. J., \& Carroll, K. R. (2013). Teachers’ barriers to introducing system dynamics in K-12 STEM curriculum. System Dynamics Review, 29(3), 157-169.

Skovsmose, O. (2005). Travelling through education: Uncertainty, mathematics, responsibility. Rotterdam, The Netherlands: Sense Publishers.

Spector, J. M. (2000). System dynamics and interactive learning environments: Lessons learned and implications for the future. Simulation Gaming, 31, 528-535.

Spector, J. M. (2008). Cognition and learning in the digital age: Promising research and practice. Computers in Human Behavior, 24, 249-262.

Spector, J. M. (2009) A modeling methodology for assessing learning in complex domains. In P. Blumschein, W. Hung, D. Jonassen, \& J. Strobel. (Eds.) ModelBased Approaches to Learning: Using Systems Models and Simulations to Improve Understanding and Problem Solving in Complex Domains (pp. 163-177). Rotterdam, The Netherlands: Sense Publishers.

Spector, J. M., Christensen, D. L., Sioutine, A. V., \& McCormack, D. (2001). Models and simulations for learning in complex domains: Using causal loop diagrams for assessment and evaluation. Computers in Human Behavior, 17, 517-545.

Springer, L., Stanne, M. E., \& Donovan, S. S. (1999). Effects of small-group learning on undergraduates in science, mathematics, engineering, and technology: A metaanalysis. Review of Educational Research, 69(1), 21-51.

Stave, K. A. (2012). What can students learn from simple simulations about accumulations? Proceedings of the 30th International System Dynamics Conference. St. Gallen, Switzerland.

Steed, M. (1992). Stella, a simulation construction kit: Cognitive process and educational implications. Journal of Computers in Mathematics and Science Teaching, 11, 39-52.

Stein, M. K., Grover, B. W., \& Henningsen, M. (1996). Building student capacity for mathematical thinking and reasoning: An analysis of mathematical tasks used in reform classrooms. American Educational Research Journal, 33 (2), 455-488.

Sterman, J. (1994). Learning in and about complex systems. System Dynamics Review, 10 (2-3), 291-330. 
Sterman, J. D. (2000). Business dynamics: Systems thinking and modeling for a complex world. Boston, MA: Irwin/McGraw-Hill.

Sterman, J. (2002). All models are wrong: Reflections on becoming a system scientist. System Dynamics Review, 18 (4), 501-531.

Sterman, J. D. (2011). Communicating climate change risks in a skeptical world. Climatic Change, 108(4), 811-826.

Stigler, J. W., \& Hiebert, J. (2009). Closing the teaching gap. Phi Delta Kappan, 91(3), 32.

Stratford, S. J., Krajcik, J. \& Soloway, E. (1998). Secondary students' dynamic modeling processes: Analyzing, reasoning about, synthesizing, and testing models of stream ecosystems. Journal of Science Education and Technology, 7(3), 215-234.

Svensson, M. G., \& Mats, G. (2002). System dynamics of learning processes: Comparing apples with pears. In Proceedings of the $20^{\text {th }}$ International System Dynamics Conference. Palermo, Italy.

Thompson, P. W. (1994). Students, functions, and the undergraduate curriculum. In E. Dubinsky, A. H. Schoenfeld, \& J. J. Kaput (Eds.), Research in Collegiate Mathematics Education, 1, 21-44.

Thompson, P. W., Byerley, C., \& Hatfield, N. (2013). A conceptual approach to calculus made possible by technology. Computers in the Schools, 30(1-2), 124-147.

Tinker, R. F. (1990) Teaching theory building: Modeling: Instructional materials and software for theory building. Technical Education Research Centers. Cambridge, MA. 1152-1163.

Van Borkulo, S. P., van Joolingen, W. R., Savelsbergh, E. R., \& de Jong, T. (2009) A framework for the assessment of learning by modeling. In P. Blumschein, W. Hung, D. Jonassen, \& J. Strobel. (Eds.) Model-Based Approaches to Learning: Using Systems Models and Simulations to Improve Understanding and Problem Solving in Complex Domains (pp. 179-195). Rotterdam, The Netherlands: Sense Publishers.

Vygotsky, L. (1978) Interaction between learning and development. In M. Cole, V. John-Steiner, S. Scribner, \& E. Souberman (Eds.) L.S. Vygotsky Mind in Society: The Development of Higher Psychological Processes, Ch 6. Cambridge, MA: Harvard University Press. 
Vygotsky, L. S. (1997). The history of the development of higher mental functions. In R. W. Rieber. The Collected Works of L. S. Vygotsky. Volume 4: The History of the Development of Higher Mental Functions (pp. 1-26). New York: Plenum Press.

Wolf, J., \& Le Vasan, M. (2008). Toward Assessment of Teachers' Receptivity to Change in Singapore. In A. E. Kelly, J. Y. Baek, \& R. A. Lesh (Eds.), Handbook of Design Research Methods in Education: Innovations in Science, Technology, Engineering, and Mathematics (pp. 265). New York: Routledge.

Yerushalmy, M. (1991). Student perceptions of aspects of algebraic function using multiple representation software. Journal of Computer Assisted Learning, 7(1), 42-57.

Zbiek, R.M., \& Hollebrands, K. (2008). A research-informed view of the process of incorporating mathematics technology into classroom practice by in-service and prospective teachers. In M. K. Heid, \& G. W. Blume (Eds.) Research on Technology and the Teaching and Learning of Mathematics: Vol 1. Research Syntheses (287-344). Charlotte, NC: Information Age Publishing, Inc. 
Appendix A: Detailed Explanation of Lessons for the Study

\section{Stage 1 \& 2: Enactive \& Iconic (linear)}

Activity 1: (Motion) The teacher will use a motion detector activity, where a motion detector is connected to a computer projection unit and will have students move in front of the detector to produce several graphs of linear function patterns described in short paragraphs. Questions will be asked (in the handout) to determine if the students can identify key graphical concepts that are related to the motion (i.e., connection between y-intercept and starting position of the person who will walk in front of the motion detector, connection between slope and velocity, the characteristic of the motion that makes the graph linear, etc.) Students will be expected to predict/sketch graphical result before actual data is captured. Students will also be expected to create velocity graphs from position graphs and position graphs from velocity graphs. Finally, students will be asked to create their own motion descriptions that will produce graphs composed of linear segments to move a person from point A to point B (on the graph). The researcher will "grade" this original motion problem the students have produced.

\section{Stage 3: Symbolic (linear)}

Activity 2: Students will be shown the STELLA software icons and, using the software, the teacher will build one linear model of motion in class. Students will then use the classroom set of computer netbooks to build various linear models based on problem descriptions. They will be expected to use the model to make predictions and answer questions about the problem scenario. Students will be expected to create an original linear model of their choice, label the icons appropriately (with units), produce a graph that is linear, and explain why the graph produced is linear, the meaning of the slope and y-intercept for their scenario. The researcher will "grade" this original model.

\section{Stage 1: Enactive (exponential)} functions)

Activity 3: (Floor stock/flow activity: Linear functions and exponential

This activity will consist of using masking tape to form a $5 \mathrm{ft}$. by $5 \mathrm{ft}$. rectangle on the floor of the classroom. There will also be an inflow path, with an arrow pointing toward the rectangle (created by masking tape on the floor). Students will walk inside the arrow path, into the rectangle, in certain constant flow patterns (used to quickly review creating a linear function). The number of people in the stock will be recorded in a table. Student will be asked to come up with ideas to produce linear decay.

Then the teacher will have one student start in the stock and have him (her) take out his (her) cell phone. A strip of masking tape will be placed on the floor connecting the stock back to the flow (in a curved pattern). The teacher will take out his (her) cell phone and, standing with his (her) back to the stock pretend to contact the person in the 
stock using the phone, asking how many people are in the stock. Then the teacher will ask that same number of people in the class to move into the stock. The teacher then asks (mimicking a call on his (her) cell phone) the person in the stock (with the cell phone) to tell him (her) how many people are in the stock. When he (she) receives that information he (she) sends in that number of new people, from the class, into the stock. (A table of the number of people in the stock will be recorded, each turn, on the board.) This process continues for two more turns. Students will come up with original ideas for descriptions that will produce a similar pattern of increase in the number of people in the stock.

\section{Stage 2: Iconic (linear and exponential)}

Activity 4: Students will graph the values that were recorded in the tables that were produced in stage 1 (for exponential functions). Students will be given some tables of values and asked to determine if they represent linear or exponential growth and if so explain how they know.

\section{Stage 3: Symbolic (exponential)}

Activity 5: Students will be reminded of the STELLA software icons and the teacher will build one exponential model of an interest-bearing bank account in class. Students will then use the classroom set of netbooks and build various exponential models, using the STELLA software, based on problem descriptions given in their handout. They will be expected to use the model to make predictions and answer questions about the problem scenario. Students will be expected to create an original exponential STELLA model of their choice, label the icons appropriately (with units), and explain why the graph produced is exponential.

Day after activity 5: The teacher will build a bank account model with constant withdrawals with the aid of students in the class, asking students how to build the model and asking them to predict behavior based on changing values in the model.

Activity 6: A random selection of one pair ${ }^{44}$ of students will be removed from each experimental class when the rest of the class is working on the drug model lesson. Each pair will build a drug model. These students will be videotaped, by the researcher, as they try to determine how to build the model and answer the questions. The student pairs will build the model identified as the IV drug model on a computer netbook provided in an empty classroom. The rest of the class will build the same model. Each student pair will be asked to: 1. explain the behavior (graph) of the model, 2. Explain how they would modify the model to include a change in the story scenario, and 3. anticipate the behavior of the modified model. The researcher will "grade" this packet.

\footnotetext{
${ }^{44}$ Student names will be placed in pairs on small papers and selected at random from a container. The pairing is designed to maintain student comfort in working with another student they usually choose to work with, if possible, on the task for activity 3 .
} 
Appendix B: Detailed Explanation of Pre- and Post-Assessments for the Study

1. Question 1: Given 4 straight line graphs with different vertical scale designations (only min and max numbers specified) and the same horizontal scale designations students are asked to determine the graph that has the largest slope.

2. Question 2: A description of filling or emptying a tub or glass is given and students are to draw a graph of the resultant volume over time.

3. Question 3: An ecosystem with a deer herd that is growing or declining is described. Students are to designate the relationship between the birth and death rates of the deer herd over time.

4. Question 4: A description of a person moving in front of a motion detector is given with four graphs to choose from showing potential representations of the described motion.

5. Question 5: A description of a scenario that produces a linear graph, and the linear graph produced. Students are to designate a label for the dependent and independent variables for the graph.

6. Question 6: Asking students how the slope of an exponential graph changes over time.

7. Question 7. Given two straight-line graphs, on the same scale, one of the inflow and the other of outflow for contents of a container, describe how the quantity in the container is changing over time.

8. Comparing the growth or the decay amounts of two items that are growing/decaying exponentially where one change rate is exactly twice the other change rate.

9. Given a STELLA linear function diagram with icons described, but no values indicated, determine if the stock value will increase or decrease and determine the pattern of change that will occur.

10. Determine if linear growth/decay of a money scenario is more efficient/productive in reaching the goal over 100 years compared to an exponential growth/decay.

11. Determine whether slope or $y$-intercept is altered if a line is shifted up/down or right/left.

12. Given 5 scenarios determine if the growth/decay is linear or exponential. 
Appendix C: Videotape of Two Student Pairs, One From Each

Experimental Class, Building the Drug Model

1. Overall Purpose 1: To capture the thinking of the students as they decide how to construct the stock/flow diagram to capture the behavior of the following problem:

"You are continuing your work as a medical resident at a local hospital. You are again working in the emergency room when a patient arrives and needs medical attention."

"For this patient you decide you must insert an IV drip into the person's arm in order to administer a therapeutic drug. You set the IV drip so it will allow a constant inflow of $1 \mathrm{~g} / \mathrm{min}$ of the drug into the person's blood system. The patient, you estimate, will eliminate $0.55 \%$ of the drug in his system each minute. (Be careful, $0.55 \%$ is less than $1 \%$ )."

b. A subordinate purpose was to determine if the students could construct a stock/flow diagram that had the students select a stock and identify it as the amount of drug in the body, and construct a constant inflow toward the stock and an exponential outflow from the stock. Note that the generic exponential growth and exponential decay stock/flow diagrams were shown in a boxed display at the top of the paper, for student reference.

The following sentence in the lesson indicated how the structure should be constructed:

"Modify the basic exponential STELLA diagram to incorporate the constant inflow of drug and the exponential outflow. Draw the STELLA diagram you now have in the space below. Label each icon to match the situation described. Be sure to place the correct value or formula in each icon."

(Note: it would have been much more useful to the analysis not to have specified that the inflow was constant and the outflow was exponential. It would have been better to see if the students could have performed this construction merely from the description of the scenario given above.)

An unintended bias on the part of the researcher was that, if the students did not get the model structure constructed correctly they could not proceed with the rest of the lesson that was to enhance and experiment with the model.

Another unintended bias on the part of the researcher was that, since the researcher was videotaping the two students working on the Drug Model lesson at the same time the classroom teacher was having the rest of the class work on constructing and exercising the Drug Model in class, the flow description would 
help the teacher troubleshoot questions, making this part of the lesson easier, since students could not proceed without producing at least a correct basic model.

As it turns out the two videotaped pairs did not proceed in the same way at this point. In fact the first pair overlooked the "Modify the basic exponential..." sentence completely, that specified that the inflow should be constant and the outflow should be exponential.

Team from Teacher 1's class build the correct structure immediately:

$$
\mathrm{S} 1=\text { student } 1, \mathrm{~S} 2=\text { student } 2
$$

S1: [reads the problem description] ...be careful .55 is less than one. Modify the STELLA diagram. So we're supposed to draw the STELLA diagram different or the same and just label it?

S2: So stock is like medicine in the system and then inflow

S1: So it's inflow or outflow cause it's...

S2: Well there's both.

S1: So there's one going in and one going out?

$\mathrm{S} 2$ : Because there's 1 gram a minute going in and then you lose $.55 \%$ of it.

$\mathrm{S} 1$ : And there's a connection on the outflow right because its $.55 \%$ ?

S2: Yeah.

S1: Of the drug it's one gram per minute so

S1: Because it's $.5 \%$ so would be .0055

S2: Yeah.

S1: And then the initial is, there is no initial, so it's zero and then for the inflow it's one. What's next? ...

Team from Teacher 2's class build the incorrect inflow structure initially, then correct their mistake later:

$$
\mathrm{P} 1=\text { pupil } 1, \mathrm{P} 2=\text { pupil } 2
$$

P1: [reads the problem description] ...be careful 0.55 percent is less than one percent. Modify the basic exponential STELLA diagram to incorporate the constant inflow of drug and the exponential outflow. Draw the STELLA diagram you now have in the space below. Label each icon to match the situation described. Be sure to place the correct value or formula in each icon.

P2: So we make this one first.

$\mathrm{P} 1$ : All right. So we're making a model.

[Instead of drawing the structure first, as indicated in the lesson, the students go directly to the computer to build the model.]

P2: We pull down the stock.

P1: Name it.

P2: I'm just going to name it later. Okay, I'll name it now. So what would be the name of the stock? Drug in system, wouldn't it be? 
P1: I guess, yes.

P2: What percentage of drug is in the system? That's what it would be right. [P2 labels the stock Drug in System] How much should we start of with?

P1: That's a good question. Hold on, let's just get all this stuff down first. [P1 draws an inflow]

P2: Wouldn't it be an outflow for how much is leaving or would it be both?

P1: Well, this is the IV drip thing [P1 is drawing an exponential structure for the inflow]

P2: But it's also saying

P1: There's stuff going out of it.

P2: Yeah. There's how much is getting out of the system.

$\mathrm{P} 1$ : [P1 is now drawing an exponential outflow]

P2: There's one percent going in.

P1: There's less than 1 percent going in.

P2: No, there's one percent going in and less than $.55 \%$ going out. Yeah.

P1: I got you. I got you.

$\mathrm{P} 2$ : So this is the rate of drug going into the system [P2 is pointing go the converter on the inflow side.]

P1: So that's one. You said there was a constant inflow of one g per minute of drug going into the blood stream.

P2:[P2 is renaming the converter on the inflow side as Rate of Drug Entering] And this is the drug entering the system. [P2 is now labeling the inflow Amount of drug entering system] This is the amount, the rate of drug leaving the system. [P2 is labeling the converter on the outflow side as Rate of Drug Leaving System and then labels the outflow Amount of Drug Leaving System]. P2 now goes back to the converter on the inflow side of the diagram.] So the rate of drug entering the system is $1 \%$ so we have to put that as a decimal right?

P1: It's not $1 \%$ it's 1 gram a minute.

P2: Oh, just kidding.

P1: So that's not a exponential that would be

P2: That would be linear.

$\mathrm{P} 1$ : [P1 starts erasing the converter on the inflow and tries to erase the flow from the stock to the inflow but is unsuccessful.]

Researcher: put the arrow point in the little circle tail, in the little circle tail, and hit backspace. [Researcher explains how to erase a connection on the diagram]

P1: Adios. So this is one [P1 is defining the inflow value] gram a minutes.

P2: Yeah.

$\mathrm{P} 1$ : [P1 is now double-clicking on the outflow converter] this would be the

P2: That would be the

P1: So it's less than $1 \%$ so would be .0055 ?

P2: No.

P1: Because .55

P2: Yeah, yeah, yeah. You move it over two it's .0055. Yeah. So we start out 
with zero in the drug in the system.

P1: [P1 double-clicks on the outflow] and this would be drug in system times rate of drug leaving system.

P2: Okay, so we have to draw that on here [referring to drawing the stock/flow structure they just built on the computer, in the packet].

So the team from teacher 2 started out with an incorrect inflow structure but realized, since the inflow was a constant they need to remove the exponential inflow structure and replace it with a constant inflow structure. They completed this alteration correctly. They also defined the model components correctly.

2. Overall Purpose 2: To determine if students can explain what is happening with the dynamics of the problem that causes the shape of the stock graph to be produced when the model is simulated? That is, can the students interpret the model output to the real world problem?

c. It is typical in System Dynamics modeling lessons to request that students anticipate model behavior before simulation runs are executed. Most students, initially, have a great deal of trouble doing this, as it is not something that is typically asked of them in their math classes. This situation is no different.

- The first pair of students drew an exponential growth curve that was incorrect. S1: I think it's going to start really slow because it's removing little of the body. Then as it gets bigger it's going to be, like, would it be growing or decreasing?

S2: It be growing, I think.

S1: Yeah, because it's adding one and $.05 \%$, so the amount leaving would be bigger but it would be more in the body

S2: So wouldn't it stay like

S1: It be starting flat and then get steeper over time, right?

S2: Yeah, I think so.

- The second pair creates a linear graph where they move by blocks, in time, and increase the next point vertically by 1 block but then subtract .5 of a block from that, creating a line that has essentially a slope of .5 of a block. This is incorrect on many levels.

P2: Oh yeah, the prediction. So there is going to be more drugs going into the system than leaving. It goes in one and only leaves at half a percent, or whatever.

P1: So for every one it goes up it goes back down.5, yes?

P2: What?

P1: It goes up one $\mathrm{g}$.

P2: It goes up one, so.

$\mathrm{P} 1$ : And then half of that so it goes up one and leaves half [P1 goes to the first 
block on the grid on the lesson packet (that is actually at $360 \mathrm{~min}$ ) and puts a dot half way up the block from the horizontal axis. Then he goes to the next block (actually at $720 \mathrm{~min}$ ), and increases by one block and then reduces half a block and places a dot there] and then one and then half and then one and then half [P1 places another dot at the 3rd block -at 1080 min- at the 1.5 block mark up from the horizontal axis. P1 shows P2 what he is doing. He finished by placing a dot half-way up the vertical axis i.e. at the top to the second box at the far right of the grid -the $1440 \mathrm{~min}$ time. Then P1 connects his dots with a straight line.]

c. Students are now asked how the simulation produced the graph shown on the computer (whose appearance shows an exponential convergence upward from 0 to about $173 \mathrm{~g}$, reaching steady state about $1 / 3$ the way through the simulation).

- The first pair of students reaches a reasonable conclusion:

S2: So the inflow is

$\mathrm{S} 1$ : Equal to the percentage going out, like, over time. Or closer to being equal to.

S2: Yeah.

S1: Cool.

S2: so we should do this [he selects and places the table in the modeling window and double clicks to define the table. He selects "medicine in the body" and moves it to the selected window, and moves elimination of medicine and medicine entering to the selected window] let's see how it changes as we run the thing. The elimination is eight it's slowly getting closer to it. I'm going to start writing because we already know what happens the medicine is eliminated slowly approaches the value of the medicine entering till it let's see how far it gets.

S1: We're only at 400. We need to get to, what? We're only a third of the way there.

S2: I'm going to hit on fast-forward what's going on there so it's slowly reaches it but it never actually gets there you know that rule you know

S1: Will never actually reach a point where it's decreasing

S2: It's staying at .99

In the packet the students wrote: The medicine being eliminated slowly approaches the value of the medicine entering but never will reach the same value or decrease.

Unfortunately, they do not explain why the medicine level should not decrease. But it is a valuable insight that they did consider this option.

- The second pair, after exclaiming how different the simulation graph was from their prediction, comes to a reasonable explanation for the shape of the 
simulation graph.

The students observe the graph, then set up a table with the drug in the system, the inflow value and the outflow value.

P1: So we have one g per minute entering the system and then $55 \%$ of it, point $55 \%$ of it leaving the system.

P2: So the same goes in every single time, $1 \mathrm{~g}$, right? So how much is leaving? So then $.55 \%$ of the drug is leaving each time. So eventually, like it starts to catch up, see. like now. .96 of a gram or whatnot is leaving but only one more is going in so even though that's like $.55 \%$ of the entire drug in the system it's almost like the same, that's why it flattened out of the top.

P1: I got it. So, yeah, it will eventually catch up to like, one. So this is when I start not giving him the drug, so like, here.

P2: Yeah. So even, like $.55 \%$, is really a really small amount of the entire drug

P1: Since it's exponential it will catch up pretty quickly.

P2: Yeah, because this is constant and it doesn't get higher.

P1: So now it's caught up and this is kind of flat line, hopefully not like the patient. So what are we writing

P2: I don't know how to put into words the inflow is the same amount but the outflow is exponential so eventually it will catch up and be the same amount as the inflow and it will be as if no new drugs are entering. It eventually won't. Does it get to be more than it or no?

P1: No, this won't become more than this [pointing first to the outflow value in the chart and then to the inflow value in the chart]. That's it. That's all the drug going in.

P2: Well, yeah, but eventually. Like, no, that makes sense. When they stop giving him drugs he'll start [unintelligible]. That makes sense so the inflow is constant the outflow is [unintelligible] so as more drugs enter the system the outflow of $.55 \%$, at a rate of $.55 \%$. Eventually the outflow will grow to be the same as the inflow ...

In the packet the students wrote: The inflow is constant but the outflow is exponential so as more drugs enter the system the outflow at a rate of $.55 \%$ the outflow will grow to be the same as the inflow.

3. Overall Purpose 3: The final objective was to determine if the students are becoming comfortable enough understanding the model dynamics that they can correctly predict what would happen to the graphical model output if a modification of the model is made. The following description is given to the students:

"A complication occurs with this patient about 8 hours after the IV is administered. One of his kidneys quits functioning, causing the elimination 
rate to reduce to half. Predict what you think will happen to the drug level in the patient's body, recording your prediction on the grid below."

Both pairs correctly predict the new behavior and are able to identify where the model needs to be modified, and how the definition of the selected component needs to be modified. Although they do not know exactly how to get the modification to happen at 8 hours and not before, the research tells them the command to use, as this is not a command the students have learned.

The first pair of students:

S1: We have that [referring to the first simulation graph recorded on his paper]. That's not the new one

S2: It's like that one for eight hours.

S1: Then it's going to get really flat again. Or is it actually going to go back down. No.

S2: Yeah. It would go back down wouldn't it and then it would go?

S1: But it's decreasing by half so wouldn't it go back up?

S2: The medicine in the system would go up and then back down to whatever.

S1: Well, it's half so as soon as it hits eight hours it would go back up again. It would be back just like.

S2: So at eight hours it would start going up again.

S1: Yeah. What would it go up to? 400? Yeah. It would go up to 400. Let's see what happens.

[We ran out of time to see the simulation run, so they could check their prediction. Both students drew prediction graphs in their lesson packet that indicated an initial jump upward at 8 hours followed by a leveling off of the drug at a higher equilibrium. This is the correct behavior the model would have produced.]

The second pair of students:

P2: It's going to continue growing [P2 is pointing at the original Drug in System graph starting at about 720 minutes and pointing her finger to rise above the Therapeutic Maximum line that is at $200 \mathrm{~g}$ ] and it's going to go quicker [P2 pointing to the initial increase in the Drug in the System graph] because it's not going to have

P1: Well, it's after eight hours. How much is eight hours in minutes?

P2: Well, there's 60 minutes, so it's 60 times eight, which is 480 , so would be, like

P1: So it be around here-ish. The kidney's going to fail, so I think it'1l, like, keep going along this [P1 is pointing to the original Drug in System graph] until it gets here [pointing to the place on the graph that is at about 480 minutes] and then [he points as if the graph would start increasing quite a bit]. 
P2: It will spike up, yeah. [P2 indicates a curving of the increased prediction.] P1: Yeah. It'll still be curved.

P2: It's about a quarter of the way-in so, it's doing its thing, and once it gets there it's going to spike. How far did you say it was going to go up?

These students drew both the prediction (using a dotted curve) and the actual simulation run (using a solid curve). The dotted curve increased in a more gradual fashion, indicating a smoother upward transition at 8 hours, than the simulation graph that made a more pronounced upward jump at 8 hours.

The transcripts indicate that the students were able to mathematize the problem without much difficulty, even after a faulty start with the second pair. They were able to use the software to explain the dynamic behavior represented in the simulation graph of the initial model. That was a key point. Once they had an understanding of the cause of the dynamic behavior pattern of the original model they were able to modify the model and were reasonably successful predicting the new behavior of the modified model. All of this work was on a model whose behavior was not typical of functions they had seen in class at that point.

The student problem solving scenario captured in these two videotapes supports the claim that students are able to mathematize new scenarios that are combinations of behaviors they already know and are able to analyze and modify and reanalyze the problem with relative ease. The videotaping lasted about 33 minutes for each pair of students.

This analysis was done comparing three problems across both student pairs (horizontal analysis) and also analyzing the improvement in thinking over the full time frame (vertical analysis) for each pair of students. 